UNIVERSIDADE DE SÃO PAULO

FACULDADE DE ECONOMIA, ADMINISTRAÇÃO E CONTABILIDADE DEPARTAMENTO DE ADMINISTRAÇÃO PROGRAMA DE PÓS-GRADUAÇÃO EM ADMINISTRAÇÃO

ANÁLISE DE FATORES QUE INFLUENCIAM O USO DE SERVIÇOS DE GOVERNO ELETRÔNICO NO BRASIL

Marcelo Henrique de Araujo

Orientador: Prof. Dr. Nicolau Reinhard

SÃO PAULO 
Prof. Dr. João Grandino Rodas

Reitor da Universidade de São Paulo

Prof . Dr. Reinaldo Guerreiro

Diretor da Faculdade de Economia, Administração e Contabilidade

Prof. Dr. Adalberto Américo Fischmann

Chefe do Departamento de Administração

Prof. Dr. Lindolfo Galvão de Albuquerque

Coordenador do Programa de Pós-Graduação em Administração 


\section{ANÁLISE DE FATORES QUE INFLUENCIAM O USO DE SERVIÇOS DE GOVERNO ELETRÔNICO NO BRASIL}

Dissertação de Mestrado apresentada ao Departamento de Administração da Faculdade de Economia, Administração e Ciências Contábeis da Universidade de São Paulo, como requisito para obtenção do título de Mestre em Ciências.

Orientador: Prof. Dr. Nicolau Reinhard

Versão Corrigida

(versão original disponível na Faculdade de Economia, Administração e Contabilidade) SÃO PAULO 
FICHA CATALOGRÁFICA

Elaborada pela Seção de Processamento Técnico do SBD/FEA/USP

Araujo, Marcelo Henrique de

Análise de fatores que influenciam o uso de serviços de governo eletrônico no Brasil / Marcelo Henrique de Araujo. -São Paulo, 2013.

$121 \mathrm{p}$.

Dissertação (Mestrado) - Universidade de São Paulo, 2013. Orientador : Nicolau Reinhard.

1. Tecnologia da informação 2. Internet 3. Inclusão digital 4. Análise multivariada I. Universidade de São Paulo. Faculdade de Economia, Administração e Contabilidade. II. Título.

CDD -658.4038 
Dedico esta dissertação aos meus pais João Batista de Araujo e Telma Maria do Nascimento Araujo. Por todo amor, carinho e dedicação. 


\section{AGRADECIMENTOS}

Inicialmente agradeço a Deus por iluminar a minha vida, me dando força e coragem para superar os desafios mais árduos desta jornada.

Agradeço ao meu orientador Prof. Nicolau Reinhard pela sua sabedoria, dedicação, apoio e oportunidades. Tais elementos foram fundamentais para o meu crescimento pessoal e acadêmico.

Deixo meus sinceros agradecimentos à Lícia Mutsuko Abe por sua valiosa e constante ajuda durante todo período do Mestrado.

Agradeço aos amigos da FEA/USP que acompanharam a longa trajetória no desenvolvimento desta dissertação. Especialmente aos amigos: Durval Lucas Júnior, Regina Ornellas, Cláudio Albano e Samuel Schmidt.

Agradeço a todos os professores do Programa de Pós-Graduação em Administração (PPGA/FEA-USP), em especial a Profa. Adriana Backx Noronha Viana, pela ajuda no planejamento das análises estatísticas desta investigação.

Agradeço especialmente a equipe do Centro de Estudos sobre as Tecnologias da Informação e Comunicação (CETIC.br) por toda disponibilidade e esforço na disponibilização dos dados vitais para esta dissertação. Deixo meus sinceros agradecimentos ao Dr. Alexandre Fernandes Barbosa por todo seu apoio e colaboração na melhoria e desenvolvimento deste trabalho.

Agradeço a CAPES pelo apoio financeiro no decorrer do mestrado e a FIA (Fundação Instituto de Administração) por todo suporte e auxílio na participação dos eventos científicos.

Agradeço a minha família por todo amor, carinho, suporte, paciência ( muita!!) e compreensão, vitais para meu crescimento pessoal e profissional. Em caráter especial, deixo meus sinceros agradecimentos a minha querida mãe Telma Maria do Nascimento Araujo, por ser exemplo de força, coragem e dedicação no qual eu sempre pude me inspirar.

Agradeço aos amigos: Anderson Miranda, Valéria de Oliveira, Paulo Degering, Maria Belarmino, por sua amizade e confiança.

Por fim, mas não menos importante. Sou MUITO grato a minha querida namorada Luisa Veras de Sandes Guimarães (maior presente deste mestrado) por todo seu amor, carinho, dedicação, gentileza e toda uma lista de adjetivos que não caberiam nesta seção de agradecimentos. Obrigado por tudo!

Agradeço a todos que colaboram de maneira direta ou indireta na realização deste trabalho. 


\section{RESUMO}

A presente investigação científica tem como objetivo compreender de que maneira o uso de serviços de governo eletrônico (e-gov) é influenciado pelos diferentes "locais de acesso à internet" e pelas competências de uso do internauta. Para tanto, foram utilizados os microdados da pesquisa TIC Domicílios (desenvolvida pelo Centro de Estudos sobre as Tecnologias da Informação e Comunicação) referente aos anos de 2007, 2009 e 2011, se caracterizado um estudo longitudinal. Os procedimentos referentes ao tratamento e análise dos dados se deram por meio da aplicação de técnicas estatísticas de cunho descritivo (mediana, distribuição de frequência) e multivariado (Análise de Correspondência, Análise Fatorial Binária e Regressão Logística Binária). O eixo teórico deste trabalho se fundamenta na abordagem das Capacidades desenvolvida pelo economista Amartya Sen. Os resultados desta investigação demonstram que para todas as classes socioeconômicas o uso dos serviços de governo eletrônico está fortemente relacionado às seguintes competências de uso: e-mail, ecommerce (busca de produtos e serviços) e serviços financeiros (consultas). Tais competências são favorecidas pelo acesso à internet preferencialmente em "casa" e no "trabalho", sobre as demais alternativas de acesso como as lan houses (centros públicos de acesso pago) e os telecentros (centros públicos de acesso gratuito). Esses resultados oferecem indícios de que as políticas públicas que promovem o acesso à internet preferencialmente do ambiente domiciliar (em consonância a ações que auxiliem o desenvolvimento de competências de uso da internet) são mais eficazes para promover um aumento no uso do e-gov, do que os esforços de se redefinir o papel dos centros públicos de acesso (telecentro e lan house), a fim de que estes se tornem ponto de acesso aos serviços de e-gov.

Palavras-Chave: Fatores condicionantes; Governo Eletrônico; Abordagem das Capacidades; Análise Multivariada; Inclusão Digital 


\begin{abstract}
This scientific research aims to understand how the individuals' use of e-government services (e-gov) is influenced by different "location of access to the internet" and their usage capabilities. For this purpose, the microdata from ICT Households Survey (developed by Center of Studies on Information and Communication Technologies CETIC.br) for the years of 2007, 2009 and 2011 was used, featuring a longitudinal study. For the processing and analysis of the data, descriptive (median, frequency distribution) and multivariate (Correspondence Analysis, Binary Factor Analysis and Binary Logistic Regression) statistical techniques were applied. The theoretical basis of this research is based on the Capability Approach developed by the economist Amartya Sen. The results of this investigation states that for all social classes the use of $e$ government services is strongly related to the following usage competencies: e-mail, $e$ commerce (search for products and services) and financial services (consultations). These capabilities are favored by the Internet access preferably at "home" and "work", more than on the other location of access to the internet alternatives such as lan houses (paid public access centers) and public telecenters (free public access centers). These results provide evidence that public policies that promote access to the internet preferably at home environment (with other actions that encourage the development of internet usage competencies) are more effective in promoting an increase in the use of e-gov, than efforts to redefine the role of public access centers (telecenters and lan houses), so that they become a point of access to e-government services.
\end{abstract}

Key Words: Conditioning factors; Electronic Government; Capabilities Approach; Multivariate Analysis, Digital Inclusion. 
SUMÁRIO

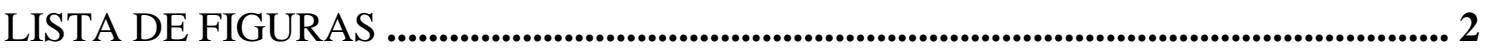

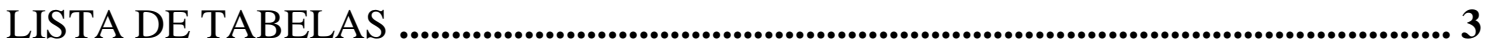

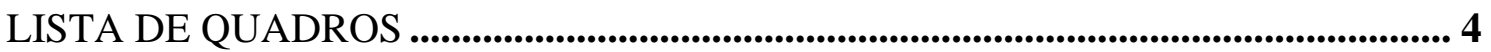

1 INTRODUÇÃO E PROBLEMA DE PESQUISA .......................................................... 5

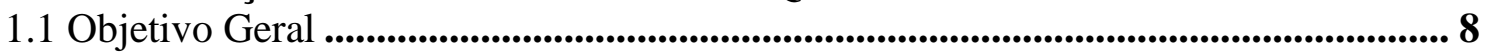

1.2 Objetivos Específicos ..................................................................................................................... 8 8

1.3 Justificativa e Relevância do Estudo ...................................................................9

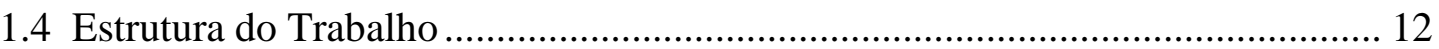

2 REVISÃO DA LITERATURA E MODELO DE REFERÊNCIA ....................... 13

2.1 Princípios da Sociedade da Informação .................................................................. 13

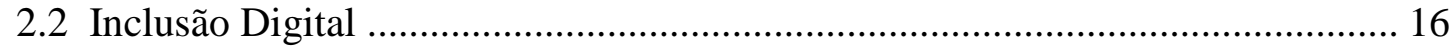

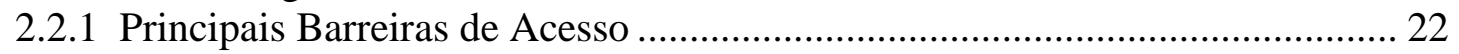

2.3 Governo Eletrônico.............................................................................................. 25

2.3.1 Modelo de Adoção de e-gov $\quad 30$

2.3.2 E-Government Readiness Index 31

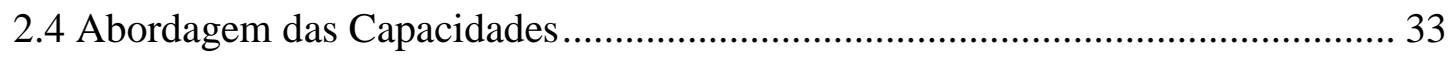

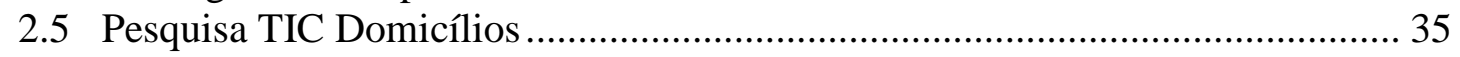

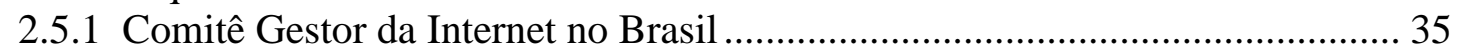

2.5.2 Núcleo de Informação e Coordenação do Ponto BR (NIC.br) .......................... 37

2.5.3 Centro de Estudos sobre as Tecnologias da Informação e Comunicação ........ 39

2.5.4 Histórico da Pesquisa TIC Domicílios ........................................................ 42

2.5.5 Caracterização da Pesquisa TIC Domicílios ................................................ 43

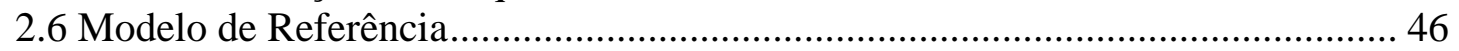

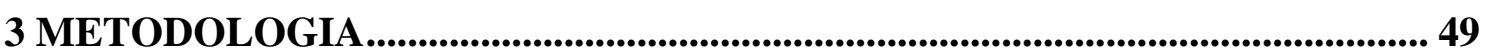

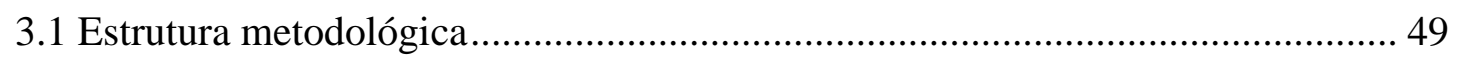

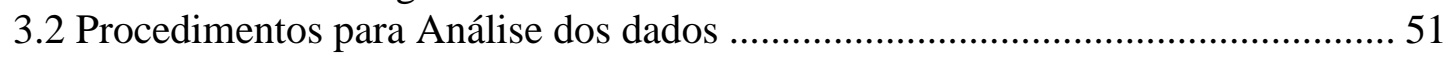

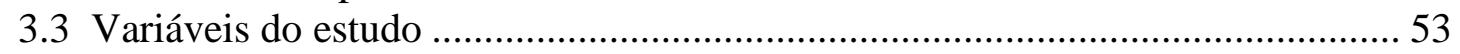

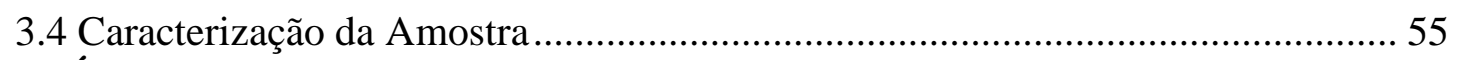

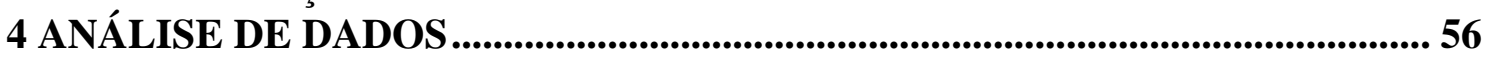

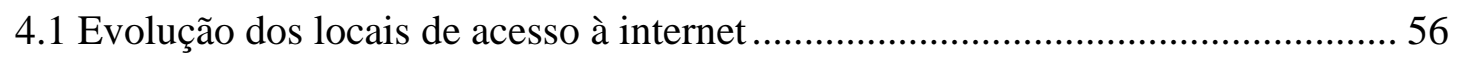

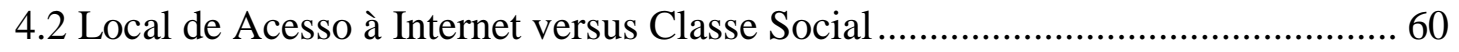

4.3 Explorando as Competências e Uso de Serviços de Governo Eletrônico .............. 67

4.4 Fatores que influenciam a adoção dos serviços de e-gov ..................................... 71

4.5 Categorizando os diferentes tipos de serviços de e-gov .................................... 77

4.6 Impacto dos diferentes tipos de serviços de e-gov ............................................ 91

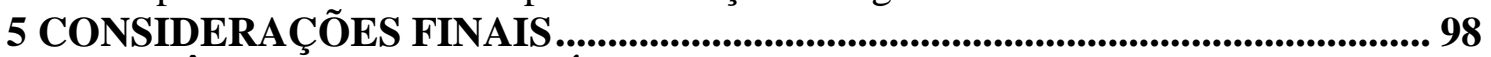

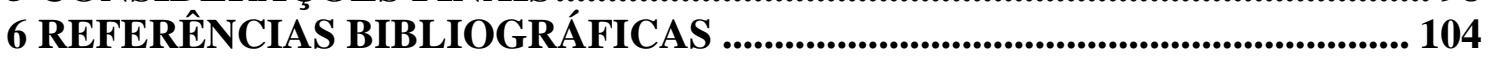




\section{LISTA DE FIGURAS}

Figura 1- Dimensões da Inclusão Digital proposta por Sorj..................................... 21

Figura 2- Dimensões do E-Government Readiness Index. ...................................... 32

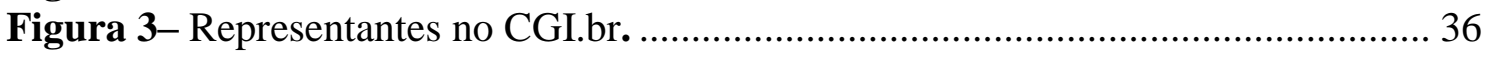

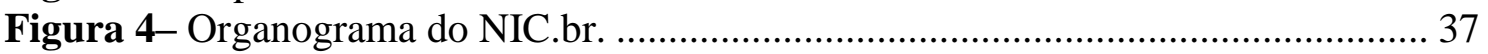

Figura 5- Procedimento do Desenho Amostral da Pesquisa TIC Domicílios 2010 ..... 44

Figura 6- Modelo de Referência: Abordagem das Capacidades de Amartya Sen........ 46

Figura 7- Mapa Perceptual do "Local de Acesso" versus "Classe Social" (2007)....... 63

Figura 8 - Mapa Perceptual do "Local de Acesso" versus "Classe Social" (2009)..... 64

Figura 9 - Mapa Perceptual do "Local de Acesso" versus "Classe Social” (2011)..... 65

Figura 10 - Evolução das competências de uso (classes agregadas) ...............................67

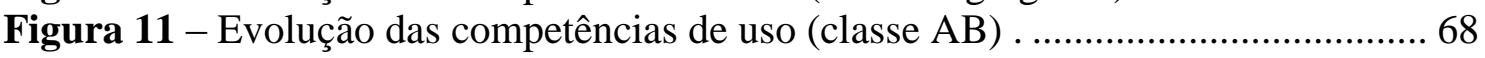

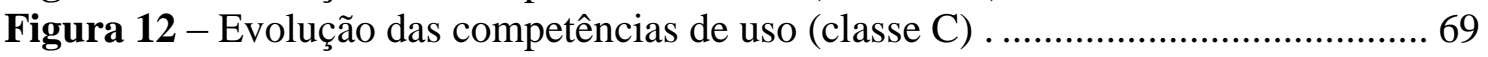

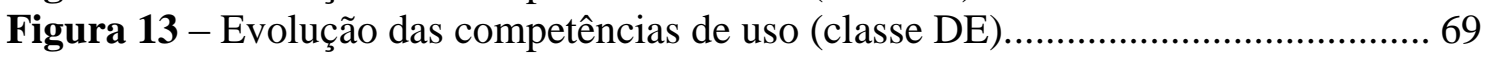

Figura 14 - Evolução da utilização de serviços de governo eletrônico (e-gov)............. 70 


\section{LISTA DE TABELAS}

Tabela 1 - Caracterização da amostra para Análise de Dados ........................................ 56

Tabela 2 - Distribuição do local de acesso à internet mais frequente............................. 56

Tabela 3 - Distribuição do local de acesso à internet mais frequente (classe $\mathrm{AB}$ ) ........ 58

Tabela 4 - Distribuição do local de acesso à internet mais frequente (classe C) ........... 58

Tabela 5 - Distribuição do local de acesso à internet mais frequente (Classe DE) ........ 58

Tabela 6 - Tabela de Contingência: Local de Acesso versus Classe Social (2007) ...... 62

Tabela 7 - Tabela de Contingência: Local de Acesso versus Classe Social (2009) ...... 62

Tabela 8 - Tabela de Contingência: Local de Acesso versus Classe Social (2011) ...... 62

Tabela 9 - Diagnóstico para multicolinearidade. ........................................................ 73

Tabela 10 - Contribuição do local de acesso no uso de e-commerce (odds ratio) ........ 74

Tabela 11 - Contribuição do local de acesso no uso de e-mail (odds ratio) .................. 74

Tabela 12 - Contribuição do local de acesso no uso de serviços financeiros (odds ratio)

Tabela 13- Contribuição das competências no uso de governo eletrônico (odds ratio) 76

Tabela 14 - Contribuição dos locais de acesso à internet no uso de e-gov (odds ratio) 76

Tabela 15- Matriz de correlação tetracórica dos serviços de governo eletrônico (2007)

Tabela 16- Matriz de correlação tetracórica dos serviços de governo eletrônico (2009)

Tabela 17 - Matriz de correlação tetracórica dos serviços de governo eletrônico (2011)

Tabela 18- Resultados da Análise Fatorial (2007) ..................................................... 85

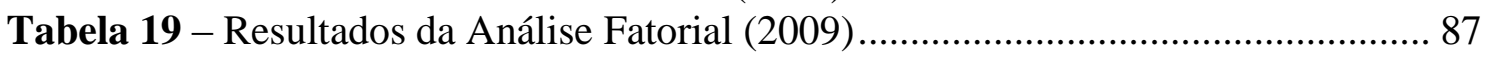

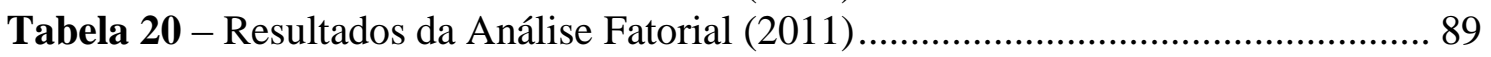

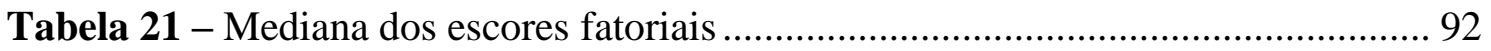

Tabela 22 - Contribuição das "competências de uso" nas atividades relacionadas à

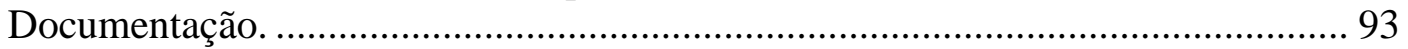

Tabela 23 - Contribuição das "competências de uso" nas atividades relacionadas ao Pagamento de Impostos e Taxas........................................................................ 93

Tabela 24 - Contribuição das "competências de uso" nas atividades relacionadas à

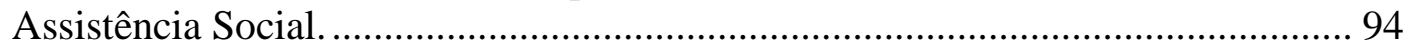

Tabela 25 - Contribuição das "competências de uso" nas atividades relacionadas aos serviços de Justiça e Trânsito.

Tabela 26 - Contribuição das "competências de uso" nas atividades relacionadas à Educação e Trabalho.

Tabela 27 - Contribuição do "local de acesso à internet" nas atividades relacionada à Documentação

Tabela 28 - Contribuição das "competências de uso" nas atividades relacionadas ao Pagamento de Impostos e Taxas.......................................................................... 96

Tabela 29 - Contribuição das "competências de uso" nas atividades relacionadas à

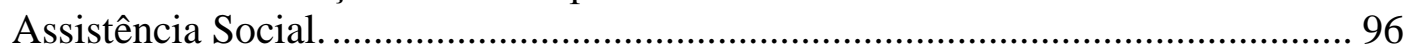

Tabela 30 - Contribuição das "competências de uso" nas atividades relacionadas aos serviços de Justiça e Trânsito.

96

Tabela 31 - Contribuição das "competências de uso" nas atividades relacionadas à Educação e Trabalho. 


\section{LISTA DE QUADROS}

Quadro 1- Definições sobre Governo Eletrônico ………….......................................... 26

Quadro 2 - Estágios de adoção de governo eletrônico ................................................. 31

Quadro 3 - Conjunto de estudos coordenado pelo CETIC.br...................................... 40

Quadro 4 - Precisão Amostral da Pesquisa TIC Domicílios ........................................ 45

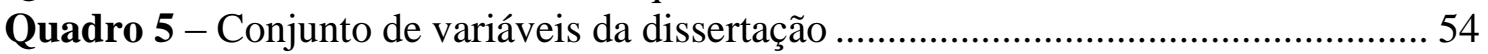

Quadro 6 - Tipos de serviços de e-gov abordados na pesquisa TIC Domicílios 2007. 79

Quadro 7 - Tipos de serviços de e-gov abordados na pesquisa TIC Domicílios 2009. 79

Quadro 8 - Tipos de serviços de e-gov abordados na pesquisa TIC Domicílios 2011. 80

Quadro 9 - Composição e Nomeação dos Fatores (2007) .......................................... 86

Quadro 10 - Composição e Nomeação dos Fatores (2009) ........................................... 88

Quadro 11 - Composição e Nomeação dos Fatores (2007) ......................................... 90 


\section{INTRODUÇÃO E PROBLEMA DE PESQUISA}

Os últimos anos do século XX e início do século XXI foram marcados por inúmeras transformações, entre estas se pode citar a grande disseminação e uso dos recursos de Tecnologia da Informação e Comunicação (TIC), nas mais diversas atividades e esferas do conhecimento. Tal propagação, segundo Castells (2007), possibilitou a criação de uma revolução tecnológica e informacional, na qual os artefatos de TIC assumem um papel central no sentido de dotar as instituições sociais de novas capacidades, possibilitando que estas organizações redefinam e inovem nas suas formas de atuação, usando o ferramental tecnológico como suporte na execução das práticas sociais e organizacionais. Em particular, a Internet ganhou um papel de destaque nessa revolução, se tornando uma plataforma tecnológica de alcance global e servindo como um vetor para diversas inovações.

Embora, tais artefatos possibilitem (ou facilitem) a integração de mercados, nações, culturas e conhecimentos dentro de uma sociedade globalizada, é importante ressaltar que tais transformações não se reduzem simplesmente a estes aspectos positivos. Afinal, considerando que neste novo cenário a posse e o uso dos recursos tecnológicos se tornam um requisito, acaba-se criando uma nova forma de exclusão social, que está intimamente atrelada a uma divisão do acesso aos meios digitais. Esta forma de segregação consiste da exclusão digital, onde grupos de indivíduos são privados, devido a uma série de fatores condicionantes, de terem acesso aos recursos de Tecnologia da Informação e Comunicação (CASTELLS, 2003; 2007; SORJ e GUEDES, 2005).

Neste ambiente marcado pelo potencial de transformação das TICs, uma corrente de estudiosos vem se dedicando em analisar como a utilização de tais recursos tecnológicos pode colaborar no desenvolvimento social e econômico de uma sociedade, em suas esferas local, regional ou nacional. Tais autores partem da premissa que o uso intensivo das Tecnologias de Informação e Comunicação pode contribuir para o desenvolvimento social numa vasta gama de atividades, como saúde (MORAES; GÓMES, 2007; VIANA; ELIAS, 2007), educação (KOZMA, 2005), governo (CUNHA; MIRANDA, 2008; DINIZ et al., 2009) entre outras áreas, consequentemente colaborando na resolução de problemas sociais bastante críticos, principalmente em países em desenvolvimento. Em outras palavras, as TICs poderiam contribuir de 
maneira significativa, no intuito de expandir o acesso à informação e reduzir custos de comunicação, além de poder desempenhar um importante papel no combate à pobreza, melhorias nos sistemas de saúde e educação, na eliminação de desigualdades regionais e sociais. Esse campo de estudos é conhecido internacionalmente pelo acrônimo ICT4D (Information and Communication Technologies for Development).

Todavia, apesar da importância de estudos que se dediquem em analisar o impacto e as implicações das TICs na questão do desenvolvimento (ICT4D) é fundamental a existência de mecanismos de medição, isto é, indicadores que possibilitem mensurar e consequentemente avaliar as reais implicações do uso das TICs em diversos cenários e compreender a diversidade e peculiaridade dos diferentes integrantes de uma sociedade da informação.

Assim, perante a necessidade de se mensurar as características referentes à disponibilidade e apropriação dos recursos de tecnológicos, organizações internacionais de desenvolvimento (e.g. Fórum Econômico Mundial, OECD, ONU) vem realizando esforços no intuito de desenvolver metodologias para geração de indicadores, isto é, métricas que permitam melhor avaliar e compreender os diversos aspectos referentes à Sociedade da Informação - acesso, posse e uso dos recursos de TIC - possibilitando, em alguns casos, realizar uma comparação dos indicadores de diferentes nações (PORCARO, 2006). Todavia, convém ressaltar que devido à grande variedade de indicadores gerados pelas mais diversas organizações, que se fundamentam em diferentes metodologias, o grau de comparabilidade destas métricas, referentes à Sociedade da Informação, acabam sendo reduzidas.

No que se refere à realidade brasileira convém destacar os esforços empreendidos pelo Comitê Gestor da Internet no Brasil (CGI.br) e o Núcleo de Informação e Coordenação do Ponto BR (NIC.br), que criaram o Centro de Estudos sobre as Tecnologias da Informação e da Comunicação (CETIC.br), setor responsável pela coordenação e publicação de estatísticas e indicadores referentes a disponibilidade e uso da Internet no Brasil (CGI, 2009). A fim de atender a esses objetivos, desde 2005 o CETIC.br vem realizando levantamentos (Survey) junto a população brasileira, no intuito de gerar indicadores que possibilitem melhor compreender os seguintes aspectos referentes ao (i) acesso e posse dos recursos tecnológicos (computador e internet); (ii) habilidades e 
diferentes usos das Tecnologias da Informação e Comunicação (CGI, 2010). Assim, a pesquisa TIC Domicílios constitui um rico acervo de dados para compreensão e entendimento de diversas questões relacionadas ao processo de inclusão digital e os padrões de uso da internet no Brasil.

Os indicadores gerados pela pesquisa TIC Domicílios são um valioso insumo para auxiliar no desenvolvimento de políticas públicas referentes ao fenômeno da inclusão digital no Brasil, possibilitando explorar tanto as dimensões referentes ao acesso aos artefatos tecnológicos, quanto compreender de que maneira esses recursos são utilizados pelo usuário brasileiro de TIC. Nesta linha de raciocínio, a discussão empreendida neste estudo se insere no campo da inclusão digital. Todavia, não se centrando na mera e propalada dicotomia do acesso versus não acesso às TICs, mas explorando o cenário dos diferentes padrões de uso da Internet (e.g. entretenimento, educação, e-commerce, e-gov).

Visto que a esfera governamental (em nível federal, municipal e estadual) é um dos setores da sociedade que mais vem se utilizando dos artefatos tecnológicos, no intuito de inovar e melhorar na prestação de serviços públicos ao cidadão, por meio de uma abordagem comumente conhecida como governo eletrônico ou e-gov (CUNHA; MIRANDA, 2008; DINIZ et al., 2009). Optou-se, para fins desta investigação, por explorar as iniciativas de governo eletrônico, no intuito de aumentar a compreensão dos aspectos que influenciam na utilização de serviços de e-gov no contexto brasileiro.

À luz do aporte teórico da abordagem das capacidades desenvolvida pelo economista Amartya Sen (2000), neste estudo foram analisados de que maneira os diferentes locais de acesso (infraestrutura) e domínio de determinadas atividades na internet - uso de email, e-commerce e serviços financeiros - (medida de competência) impactam no grau de propensão ao uso de serviços de e-gov. Nesta linha de raciocínio, esta dissertação se fundamenta no seguinte problema de pesquisa: Como o uso de serviços de governo eletrônico é influenciado pelos diferentes locais de acesso à internet e pelas competências de uso do internauta?

No intuito de responder a supracitada interrogativa adotou-se uma abordagem metodológica de caráter quantitativo dedutivo (SAMPIÉRI et al., 2006; CRESWELL, 
2009), tendo como base os microdados da pesquisa TIC Domicílios (pesquisa em dados secundários) referente aos anos de 2007, 2009 e 2011, portanto se configurando uma série histórica com intervalo de cinco anos (estudo longitudinal). A fim de delimitar o escopo do trabalho, foram considerados apenas respondentes classificados como "internautas" (i.e. aqueles que utilizaram a internet pelo menos uma vez nos últimos três meses) e que residam em regiões urbanas do país.

Os resultados desta investigação permitirão contribuir para um melhor entendimento sobre os fatores de propensão ao uso de serviços de governo eletrônico no país, sendo um potencial instrumento no auxílio de políticas públicas referentes à questão da inclusão digital no Brasil.

\subsection{Objetivo Geral}

A partir da definição do problema de pesquisa, exposto na seção anterior, a presente dissertação tem como objetivo geral:

- Analisar, sob uma perspectiva longitudinal, de que maneira os locais de acesso à internet e as competências de uso da internet (uso de e-commerce, e-mail, serviços financeiros) influenciam (ou atuam como mediadores) na decisão de uso de serviços de governo eletrônico.

\subsection{Objetivos Específicos}

- Mapear a evolução do uso da internet em relação aos diferentes locais de acesso disponíveis e como estes se diferenciam em relação à classe socioeconômica do internauta;

- Analisar de que maneira os diferentes locais de acesso à internet e as competências de uso do internauta (uso de e-mail; e-commerce e serviços financeiros) impactam na utilização de serviços de governo eletrônico no Brasil;

- Categorizar os diferentes tipos de serviços de governo eletrônico explorados na pesquisa TIC Domicílios; 
- Avaliar como os diferentes locais de acesso à internet e as competências de uso impactam no grau de propensão de uso de cada uma das categorias dos serviços de governo eletrônico;

\subsection{Justificativa e Relevância do Estudo}

Nos últimos anos a disseminação e apropriação dos recursos de Tecnologia da Informação e Comunicação (TIC) nas mais diversas áreas do conhecimento possibilitou a criação de um novo cenário em que as práticas sociais e artefatos tecnológicos estão intimamente relacionados. Tal ambiente é comumente conhecido como Sociedade da Informação, Sociedade em Rede, Sociedade do Conhecimento ou Economia do Conhecimento (CASTELLS, 2007).

A emergência (ou o desenvolvimento) de uma Sociedade da Informação vem sendo alvo de amplo debate e discussão por diversas instituições internacionais e países. Estes últimos, por sua vez, visam compreender o impacto e as implicações deste fenômeno, no intuito de desenvolver estratégias que lhes permitam melhor usufruir dos potenciais benefícios das TICs.

Entretanto, além dos aspectos positivos (benefícios) relacionados ao desenvolvimento de uma Sociedade da Informação, convém ressaltar que o referido fenômeno não se restringe simplesmente a esta dimensão, afinal a disseminação das TICs também cria uma nova formação de exclusão atrelada aos recursos tecnológicos, conhecida como exclusão digital ou divisão digital (SILVEIRA, 2001; CASTELLS, 2003; SORJ, 2005; RIGGINS; DEWAN, 2005; VICENTE; LOPES, 2011). Assim, um desafio crucial na construção de uma Sociedade da Informação efetiva recai em compreender o fenômeno da exclusão digital e desenvolver iniciativas (inclusão digital) para superar esse cenário.

No que tange a discussão referente à questão da inclusão digital ou divisão digital (termo mais comumente utilizado pela literatura internacional) convém destacar o desenvolvimento de indicadores, isto é, um conjunto de métricas, no intuito de avaliar como se dá a apropriação e uso das Tecnologias da Informação e Comunicação. Tais iniciativas são insumos valiosos para compreender as características e peculiaridades da 
Sociedade da Informação, assim como podem orientar na construção e desenvolvimento de políticas públicas que lidem com o fenômeno da divisão digital.

Uma análise da literatura acadêmica produzida nos últimos anos sobre a questão da inclusão digital demonstra que os esforços de investigação científica nesta área tem se focado em três grandes eixos: (1) Refinamentos e Construção de indicadores para Sociedade da Informação (CHEN et al., 2008; HANAFIZADEH et al., 2009a; HANAFIZADEH et al., 2009b; KYRIAKIDOU et al., 2011); (2) Análise Quantitativa dos dados e métricas gerados pelas instituições internacionais, visando comparar e compreender a realidade das diferentes nações no que se refere ao acesso e uso das Tecnologias da Informação e Comunicação (ALAMPAY, 2006; CHINN; FAIRLIE, 2004, DOONG; HO, 2012, GAMBOA; GUTIÉRREZ, 2010; MUTULA, 2008; ROBERTSON et al., 2007; VEHOVAR et al. 2006); (3) Discussão sobre iniciativas locais e/ou políticas públicas de inclusão Digital (KLECUN ,2008; MADON et al.,2009; MORI; ASSUMPÇÃO, 2007);

A partir de uma análise da literatura explicitada, nota-se que os estudos produzidos pela comunidade internacional acabam se focando fortemente na utilização dos dados e indicadores gerados pelas mais diversas organizações internacionais. Além disso, evidencia-se que o debate referente à inclusão digital não se limita simplesmente a dimensão de disponibilização do acesso aos recursos de TIC, mas também envolve uma discussão mais profunda sobre questões cognitivas (habilidades e usos) e motivacionais para a adoção dos referidos artefatos tecnológicos, além de qualificar os diferentes padrões de uso das TICs, permitindo enxergar a divisão digital como um fenômeno multidimensional.

No que se refere à literatura nacional, Sorj e Guedes (2005) apontam para as seguintes lacunas em relação aos estudos que lidam com a questão da inclusão digital: (i) a maior parte das investigações acaba tendo o foco simplesmente em iniciativas locais, como estudos empíricos sobre projetos de inclusão digital em comunidades. Tradicionalmente, tais trabalhos acabam tendo como foco as peculiaridades das iniciativas locais, sem realizar o devido diálogo com outros estudos ou dados quantitativos, o que acaba restringindo os achados dessas pesquisas a uma esfera local. A segunda lacuna apontada por Sorj e Guedes (2005) refere-se aos (ii) estudos 
quantitativos, cujas análises estatísticas se baseiam simplesmente na dicotomia entre os indivíduos que possuem acesso e não acesso ao aparato tecnológico. Embora, a referida discussão tenha sua importância, Sorj e Guedes (2005) ressaltam que o fenômeno da Inclusão Digital, não se reduz apenas a essa dimensão, evidenciando, portanto, a necessidade de investigações que se dediquem em analisar os diferentes tipos de uso das TICs (qualificação do padrão de uso).

Nesta linha de raciocínio, a presente pesquisa se propõe a realizar uma análise sobre o fenômeno da inclusão digital no cenário nacional. Todavia, não se focando na referida dicotomia entre "acesso" versus "não acesso" (embora esta seja um dimensão importante), mas sim explorando um padrão de uso da internet, mais especificamente o uso de governo eletrônico e os fatores que condicionam/propiciam a utilização deste tipo de serviço. As referidas análises dar-se-ão em uma perspectiva longitudinal abrangendo os anos de 2007, 2009 e 2011, portanto se configurando uma série de histórica com intervalo de cinco anos.

Uma das contribuições desta investigação se dá na exploração dos microdados da pesquisa TIC Domicílios. Dessa forma, as análises empreendidas neste estudo, se somam as contribuições de Barreto (2012), o qual analisou os dados secundários da pesquisa TIC Domicílios 2010, por meio da técnica de Redes Bayesianas no intuito de compreender o fenômeno da divisão digital no Brasil. Comparativamente, em termos de exploração dos microdados, o diferencial da presente dissertação se dá no caráter longitudinal das análises, possibilitando avaliar (em um intervalo de cinco anos) os fatores que influenciam o uso de serviços de governo eletrônico no contexto brasileiro. Além destas, convém ressaltar como contribuição para teoria, a aplicação da abordagem das Capacidades, no intuito de aumentar a compreensão do fenômeno estudado.

Portanto, os resultados deste trabalho visam se somar aos demais estudos que discutem o fenômeno na inclusão digital, porém, explorando o universo (apenas) dos internautas. Logo, permitindo superar a lacuna apontada por Sorj e Guedes (2005) sobre a dicotomia entre aqueles que possuem e não possuem acesso às TICs.

Do ponto de vista da contribuição para a prática, os resultados desta investigação permitirão um melhor entendimento do fenômeno da divisão digital e dos fatores 
condicionantes ao uso de e-gov no Brasil, sendo uma potencial contribuição no desenvolvimento de políticas públicas referentes à construção de uma Sociedade da Informação no Brasil (REINHARD, 2010).

\subsection{Estrutura do Trabalho}

A presente dissertação esta estruturada da seguinte maneira: na Seção 1 é realizada uma descrição introdutória sobre a temática desta investigação científica, a fim de explicitar o (i) problema de pesquisa; (ii) os objetivos e escopo da dissertação; (iii) justificativa e relevância do estudo. Em seguida, na Seção 2 são apresentados os pressupostos teóricos que fundamentam este trabalho. A Seção 3 descreve e discute os procedimentos metodológicos empreendidos neste estudo. Na Seção 4 são apresentados os principais resultados da aplicação das técnicas estatísticas propostas e são discutidos os resultados. Por fim, a Seção 5 tece as considerações finais da dissertação, evidenciando as principais implicações deste estudo, tanto para teoria, quanto para a prática, 


\section{REVISÃO DA LITERATURA E MODELO DE REFERÊNCIA}

O foco desta seção recai em apresentar os princípios teóricos que norteiam esta dissertação, portanto, serão exploradas as seguintes temáticas: (i) princípios inerentes à Sociedade da Informação; (ii) fenômeno da inclusão digital; (iii) iniciativas de governo eletrônico (e-gov); (iv) abordagem das capacidades; (v) pesquisa TIC Domicílios. Por fim, a partir destes fundamentos, na seção 2.6 é apresentado o modelo de referência subjacente a esta investigação científica.

\subsection{Princípios da Sociedade da Informação}

Os últimos trinta anos foram marcados por inúmeras mudanças no cenário político, econômico e social. Uma das principais transformações deste período refere-se ao desenvolvimento e disseminação dos recursos de Tecnologia da Informação e Comunicação em todos os domínios da atividade humana, configurando-se assim uma revolução tecnológica. Segundo Castells (2007) o impacto dessa revolução proporcionou a criação de um padrão de descontinuidade nas bases materiais da economia, sociedade e cultura, promovendo assim, uma ruptura com a Sociedade Industrial e, consequentemente, iniciando um novo período denominado Era da Informação ou Sociedade da Informação (CASTELLS, 2007; MATTOS; CHAGAS, 2008; WERTHEIN, 2000; FERREIRA, 2003).

Segundo Werthein (2000, p. 71) a expressão Sociedade da Informação passou a ser utilizada, nós últimos anos do século XX, no intuito de substituir o complexo conceito de Sociedade Pós-Industrial e como forma de transmitir o conteúdo referente a um "novo paradigma técnico-econômico". Em outras palavras, a característica desse novo período recai nas transformações técnicas e organizacionais que têm como elemento principal, não mais os insumos baratos de energia (característica da Sociedade Industrial), mas sim, o insumo informacional alcançado por meio dos avanços tecnológicos nas áreas de microeletrônica e telecomunicação (WERTHEIN, 2000).

Vale ressaltar que a constituição dessa sociedade informacional está intimamente atrelada a um processo de expansão e reestruturação do sistema capitalista que ocorre 
desde a década de 80, denominado por Castells (2007) de Capitalismo Informacional. As Tecnologias da Informação e Comunicação (TIC) e seu uso com ênfase na flexibilidade vêm permitindo realizar com rapidez e eficiência processos de desregulamentação, privatização e ruptura do modelo de contrato social entre capital e trabalho característicos do modelo capitalista industrial (WERTHEIN, 2000, p. 72).

Segundo Werthein (2000) as transformações provocadas rumo à propalada Sociedade da Informação se encontram em um estágio avançado nos países desenvolvidos. Todavia, tais transformações são uma inevitável tendência - mesmo estando em estágios iniciais - em países subdesenvolvidos, configurando, portanto, um paradigma informacional. Castells (2007) ressalta as seguintes características deste paradigma:

- Informação como matéria-prima: A primeira característica deste novo paradigma é que a informação é sua matéria prima, ou seja, as Tecnologias da Informação e Comunicação são instrumentos para se agir sobre a informação. Diferenciando-se, portanto, das revoluções anteriores (Sociedade Industrial) em que as informações eram usadas simplesmente para agir sobre as tecnologias;

- Alta penetrabilidade do efeito das novas tecnologias: Dado que a informação é uma parte integral de toda atividade humana, todos os processos de nossa existência individual e coletiva são diretamente moldados (não determinados) pelos novos meios tecnológicos (CASTELLS, 2007, p.108).

- Predomínio da lógica de redes: As tecnologias da informação e comunicação proporcionaram a adoção da lógica de redes em sistemas ou conjunto de relações. A estrutura da rede parece estar bem adaptada à crescente complexidade de interação e aos modelos imprevisíveis do desenvolvimento derivado do poder criativo dessa interação. Essa configuração topológica, a rede, agora pode ser implementada materialmente em todos os tipos de processos e organizações graças a recentes tecnologias da informação. Sem elas, tal implementação seria bastante complicada. E essa lógica de redes, contudo, é necessária para estruturar o não estruturado, porém preservando a flexibilidade, pois o não estruturado é a força motriz da inovação da atividade humana. (CASTELLS, 2007, p.108) 
- Flexibilidade: os recursos das novas tecnologias permitem favorecer processos reversíveis, possibilitando a modificação por reorganização de componentes e tem alta capacidade de reconfiguração.

- Convergência Tecnológica: Perante um contexto de desenvolvimento tecnológico nas áreas de microeletrônica, telecomunicações, optoeletrônica e computadores, tais tecnologias tornam-se cada vez mais interligadas.

À luz dos princípios do paradigma tecnológico que fundamenta essa Era da Informação, Takase (2007, p. 35) elucida as principais características desta Sociedade da Informação:

- O surgimento das novas Tecnologias de Informação e Comunicação alterou profundamente o modus operandi e o modus vivendi da sociedade;

- Esta sociedade não é caracterizada pela centralidade de conhecimentos e informações, mas pela aplicação desses conhecimentos e informações, no intuito gerar novos conhecimentos e dispositivos de TIC, configurando um ciclo contínuo entre a inovação e seu uso (CASTELLS, 2007, p.69);

- Crescimento exponencial das informações disponibilizadas;

- Internet, como o símbolo da estrutura desta sociedade, a sociedade em rede;

- Acesso, em tempo real, às informações localizadas em pontos remotos do planeta;

- Possibilidade de grupos de discussão, de teleconferências, de ensino à distância, de forma simultânea com pessoas em diferentes locais.

Em consonância a discussão supracitada, Takase (2007) defende que a Sociedade da Informação consiste em uma realidade irreversível, todavia, benéfica e promissora, 
possibilitando a troca de informações e conhecimentos entre os membros da sociedade, implicando, portanto em maior desenvolvimento da humanidade.

Embora o desenvolvimento e disseminação de novas Tecnologias de Informação e Comunicação (TIC) tenham um papel fundamental para a construção de uma Sociedade da Informação, Werthein (2000) alerta que este fato não deve alimentar uma visão ingênua de determinismo técnico na qual as transformações em direção à sociedade da informação resultam da tecnologia, seguem uma lógica técnica e, portanto, neutra e, consequentemente, estão fora da interferência de fatores sociais e políticos. Os processos sociais e a transformação tecnológica estão intimamente imbricados e resultam de uma interação complexa em que fatores sociais pré-existentes, a criatividade, o espírito empreendedor, as condições da pesquisa científica afetam o avanço tecnológico e suas aplicações sociais.

O determinismo técnico consiste de uma abordagem que parte da premissa de que a tecnologia é a força propulsora de mudanças sociais e culturais. Logo, nesta abordagem a tecnologia não sofre mudanças em virtude da ação dos atores sociais, diferindo-se de demais abordagens como o construtivismo social. Assim, o determinismo técnico estabelece uma relação causal e unidirecional com a sociedade, sendo que a primeira possui um papel de autonomia, com lógica e leis próprias, independente das forças sociais (MACKENZIE; WAJCMAN, 1999; ORLIKOWSKI, 2000; BARBOSA, 2008, p.73; AVGEROU et al., 2004). Em outras palavras, a estrutura tecnológica é a causa das mudanças organizacionais e sociais, portanto, tendo o poder de moldar a estrutura social.

\subsection{Inclusão Digital}

Assim como discutido nas seções anteriores, as últimas décadas foram marcadas pela difusão e adoção de inúmeras inovações tecnológicas nas mais diversas esferas da sociedade. Em virtude do grande impacto dessas transformações, convencionou-se denominar esse período fortemente baseado em conhecimento, educação e processos intensos de comunicação e informação de Sociedade da Informação ou Era da Informação (WINKLER, 2005; CASTELLS, 2003; 2007). Assim, uma das principais 
características deste período é o papel central que os recursos de TIC assumem, no sentido de dotar as instituições sociais de novas capacidades, usando o ferramental tecnológico como suporte à execução das práticas sociais e organizacionais.

Segundo Winkler (2005) embora ainda não haja um acordo entre os estudiosos sobre os reais impactos das tecnologias (tanto positivos, quanto negativos) na construção da Sociedade da Informação (SI), o único consenso entre tais autores se dá na conscientização de que boa parte da população mundial não está inserida ou participando dos processos da propalada Sociedade da Informação. Evidenciando, portanto, um cenário de segregação e aprofundamento de uma nova forma de exclusão social. Tal desigualdade refere-se ao fenômeno comumente denominado de Exclusão Digital que contempla as consequências sociais, econômicas e culturais da distribuição desigual do acesso aos computadores e à Internet (SORJ; GUEDES, 2005, p. 102).

Nessa linha de raciocínio, Balboni (2005) defende que a exclusão digital é uma das facetas da exclusão social - tendo como centro o acesso às TICs - sendo, portanto, influenciada pelas inúmeras diferenças sociais, econômicas e políticas existentes no país. Perante a necessidade de superar essa problemática, inserem-se políticas públicas de disseminação de tecnologias, como o programa brasileiro da Sociedade da Informação (TAKAHASHI, 2000) e os programas de Telecentros Públicos (MACADAR; REINHARD, 2002; BALBONI, 2005), que visam à utilização de Tecnologias de Informação e Comunicação no intuito de incluir os cidadãos brasileiros e, por extensão, melhorar a economia do país (PASSOS; ABREU, 2011, p. 2). A necessidade de se ampliar o acesso à população é um requisito para o sucesso e a disseminação de iniciativas de democracia e governo eletrônico (WINKLER, 2005).

A fim de se referir à problemática da exclusão digital e às iniciativas para superá-la, uma análise da literatura demonstra o emprego de diversas expressões como: divisão digital (digital divide), brecha digital, inclusão digital, "infoexclusão" entre outras expressões (CASTELLS, 2003; SILVEIRA, 2001; WINKLER, 2005). Visto que cada um dos referidos termos busca sintetizar o mesmo fenômeno, para fins desta dissertação optou-se por considerar todos os referidos vocábulos como sinônimos, embora, nesta pesquisa seja utilizado com mais frequência a expressão inclusão digital. No entanto, mesmo que os termos supracitados possam ser tratados como sinônimos, não há um 
consenso na literatura sobre uma definição única do conceito de inclusão digital. Estudos desenvolvidos por Assumpção (2002) Borges (2005), lizuca (2003) e Winkler (2005) reforçam essa dificuldade.

De acordo com o trabalho de Winkler (2005) o conceito de inclusão digital foi se ampliando, no decorrer dos anos, permitindo assim captar suas diversas dimensões. Inicialmente, a questão da Inclusão (ou exclusão) Digital estava unicamente atrelada aos aspectos técnicos, isto é, possibilitar o acesso aos recursos tecnológicos. Em conformidade com esta corrente, Afonso (2000) entende a exclusão digital como a impossibilidade de se utilizar dos recursos de TIC. Nesta mesma linha de raciocínio, Silveira (2001) afirma que privação ao (i) computador, (ii) linha telefônica e (iii) provedor de acesso eram os elementos que impediam os indivíduos de usufruírem dos recursos das Internet, consequentemente implicando na exclusão digital.

Embora seja inegável a necessidade de se criar condições para o acesso universal aos equipamentos tecnológicos, enxergar o fenômeno da inclusão digital apenas sob a perspectiva técnica implicará em uma redução ou simplificação deste fenômeno. Limitando, assim, a discussão referente à exclusão digital à propalada dicotomia entre aqueles que possuem e os que não possuem acesso ao computador e à Internet (EISENBERG; CEPIK, 2002 apud WINKLER, 2005). Além disso, tais trabalhos baseiam-se na premissa de que o simples acesso às TICs será o suficiente para que a população tenha condições de usufruir dos (potenciais) benefícios de tais artefatos tecnológicos. Portanto, pode-se afirmar que tais trabalhos acabam tendo um viés baseado no determinismo técnico (AVGEROU, 2003).

Sorj e Guedes (2005) criticam tais trabalhos que se baseiam unicamente na divisão entre aqueles que possuem ou não possuem acesso à informática e à Internet. Afinal, embora essa seja uma dimensão importante, ela é insuficiente para a compreensão da dinâmica social e da exclusão digital. Neste sentido, Sorj e Guedes (2005, p.103) apontam para três grandes limitações de políticas públicas de universalização do acesso que se baseiem unicamente no princípio dicotômico supracitado: (i) não identificar $a$ qualidade do acesso - velocidade da conexão, custo e tempo disponível para o acesso em particular nos grupos menos favorecidos da população; (ii) supor o universo de usuários entre os que possuem computador no domicílio na diferenciação das camadas 
socioeconômicas; (iii) não oferecer pistas sobre a diversidade de usos e relevância da inclusão digital para os usuários. Assim, a questão da inclusão digital não se trata de um fenômeno simples, indicando a necessidade de se considerar outros fatores e dimensões envolvidas, além da polaridade entre incluídos e excluídos (SORJ; GUEDES, 2005).

A fim de superar as limitações discutidas e considerar os demais elementos que estão envolvidos no fenômeno da inclusão/exclusão digital, diversos autores (SORJ, 2003; PASSOS; ABREU, 2011; MENEZES et al., 2009) vêm propondo modelos que consideram o conceito de inclusão digital sob a ótica de diversas perspectivas ou dimensões (conceito multidimensional).

No estudo conduzido por Menezes et al. (2009) os autores denominam as diferentes dimensões referente ao fenômeno da exclusão digital, sob a ótica das diversas barreiras impeditivas que dificultam a inserção do indivíduo efetivamente na Sociedade da Informação, possibilitando a produção e fruição de conteúdos. Segundo esses autores, as barreiras à inclusão digital podem ser classificadas como: (i) barreiras de ordem física e econômica; (ii) barreias de ordem psicológica; (iii) barreiras de ordem cognitiva e (iv) barreiras de ordem linguística (MENEZES et al., 2009).

No trabalho desenvolvido por Passos e Abreu (2011), os autores analisam iniciativas de inclusão digital, no intuito de compreender como os benefícios dessas iniciativas avaliadas impactam na inclusão social. Para fins do referido estudo, foram consideradas as seguintes dimensões de inclusão digital:

- Aspectos Econômicos: refere-se às condições financeiras para ter acesso às novas tecnologias. Em alguns dos trabalhos anteriormente citados, esta dimensão é denominada como "técnica", mas independente dos rótulos serem diferentes, o foco recai em possibilitar o acesso aos recursos tecnológicos;

- Aspectos Cognitivos: nessa dimensão considera-se que o usuário necessita ter uma visão crítica e a capacidade, independente do uso e da apropriação dos novos meios digitais; 
- Aspectos Técnicos: o foco desta dimensão recai nos conhecimentos operacionais básicos que os usuários precisam dispor na utilização de ferramentas de softwares e proficiência de uso da plataforma da internet.

Visando elencar os diversos aspectos envolvidos no conceito de inclusão digital, Sorj (2003) defende que o referido fenômeno pode ser classificado em cinco diferentes níveis:

1) Infraestruturas de acesso: Assim, como o próprio nome sugere, refere-se à existência e disponibilização de sistemas de transmissão, como telefone, satélite e uso de fiação telefônica e elétrica. Em outras palavras, neste primeiro estágio o foco recai na existência uma infraestrutura de telecomunicações;

2) Equipamento de acesso individual: Refere-se à existência do computador, com modem e provedor de acesso, elementos esses que possibilitam ao indivíduo ter acesso à Internet;

3) Treinamento: Basicamente consiste do processo de alfabetização digital e capacitação dos indivíduos no uso do computador e da Internet (WINKLER, 2005, p.43);

4) Capacitação Intelectual: Neste nível o usuário possui a capacidade de buscar e utilizar as informações disponíveis na Internet como uma fonte de conhecimento e desenvolvimento, tanto intelectual, quanto profissional;

5) Produção e uso de conteúdo: No último nível, espera-se que o usuário tenha a competência de desenvolver conteúdos específicos adequados à sua necessidade ou de diferentes segmentos da população.

Vale ressaltar que estes níveis são sequenciais, de forma que cada nível é condição de existência do nível superior, conforme ilustrado na Figura 1. Segundo Sorj (2003), os programas públicos de universalização dos serviços de comunicação - comum em países em desenvolvimento - focalizam em geral o primeiro e o segundo nível, que são somente parte das precondições para transformar a Internet num serviço público. 


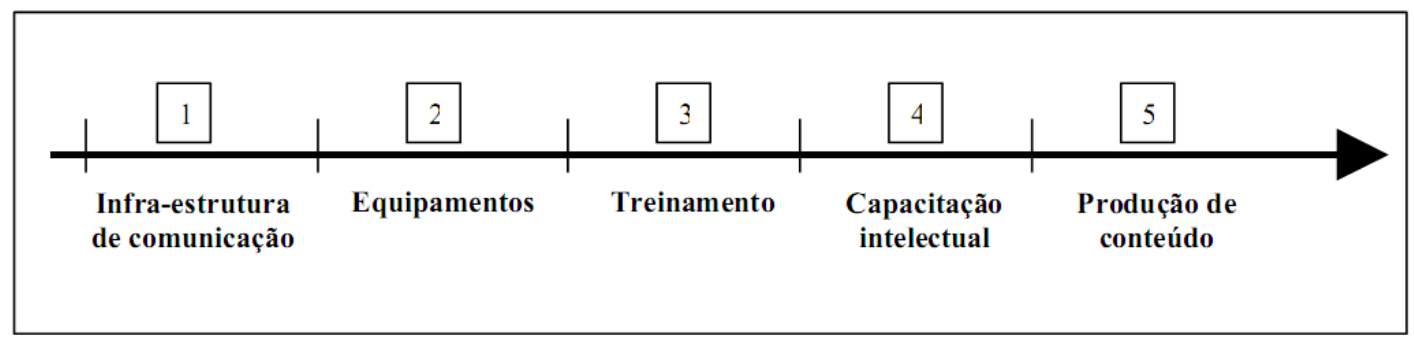

Figura 1- Dimensões da Inclusão Digital proposta por Sorj.

Fonte: Winkler (2005).

Os níveis ou dimensões de inclusão digital (Figura 1) indicam o maior ou menor nível de apropriação das Tecnologias da Informação e Comunicação (TIC). Assim, no que se refere ao nível 1, Sorj (2003) destaca que este é um estágio básico, em que o foco recai na universalização do acesso à infraestrutura, questão praticamente já superada em países desenvolvidos, mas que ainda é um problema em países em desenvolvimento, em que a infraestrutura que possibilita o acesso à Internet fica concentrada nos centros urbanos desses países. No que se refere ao nível 2, uma discussão pertinente recai nas barreiras que impedem que a população tenha acesso aos equipamentos eletrônicos. Neste sentido, Winkler (2005) ressalta que o alto custo é uma das principais barreiras na aquisição e acesso às TICs. Conforme já explicitado, estes dois primeiros níveis exprimem problemas ainda críticos em países em desenvolvimento, justificando a criação de políticas públicas (e.g. telecentros, incentivos fiscal para aquisição de equipamentos eletrônicos) que atuem nestes dois primeiros níveis.

Em relação ao nível 3 (Treinamento) Sorj (2003) alerta para a necessidade imprescindível da alfabetização digital (e-literacy) nas escolas, visando orientar e preparar os estudantes na utilização de maneira crítica da Internet.

O Nível 4 Capacitação Intelectual, consiste do estágio em que o indivíduo possui a capacidade de se utilizar das informações disponíveis na Internet como fonte de conhecimento. Sorj (2003) enfatiza a necessidade da alfabetização e formação intelectual oferecida pelo sistema escolar, como requisitos para se atingir esse nível. Assim, nota-se que o uso efetivo dessas novas tecnologias depende de qualificações intelectuais básicas, de modo que para um usuário com competência analítica, a Internet 
é um instrumento de informação, enquanto que para um usuário com maior capacidade de análise, a Internet se torna um instrumento de conhecimento (WINKLER, 2005).

Por fim, no último nível (Nível 5), a capacitação intelectual do usuário é fundamental, possibilitando que este transforme a Internet em um ambiente em que se possa explorar a cultura e criatividade social, consequentemente permitindo que o internauta não seja apenas um consumidor da informação, mas sim um produtor de conteúdo (SORJ, 2003).

Assim, conforme os estudos discutidos anteriormente o conceito de inclusão digital, refere-se a um fenômeno complexo, com vários níveis (ou dimensões), de tal forma que quaisquer iniciativas que visem minorar os efeitos da exclusão digital, devem buscar estratégias para ultrapassar a simples dimensão da disponibilização dos recursos de TIC, no intuito de explorar os potenciais benefícios das novas tecnologias na promoção da inclusão digital.

\subsubsection{Principais Barreiras de Acesso}

Em relação ao fenômeno da exclusão digital, uma corrente alternativa de estudos, vem se dedicando a identificar como se dá a distribuição dos recursos tecnológicos entre a população, visando identificar quais são os elementos que mais condicionam ao uso e não uso (caracterizando uma barreira de acesso) das Tecnologias da Informação e Comunicação (TIC). Uma análise da literatura identifica alguns elementos considerados como barreiras à inclusão digital: (i) renda; (ii) grau de instrução; (iii) idioma; (iv) raça/etnia entre outros. Todavia, apesar da diversidade de fatores, existe certo consenso entre os estudiosos de que os atributos relacionados ao grau de instrução e nível de escolaridade são os elementos que mais segregam grupos de incluídos e excluídos

digitalmente. Apesar deste consenso é fundamental analisar o impacto dos demais fatores condicionantes em relação ao processo de inclusão digital (WINKLER, 2005).

Alinhado a essa corrente de estudos, Castells (2003) realiza uma análise sobre a divisão digital nos Estados Unidos, buscando compreender cada um dos aspectos relacionados à exclusão digital naquele país. Segundo o autor fica evidente que quanto maior a renda da família ou do indivíduo, maior será a chance que este tenha acesso à Internet. 
Conforme os dados apresentados por Castells (2003) das pessoas com renda acima dos $\$ 75.000$ (anualmente) a taxa de acesso estava em torno de $70,1 \%$, contrastando com aqueles que ganham até $\$ 15.000$, cuja taxa ficava em torno dos $18,4 \%$.

A educação ou nível de escolaridade também é um fator discriminante, a taxa de acesso do grupo de indivíduos com curso superior ou nível mais elevado era de 74,5\%, distinguindo do grupo de indivíduos que não tinham concluído o Ensino Médio, no qual a taxa de acesso à Internet ficava em 21,7\%. A faixa etária, também se mostrou um elemento fortemente discriminador, demonstrando que os adolescentes tinham quase duas vezes mais chances de acesso, quando comparados à pessoas com mais de 50 anos de idade. Analisadas as faixas etárias, demonstra-se que entre o grupo de 9 a 17 anos, a taxa de acesso à Internet fica em 53,4\%, este percentual eleva-se para 56,8\% quando analisados indivíduos com idade entre 18 e 24 anos; apresenta uma leve redução para $55,4 \%$ no grupo etário de 25 a 49 anos e cai drasticamente (a taxa de acesso à Internet) para 29,6\% no grupo composto por pessoas com mais de 50 anos.

A situação do emprego também se mostrou um fator discriminador, no qual os indivíduos que se declaram empregados, possuem uma taxa de acesso à internet de $56,7 \%$, em contraste com os indivíduos desempregados cujo percentual cai para $29 \%$. Em relação à etnia, os dados apontam haver uma desigualdade no acesso. A taxa de acesso entre os indivíduos que se declararam como brancos, ficou em 50,3\%, essa taxa tem uma leve redução para 49,4\% entre membros asiático-americanos (amarelo) e cai para 29,3\% entre os afro-americanos (negros) e fica em 23,7\% entre os hispânicos.

O fator área geográfica também apresentou uma grande disparidade, no que se refere à taxa de acesso à internet. Indicando que indivíduos que residem em áreas urbanas apresentam maiores chances de terem acesso à internet do que indivíduos situados na zona rural. Um último aspecto apontado por Castells (2003) refere-se à questão da deficiência física. A taxa de acesso à Internet entre os indivíduos sem nenhuma deficiência era de $43,3 \%$, em contraste com os $71,6 \%$ dos indivíduos que declaram possuir alguma deficiência. Quando segmentados por tipo de deficiência, evidenciavase que entre as pessoas com problemas de visão, o percentual de acesso fica em 78,9\%, enquanto que pessoas com problemas de locomoção tinham uma taxa de acesso à Internet de $81,5 \%$. 
Embora os dados apresentados, permitam retratar um esboço da distribuição dos recursos tecnológicos na sociedade americana, Castells (2003) ressalta a limitação na comparação da realidade dos Estados Unidos em relação aos demais países. Pois, visto que o país foi pioneiro na inovação e produção de diversos recursos tecnológicos, naturalmente a taxa de difusão das TICs entre a população americana é maior do que em relação aos demais países.

No intuito de compreender como se dá a distribuição do acesso à Internet, Fernandes e Dutt-Ross (2006) se utilizaram dos dados do PNAD, referente aos anos de 2001 e 2002 para identificar as principais barreiras de inclusão digital. Todavia, na análise desenvolvida pelos autores foram considerados apenas os seguintes fatores: (i) Idade; (ii) Nível de Escolarização; (iii) Sexo; (iv) Etnia; (iv) Região. Segundo Fernandes e Dutt-Ross (2006) o atributo de Gênero (Sexo), não se mostrou um elemento discriminador, de modo que as chances de acesso à Internet entre homens e mulheres são praticamente uniformes.

Em relação à etnia, nota-se que as pessoas de cor amarela (origem asiática) possuem no mínimo duas vezes mais chances de ter acesso à Internet, quando comparadas às pessoas de cor Branca. Em contrapartida, pessoas de cor branca possuem mais propensão a serem incluídas digitalmente do que pessoas que se declararem de cor negra, evidenciando desigualdade de acesso, quando analisado em relação ao atributo cor/etnia.

O aspecto referente à região geográfica também se mostrou elemento de forte discriminação, refletindo as desigualdades existentes entre as regiões geográficas do país. As regiões geográficas, cujos indivíduos possuem maior probabilidade de terem acesso à Internet são o (i) Centro Oeste e o (ii) Sudeste. Em contrapartida, a região Norte, apresenta a menor chance de acesso à Internet, quando comparada às demais regiões do país.

Em relação ao elemento idade, nota-se que as faixas etárias que mais contribuem para inclusão (com maior taxa de acesso à Internet) são os indivíduos na faixa etária dos 15 
aos 19 anos idade e dos 20 aos 25 anos, contrastando com os indivíduos com idade igual ou acima aos 65 anos, que apresentaram a menor taxa de acesso.

Em consonância aos princípios acima discutidos, a discussão empreendida nesta investigação se enquadra dentro da temática de inclusão digital. Porém, não explorando as questões relativas ao acesso versus não acesso ao computador e internet, mas analisando como os usuários se utilizam dos recursos disponibilizados na Internet (padrões de uso da internet), tendo como foco deste trabalho os serviços de governo eletrônico. Embora, a literatura anteriormente discutida demonstre uma série de fatores (barreiras) que discriminem o acesso aos diversos recursos de TIC, para fins desta dissertação optou-se por fundamentar às análises nas diferenças entre classes socioeconômicas.

\subsection{Governo Eletrônico}

A emergência de uma Sociedade da Informação, em conformidade às seções anteriores, impactou diversas áreas do conhecimento, permitindo aos indivíduos e instituições sociais, redefinirem a sua forma de atuação e interação, sendo esta fortemente suportada pelos recursos de Tecnologia da Informação e Comunicação (TIC).

Assim, a esfera governamental é uma das áreas que vem explorando intensamente o potencial desses recursos tecnológicos, no intuito de aperfeiçoar e tornar mais eficiente a prestação de serviços públicos ao cidadão. A esse conjunto de inciativas que se baseiam no uso das TICs para suportar e otimizar os processos no contexto da administração pública é dado nome de governo eletrônico (e-gov) ou e-governo (DINIZ et al., 2007; SANTOS; REINHARD, 2011).

Embora nos últimos anos tenha ocorrido uma popularização da expressão "e-gov", (provavelmente em virtude da disseminação de serviços eletrônicos como imposto de renda etc.) deve-se salientar que este ainda é um fenômeno recente, portanto, não havendo uma única definição consensual para o referido vocábulo (GRANDE; ARAUJO; SERNA, 2002; MARTINS; RAMOS, 2008). 
No intuito de compreender e elucidar as características inerentes ao fenômeno estudado buscou-se explorar as diversas definições do termo governo eletrônico, provenientes tanto da literatura acadêmica, quanto de relatórios e informações de instituições e organizações internacionais. Visando sistematizar os referidos conceitos, foi desenvolvido um quadro teórico (Quadro 1) que sintetiza as principais definiçõoes do termo e-gov.

\begin{tabular}{|c|c|}
\hline Autor(es) & Definição \\
\hline $\begin{array}{l}\text { Banco Mundial (LANVIN; } \\
\text { LEWIN, 2007) }\end{array}$ & $\begin{array}{l}\text { "Governo eletrônico refere-se ao uso, por meio de agências } \\
\text { governamentais, das Tecnologias da Informação (como redes de longa } \\
\text { distância (WAN), Internet e computação móvel) capazes de transformar } \\
\text { as relações entre cidadãos, empresas e outras unidades governamentais. } \\
\text { Essas tecnologias podem servir a diferentes fins, como: melhoria na } \\
\text { prestação de serviços aos cidadãos, interações mais eficazes entre as } \\
\text { empresas e a indústria, empoderamento do cidadão, por meio do acesso } \\
\text { a informaçãao ou mais eficiência na administração governamental". }\end{array}$ \\
\hline OECD $(2003$, p.23) & $\begin{array}{lcccc}\text { Uso das } & \text { Tecnologias da Informação e Comunicação } & \text { (TIC), } \\
\text { particularmente a Internet, para alcançar melhorias no governo. } & \end{array}$ \\
\hline Nações Unidas (UN, 2003) & $\begin{array}{l}\text { E-gov refere-se ao uso da Internet e da web, no intuito de oferecer } \\
\text { informações e serviços governamentais aos cidadãos. }\end{array}$ \\
\hline União Européia (EU, 2004) & $\begin{array}{l}\text { Refere-se ao uso das TICs na administração pública combinada com as } \\
\text { mudanças organizacionais e novas habilidades, a fim de melhorar a } \\
\text { prestação dos serviços públicos e processos democráticos. }\end{array}$ \\
\hline $\begin{array}{l}\text { Gartner Group (2000 apud } \\
\text { Martins e Ramos, 2008) }\end{array}$ & $\begin{array}{l}\text { "contínua melhoria da prestação dos serviços governamentais, } \\
\text { participação do eleitorado e governança mediante a transformação de } \\
\text { relacionamentos internos e externos por meio das tecnologias, internet e } \\
\text { novas mídias" }\end{array}$ \\
\hline Criado; Ramilo (2001) & $\begin{array}{l}\text { Adoção das TICs pela administração pública, com diferentes vias por } \\
\text { meio das quais é possível que as pessoas e outras organizações se } \\
\text { conectem, especialmente por meio de páginas web, correio eletrônico, } \\
\text { além de outras ferramentas como telefone móvel, PDAs, } \\
\text { videoconferência, intranets, extranets, TV a cabo, ondas de rádio e } \\
\text { satélite. }\end{array}$ \\
\hline Agune; Carlos (2005) & $\begin{array}{l}\text { O governo eletrônico, ou e-governo, pode ser entendido como um } \\
\text { conjunto de ações modernizadoras vinculadas à administração pública. }\end{array}$ \\
\hline $\begin{array}{l}\text { Cunha; Duclós; Barbosa } \\
\text { (2006) }\end{array}$ & $\begin{array}{l}\text { Pode-se dizer que o e-governo refere-se também à transformação da } \\
\text { maneira com que o governo, através do uso da TIC, atinge os seus } \\
\text { objetivos para cumprimento do papel do Estado. }\end{array}$ \\
\hline Abramson; Means (2001) & $\begin{array}{l}\text { Além de ser uma das principais formas de modernização do Estado, } \\
\text { o e-governo está fortemente apoiado numa nova visão do uso das } \\
\text { tecnologias para a prestação de serviços públicos, mudando a maneira } \\
\text { pela qual o governo interage com o cidadão, empresas e outros } \\
\text { governos, não se restringindo à simples automação dos processos e } \\
\text { disponibilização de serviços on-line na Internet. }\end{array}$ \\
\hline
\end{tabular}

Quadro 1- Definições sobre Governo Eletrônico

Fonte: baseado em Santos (2008); Martins e Ramos (2008)

As definiçõoes descritas no Quadro 1 apresentam diferentes enfoques para o conceito de governo eletrônico, sendo que alguns destes têm como foco o papel transformador das Tecnologias da Informação e Comunicação (LANVIN; LEWIN, 2007), tanto na melhoria dos processos internos, melhorias e modernização da administração pública, 
quanto o aperfeiçoamento dos serviços públicos entregues ao cidadão. Em contrapartida a essa corrente de definições, Santos e Reinhard (2011) ressaltam a conceituação desenvolvida pelo Gartner Group, pois esta (diferindo-se das demais) considera a importância da mudança, da transformação institucional e articulação de consenso entre os agentes e interesses, fundamentais para o êxito de um projeto de governo eletrônico.

Assim, perante a existência de diferentes enfoques teóricos optou-se por agrupar as iniciativas de governo eletrônico em três dimensões: (i) e-administração pública; (ii) eserviços públicos e (iii) e-democracia; em conformidade a literatura da área (CUNHA; MIRANDA, 2008; BARBOSA, 2008; HALDENWANG, 2007):

- e-Administração Pública: consiste do uso das Tecnologias da Informação e Comunicação na melhoria da gestão, recursos, processos governamentais e consequentemente o aperfeiçoamento na formulação, implementação, monitoramento e controle das políticas públicas.

- e-Serviços Públicos: caracteriza-se pelo uso dos artefatos tecnológicos, no intuito de melhorar a prestação de serviços ao cidadão, por meio de soluções eletrônicas como os portais de serviços de instituições governamentais;

- e-Democracia: consiste da utilização dos recursos de TIC, no intuito de ampliar a participação do cidadãos nos processos de informação e na tomada de decisão.

Embora a referida divisão torne mais fácil à compreensão das iniciativas de e-gov, Cunha e Miranda (2008) ressaltam que esta divisão em três dimensões é uma categorização com princípios didáticos, uma vez que na prática é difícil estabelecer fronteiras claras entre essas categorias, sendo que em alguns casos uma iniciativa de egov pode se enquadrar em mais de uma dimensão. As soluções de compras eletrônicas são um exemplo de governo eletrônico que atuam nas três dimensões, dado que alteram a estrutura do processo de compras do governo (e-Administração Pública), melhoria na eficiência e qualidade dos serviços (e-Serviços Públicos) e um aumento nos mecanismos de transparência e controle (e-Democracia) (DINIZ et al., 2001 apud BARBOSA, 2008, p.28). 
Além das características supracitadas, Santos e Reinhard (2011, p.2) detalham as principais funções inerentes às iniciativas de governo eletrônico, que são transcritas em seguida:

- Prestação eletrônica de informações e serviços;

- Regulamentação de redes de informação, envolvendo principalmente governança, certificação e tributação;

- Prestação de contas públicas, transparência e monitoramento da execução orçamentária;

- Ensino à distância, alfabetização digital e manutenção de bibliotecas virtuais;

- Difusão cultural com ênfase nas identidades locais, fomento e preservação das culturas locais;

- e-procurement: aquisição de bens e serviços por meio da Internet, como licitações públicas eletrônicas, pregões eletrônicos, cartões de compras governamentais, bolsas de compras públicas virtuais e outros tipos de mercados digitais para bens adquiridos pelo governo;

- Estímulo aos negócios eletrônicos, através da criação de ambientes de transações seguras, especialmente para pequenas e médias empresas.

O referido detalhamento das funções inerentes às iniciativas de e-gov, proposta por Santos e Reinhard (2011), demonstram a interação do setor governamental, tanto com as organizações e empresas (e.g. e-procurement), quanto com os cidadãos (e.g. entrega de serviços). Nesta linha de raciocínio, as interações entre governo e sociedade, podem ser sintetizadas em quatro categorias, cujos detalhes são apresentados em seguida: (TAKAHASHI, 2000; BARBOSA, 2008; SANTOS; REINHARD, 2008; PRADO et al., 2011):

- G2B (Government to Businesses): Consiste das relações entre a esfera governamental e as corporações do setor privado, no intuito de possibilitar a realizações de negócios (e.g. compras, licitações) com o governo, por meios eletrônicos. 
- G2C (Government to Citizens) Trata-se da interação entre governo e cidadãos, no intuito de prover ao contribuinte informações e entregar serviços públicos adequados às suas necessidades. A fim de exemplificar, pode-se destacar a prestação de serviços relacionados à Justiça e Segurança (e.g. realizar boletim de ocorrência on-line); Educação (realizar, por meio da Internet, matrícula de alunos em escolas públicas); Pagamento de Impostos (e.g. Imposto de Renda).

- G2E (Government to Employees) Consiste da interação entre o governo e os servidores públicos, visando disponibilizar informações e serviços necessários para realização das atividades profissionais destes empregados (BARBOSA, 2008, p.33).

- G2G (Government to Governments) Trata-se da relação entre governos, envolvendo diversas agências governamentais e setores de diferentes esferas governamentais, em nível federal, estadual e municipal.

Os conceitos apresentados nesta seção demonstram a amplitude e complexidade das iniciativas de governo eletrônico. Em virtude do escopo desta investigação, o foco deste trabalho recai especificamente nos serviços públicos prestados ao cidadão (e-serviços públicos), mais especificamente em um tipo de interação G2C.

Chahin et al. (2004) enfatizam a variedade de aplicações de e-gov disponíveis no Brasil, abrangendo as dimensões de e-Administração Pública; e-serviços públicos e eDemocracia. Analisando especificamente a dimensão de prestação de serviços públicos ao cidadão, pode-se destacar algumas iniciativas bem conhecidas como a processo (impreterivelmente on line, atualmente) de ajuste anual de imposto de renda; sistemas de agendamento de consultas médicas em hospitais e postos de saúde, sistemas de matricula escolar entre outros. Estes e demais exemplos de serviços públicos são explorados pela pesquisa TIC Domicílios e, consequentemente, serão analisados nesta investigação. 


\subsubsection{Modelo de Adoção de e-gov}

A adoção de iniciativas de governo eletrônico, segundo Reinhard e Santos (2011), costuma ser analisada na literatura sob a uma perspectiva de estágios de evolução que indicam os níveis de informações e serviços prestados.

Santos e Reinhard (2011, p.3) apontam a existência de diversos modelos de adoção de governo eletrônico na literatura: Deloitte e Touche (2001); Layne e Lee (2001); Moon (2002); Siau e Long (2004). Em seguida é realizado um detalhamento sobre o modelo em estágios de adoção de e-gov desenvolvido pela organização das Nações Unidas, conhecido como Web Presence Measurement Model (UN, 2003).

O modelo desenvolvido pela Nações Unidas (UN, 2003) é composto de cinco estágios: Presença Emergente (Emerging Presence); Presença Aprimorada (Enhanced Presence); Presença Interativa; (Interactive Presence); Presença Transacional; (Transactional Presence); Presença em Rede (Networked Presence). As características inerentes a cada uma destas etapas são descritas no Quadro 2.

\begin{tabular}{|c|c|}
\hline Estágio de adoção & Definição \\
\hline $\begin{array}{l}\text { Presença Emergente } \\
\text { (Emerging Presence) }\end{array}$ & $\begin{array}{l}\text { Presença na web por meio de um website oficial, um portal } \\
\text { nacional ou uma pagina oficial, links para os ministérios dos } \\
\text { governos, governos regional/local; administração indireta; a } \\
\text { informação é limitada, básica e estática. }\end{array}$ \\
\hline $\begin{array}{l}\text { Presença Aprimorada } \\
\text { (Enhanced Presence) }\end{array}$ & $\begin{array}{l}\text { Serviços on line são aperfeiçoados para incluir base de dados } \\
\text { e fontes de informação atuais e arquivadas, como as } \\
\text { políticas, leis e regulação, relatórios, informativos } \\
\text { (newsletters) e download das bases de dados. O usuário pode } \\
\text { buscar por um documento e há funcionalidade de ajuda, além } \\
\text { de um mapa de conteúdo do site que é disponibilizado. }\end{array}$ \\
\hline $\begin{array}{l}\text { Presença Interativa } \\
\text { (Interactive Presence) }\end{array}$ & $\begin{array}{l}\text { Disponibilização de serviços governamentais on line de } \\
\text { modo interativo; facilidades para o download on line; links } \\
\text { seguros; facilidades de assinatura digital; capacidade de } \\
\text { áudio e vídeo para informações públicas relevantes. Os } \\
\text { funcionários do governo podem ser contatados através de e- } \\
\text { mail, fax, telefones e correio. O site é atualizado com grande } \\
\text { regularidade. }\end{array}$ \\
\hline $\begin{array}{l}\text { Presença Transacional } \\
\text { (Transactional Presence) }\end{array}$ & $\begin{array}{l}\text { Usuários aptos para conduzir transações on-line, como pagar } \\
\text { multas por transgressões no trânsito, impostos e taxas para } \\
\text { serviços postais por meio de cartão de crédito bancário ou de } \\
\text { débito. Há algumas facilidades para realizações licitações } \\
\text { on-line para contratações pública por meio de links seguros. }\end{array}$ \\
\hline $\begin{array}{c}\text { Presença em Rede } \\
\text { (Networked Presence) }\end{array}$ & $\begin{array}{l}\text { Uma estrutura de G2C baseada em uma rede integrada de } \\
\text { agências públicas para provisão de informações, } \\
\text { conhecimentos e serviços. A ênfase está no feedback para o } \\
\text { governo. Um formulário de comentário na web é } \\
\text { disponibilizado. Um calendário de eventos futuros do } \\
\text { governo existe com um convite do próprio governo à }\end{array}$ \\
\hline
\end{tabular}


participação do cidadão. Governo solicita feedback através de mecanismos de votação on-line, fóruns de discussão e facilidades para consulta on line.

Quadro 2 - Estágios de adoção de governo eletrônico

Fonte: baseado em UN (2003, p.13)

Segundo UN (2003) o referido modelo se baseia em uma escala de cinco estágios que visa indicar a presença on line das organizações públicas dos países membros da Organização das Nações Unidas. Tais países são classificados com base nos produtos e serviços oferecidos por suas instituições organizacionais.

\subsubsection{E-Government Readiness Index}

Perante o potencial benefício referente à adoção de iniciativas de governo eletrônico e a necessidade de se avaliar o seu impacto, organizações internacionais vêm realizando esforços no sentido de criar indicadores que permitam evidenciar a capacidade e prontidão (readiness) do país em relação ao uso de governo eletrônico. Neste sentido, o Programa de Administração Pública das Nações Unidas (UNPAP) criou desde 2003 o E-Government Readiness Index (EGRI). O referido índice se baseia em uma medida composta da capacidade e disposição dos países em utilizar e-gov para o desenvolvimento (ICT4D). Conforme esquematizado na Figura 2, o EGRI consiste em uma medida composta que se baseia em três dimensões: (i) escopo e qualidade dos serviços on-line, mensurado por meio do modelo de estágios de adoção de e-gov (UN, 2003); (ii) Conectividade de Telecomunicações (infraestrutura); (iii) Capital Humano (UN, 2003; 2005). 


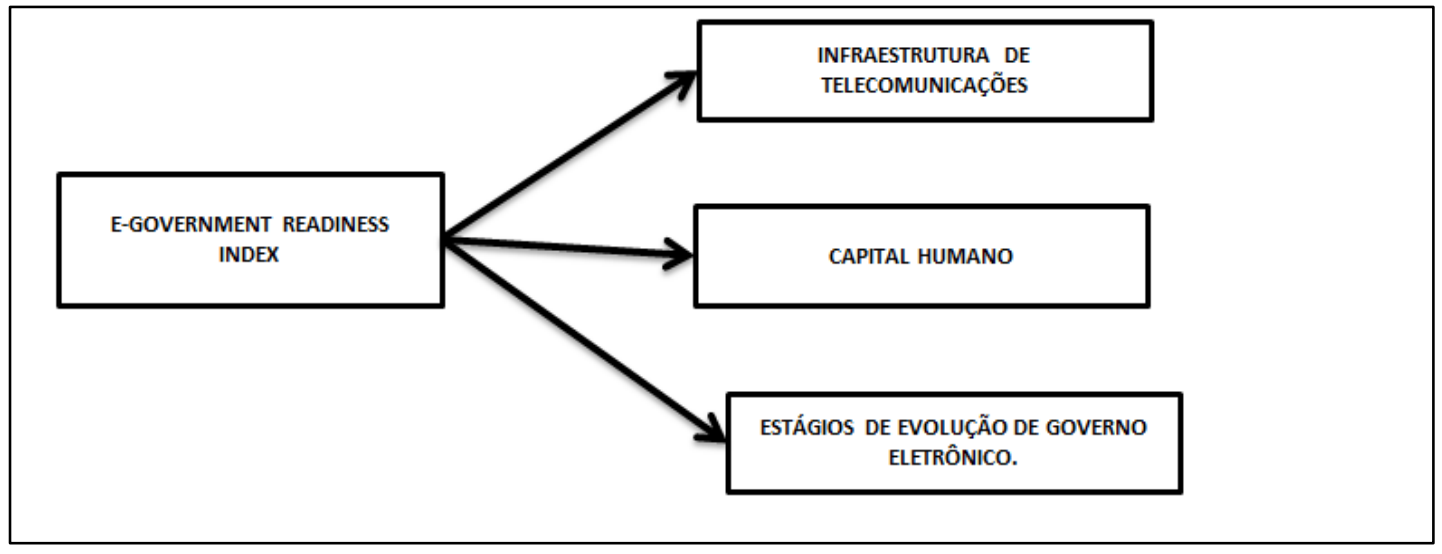

Figura 2- Dimensões do E-Government Readiness Index.

Uma das medidas que compõem o EGRI consiste do modelo de estágios de evolução das iniciativas, tal medida visa demonstrar a presença on-line dos serviços da administração pública. O referido modelo não será detalhado, visto que este já foi descrito na seção anterior.

A segunda medida visa avaliar a capacidade de infraestrutura de telecomunicações do país. Para operacionalizar esse conceito utiliza-se o Índice de Infraestrutura de Telecomunicações (IIT), que consiste em uma medida composta pelas seguintes medidas primitivas (ou índices primários): (i) número de computadores pessoais por grupo de 1000 pessoas; (ii) número de internautas por grupo de 1000 pessoas; (iii) número de linhas de telefone por grupo de 1000 pessoas; (iv) proporção da população conectada (on line population); (v) número de telefones celulares por grupo de 1000 pessoas; (vi) número de aparelhos de televisão por grupo de 1000 pessoas. Tais medidas são obtidas, por meio da ITU e do departamento de estatísticas da organização das Nações Unidas e Banco Mundial (UN, 2005, p.18).

A última dimensão EGRI esquematizada na Figura 2 consiste do Índice de Capital Humano, que consiste de uma medida avalia a competência escolar do país. Tal medida (capital humano) se fundamenta no índice de educação, desenvolvido pelo Programa das Nações Unidas para o Desenvolvimento (PNUD), que é composto pela taxa de alfabetização dos adultos e taxa bruta de alunos matriculados no ensino primário, secundário e terciário independentemente da idade, assim como o percentual da população em idade escolar para cada nível (UN, 2005, p.19). 


\subsection{Abordagem das Capacidades}

O economista e prêmio Nobel Amartya Sen é responsável por diversas contribuições teóricas em uma grande quantidade de temas. Em particular o autor se destaca pela sua Abordagem das Capacidades (Capability Approach) que é a base para o paradigma de desenvolvimento humano (SEN, 2000; MACHADO; PAMPLONA, 2008; REINHARD, 2010). Além disso, a Teoria das Capacidades é base para diversas métricas e índices de desenvolvimento, por exemplo, o IDH (Índice de Desenvolvimento Humano) e o ICT Development Index (ITU, 2010; 2011).

A abordagem teórica das Capacidades foi desenvolvida visando oferecer uma base objetiva, por meio da qual fosse possível realizar comparações interpessoais do bem estar (PRENDERGAST 2005; ROBEYNS, 2005; MACHADO; PAMPLONA, 2008;). Tal framework teórico, consequentemente, permitiria superar as limitações da abordagem utilitarista, em que este tipo de comparação - fundamental para economia do bem estar - não seria possível. Assim, a Teoria das Capacidades poderia se tornar um referencial alternativo, por meio do qual seria possível analisar a vida que as pessoas realmente levam (MACHADO; PAMPLONA, 2008).

No intuito de sistematizar o entendimento sobre a Teoria das Capacidades é necessário inicialmente assumir que os bens ou recursos possuídos, sob a ótica dessa abordagem teórica, sejam vistos em termos de suas propriedades e características. Segundo Sen (2000) tais características são denominadas como propriedades desejáveis. Dessa forma, a partir do momento que um indivíduo adquire ou toma posse de um determinado objeto (bem) a pessoa passa a ter condições de comandar essas propriedades desejáveis. No entanto, Sen (2000) alerta para o fato de que as características nada informam sobre a maneira com que as pessoas se utilizarão de um determinado bem. Assim, Machado e Pamplona (2008) afirmam que não se deve considerar simplesmente as características de um determinado bem ou recurso, pois são propriedades invariáveis em relação às pessoas que a possuem, portanto, o que muda é apenas o que as pessoas são capazes de realizar a partir desses bens e de suas características (MACHADO; PAMPLONA, 2008, p. 69). À luz desses conceitos, fica claro que a simples disponibilização de um recurso, não necessariamente implicará em 
um aumento do bem estar dos membros de um determinado local, comunidade, uma vez que a priori não se sabe como tais recursos serão utilizados.

Em virtude da limitação exposta, Sen (2000) argumenta que ao se referir ao bem-estar das pessoas, deve se considerar os seus "funcionamentos" (functioning), ou seja, "o que uma pessoa consegue realizar com as commodities (o bem) e as características que ela comanda" (SEN, 1999 apud MACHADO; PAMPLONA, 2008). Portanto, o funcionamento alcançado por um indivíduo, vai depender tanto do recurso (bem) que ele possui, mas também dos resultados obtidos referentes à maneira como tal recurso é utilizado. Vale ressaltar que um indivíduo pode ter diversos tipos de funcionamentos, tendo, então, a liberdade para escolher um dentre esses diferentes tipos de funcionamentos. Assim, a esse conjunto de diversos tipos de "funcionamentos" (isto é, as diversas maneiras que um indivíduo pode se utilizar do recurso) que uma pessoa pode atingir é dado o nome de Capacidades (MACHADO; PAMPLONA, 2008, p. 70).

Sen (2000) ressalta que o processo de conversão das “características dos bens" em "funcionalidades" é condicionado por um grande número de fatores, tanto pessoais, quanto culturais e sociais, que são denominados de fatores de conversão. Nessa linha de raciocínio, Sen (1999 apud MACHADO; PAMPLONA, 2008) alerta que ao compararmos o "funcionamento" relacionado a duas pessoas diferentes, não basta compararmos os bens que essas pessoas possuem, em virtude desses diferentes fatores de conversão. A fim de ilustrar esse conceito pode-se pensar (exemplo retirado de Machado e Pamplona (2008)) no caso de duas pessoas que possuem acesso à mesma cesta de bens alimentares. Embora esses indivíduos tenham acesso ao mesmo recurso, eles podem ter "funcionamentos" totalmente distintos no que se refere à nutrição. Essa diferenciação de funcionamentos decorre em virtude de fatores como: condições de saúde distintas ou metabolismos diferentes. Assim, haveria diversos fatores de conversão que influenciariam na determinação das capacidades - isto é, do conjunto de funcionamentos dentre os quais um indivíduo pode escolher (MACHADO; PAMPLONA, p. 71). 


\subsection{Pesquisa TIC Domicílios}

A presente investigação científica tem como objeto de estudo os dados gerados pela Pesquisa TIC Domicílios - iniciativa coordenada pelo Centro de Estudos sobre as Tecnologias da Informação e Comunicação (CETIC.br). No intuito de realizar uma contextualização sobre a estrutura institucional, que dá suporte para coleta de dados e geração de indicadores sobre a apropriação das TICs pela população brasileira, nesta seção será realizada uma breve descrição sobre (i) Comitê Gestor da Internet no Brasil (CGI.br); (ii) Núcleo de Informação e Coordenação do Ponto BR (NIC.br); (iii) Centro de Estudos sobre as Tecnologias da Informação e Comunicação (CETIC.br);

\subsubsection{Comitê Gestor da Internet no Brasil}

O Comitê Gestor da Internet no Brasil (CGI.br) é uma instituição criada por meio da Portaria Interministerial $n^{\circ} 147$, de 31 de Maio de 1995, que foi alterada pelo Decreto Presidencial $\mathrm{n}^{\circ} 4829$, de 3 de setembro de 2003. O CGI.br foi instituído, no intuito de coordenar e integrar todas as atividades de serviços de Internet do Brasil, consequentemente, promovendo qualidade técnica, disseminação e inovação aos serviços ofertados (CGI, 2012).

A estrutura do CGI.br é composta por membros do governo, setor empresarial, comunidade acadêmica e do terceiro setor. Portanto, constituindo um modelo de governança da internet pioneiro, no que se refere à efetiva participação da sociedade na tomada de decisões que envolvem aspectos de implantação, administração e uso da rede (CGI, 2012; ADACHI, 2011). Assim, desde julho de 2004, o Comitê Gestor da Internet no Brasil estabeleceu mecanismos para eleger de maneira democrática seus representantes da sociedade civil, que estão representados da seguinte forma:

- Nove representantes do Governo Federal;

- Quatro representantes do setor empresarial;

- Quatro representantes do Terceiro Setor;

- Três representantes da Comunidade Científico-Acadêmica;

- Um representante do notório saber em assunto de Internet; 


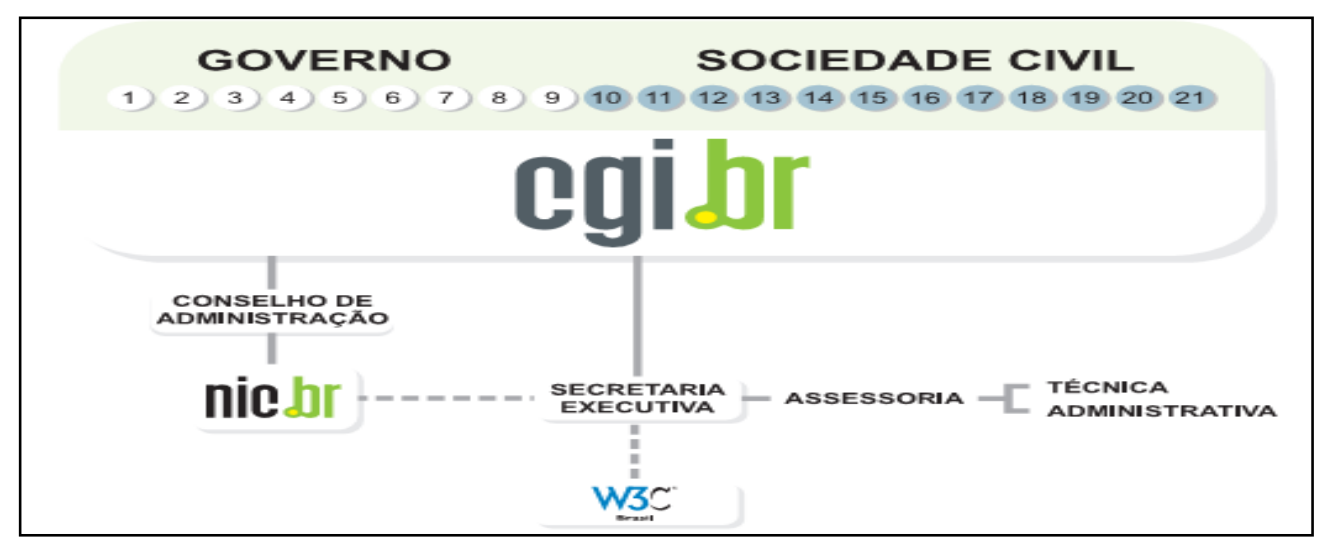

Figura 3- Representantes no CGI.br.

Fonte: NIC (2010)

A Figura 3 busca sintetizar a representação deste modelo de governança multistakeholder, composta tanto por membros da esfera governamental federal (com 9 representantes), quanto da sociedade civil (com 12 representantes, que pertencem ao setor empresarial, comunidade acadêmica, terceiro setor e representante do notório conhecimento).

Entre as principais atribuições do Comitê Gestor da Internet no Brasil, destacam-se (CGI, 2012):

- Proposição de normas e procedimentos relativos à regulamentação das atividades na internet;

- Recomendações de padrões e procedimentos técnicos operacionais para internet no Brasil;

- Promoção de estudos e padrões técnicos para segurança das redes e dos serviços ofertados no país;

- Coordenação e atribuição dos endereços de Internet (IP) e do registro de nomes de domínios usando "Ponto BR (.br)";

- Coleta, organização e disseminação de Informações sobre os serviços de internet, incluindo indicadores e estatísticas. 


\subsubsection{Núcleo de Informação e Coordenação do Ponto BR (NIC.br)}

Conforme exposto o CGI.br é responsável por coordenar e manter uma série de projetos de vital importância para manutenção e desenvolvimento da internet no país. Contudo, para execução e operacionalização das decisões CGI.br foi criada uma entidade sem fins lucrativos denominada de "Núcleo de Informação e Coordenação do Ponto BR"(NIC.br). Tal entidade civil foi instituída em dezembro de 2005, com objetivo de implementar as ações e decisões do CGI.br.

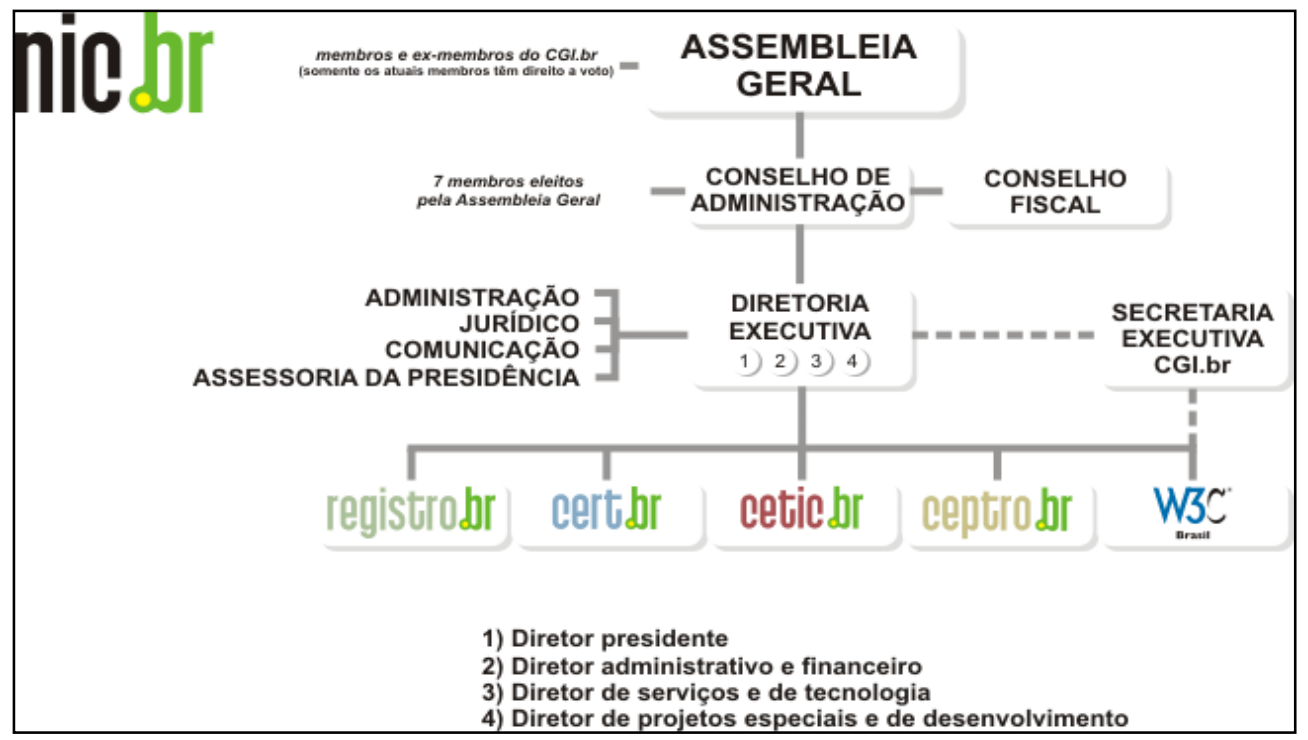

Figura 4- Organograma do NIC.br.

Fonte: CGI (2012)

A Figura 4 representa esquematicamente a estrutura organizacional do Núcleo de Informação e Coordenação do Ponto BR, composto por quatro assessorias, quatro centros, além de um escritório brasileiro do W3C (World Wide Web Consortium). A administração do NIC.br é de responsabilidade dos seguintes órgãos:

1. Assembleia Geral: Consiste do órgão supremo - composto por associados fundadores, especiais e honorários - que possui poderes para deliberar sobre quaisquer assuntos de interesse do NIC.br;

2. Conselho de Administração: Este órgão é responsável pelo controle da administração do NIC.br, sendo composto por sete membros titulares e sete 
suplentes que são eleitos pela Assembleia Geral. Convém ressaltar que esses membros são representantes tanto do setor governamental, quanto da sociedade civil, ou seja, mantendo os princípios de participação democrática da sociedade;

3. Conselho Fiscal: Órgão encarregado de realizar de fiscalização contábil e financeira do NIC.br;

4. Diretoria Executiva: Trata-se do órgão responsável pela administração executiva do NIC.br, cabendo-lhe cumprir a legislação pertinente, o Estatuto, o Regimento Interno e as deliberações do Conselho de Administração.

Além dessas quatro assessorias o NIC.br é composto por um escritório no Brasil do W3C e de quatro centros de pesquisa (CERT.br, CEPTRO.br, REGISTRO.br, CETIC.br), cujas as características são aqui descritas brevemente:

1. Registro.br: Assim, como o próprio nome já sugere, consiste do centro responsável por executar atividades de registros de domínio, administração e publicação do DNS (Domain Name System) para o domínio do “ponto br (.br)”, além de ser responsável pela manutenção e distribuição de endereços (endereços IP) na internet.

2. Cert.br: O Centro de Estudos, Respostas e Tratamento de Incidentes de Segurança no Brasil é responsável por atividades relacionadas à segurança na internet. Suas principais atribuições envolvem: (i) tratamento de incidentes de segurança; (ii) apoio a administradores de redes e usuários de internet do pais; (iii) produção de documentos relacionados à segurança de redes; (iv) manutenção de estatísticas sobre spams; (v) criação de mecanismos de alerta antecipado para redes possivelmente envolvidas em atividades maliciosas.

3. Cetic.br: O Centro de Estudos sobre as Tecnologias da Informação e Comunicação é responsável pela produção de indicadores e estatísticas que mensurem a disponibilidade e uso da internet no Brasil (CGI, 2012). 
4. Ceptro.br: O Centro de Estudos e Pesquisas em Tecnologia de Redes e Operações (CEPTRO.br) é a órgão responsável pelo desenvolvimentos de projetos que buscam melhorar a qualidade da Internet no Brasil, disseminar seu uso. Todavia, este centro tem como escopo atuar em aspectos mais técnicos da infraestrutura de internet no país.

5. O W3C (World Wide Web Consortium) consiste de um consórcio internacional, cuja missão é conduzir o desenvolvimento da web. Para tanto, este órgão e responsável pela criação de padrões e diretrizes que garantam a evolução da web de maneira permanente.

\subsubsection{Centro de Estudos sobre as Tecnologias da Informação e Comunicação}

Dentre as atividades acima apresentadas, o foco desta investigação recai nas atividades desenvolvidas pelo CETIC.br . O Centro de Estudos sobre as Tecnologias da Informação e Comunicação, fundado em 2005 é um dos departamentos do NIC.br, com a responsabilidade de coordenar estudos e publicar estatísticas e indicadores referentes à disponibilidade e uso dos recursos de TIC no Brasil (com ênfase na Internet). Os resultados dos estudos do CETIC.br são referência nacional e um importante insumo no auxílio ao desenvolvimento de políticas públicas que garantam o acesso da população às TICs.

Entre as diversas atribuições do Comitê Gestor da Internet no Brasil, o CETIC.br é responsável pelas seguintes atividades (CGI, 2012, ipsis litteris):

- Estabelecer diretrizes estratégicas relacionadas ao uso e desenvolvimento da Internet no Brasil;

- Propor programas de pesquisa e desenvolvimento que estejam relacionados à Internet, que permitam a manutenção do nível de qualidade técnica e inovação no uso, bem como estimular a sua disseminação em todo território nacional, buscando oportunidades constantes de agregação de valor aos bens e serviços a ela vinculados;

- Promover estudos e recomendar procedimentos, normas e padrões técnicos e operacionais, para a segurança das redes e serviços de Internet, bem assim para a sua crescente e adequada utilização pela sociedade; 
Os estudos desenvolvidos pelo CETIC.br, buscam oferecer dados que permitam, tanto mapear a disponibilidade e uso das TIC pela população e por organizações brasileiras, quanto o impacto socioeconômico dos recursos tecnológicos, nos mais diversos cenários. No intuito de gerar indicadores e estatísticas que possibilitem atingir os objetivos acima supracitados, atualmente, o CETIC.br, coordena cerca de dez estudos, conforme ilustrado no Quadro 3. Visto que a Pesquisa TIC Domicílios é alvo desta dissertação, suas características e princípios serão discutidos especificamente na próxima seção.

\begin{tabular}{|c|c|}
\hline \multicolumn{2}{|c|}{$\begin{array}{l}\text { Pesquisas desenvolvidas pelo Centro de Estudos sobre as Tecnologias da Informação e } \\
\text { Comunicação (CETIC.br) }\end{array}$} \\
\hline 1. TIC Empresas & 6. TIC Educação \\
\hline 2. TIC Crianças & 7. TIC Provedores \\
\hline 3. TIC Kids Online & 8. TIC Lan Houses e Telecentros \\
\hline 4. TIC Governo Eletrônico & 9. TIC Organizações sem fins lucrativos \\
\hline 5. TIC Domicílios & 10. TIC Saúde \\
\hline
\end{tabular}

Quadro 3 - Conjunto de estudos coordenado pelo CETIC.br.

Fonte: desenvolvido pelo autor

Tendo sua primeira edição realizada em 2005, a pesquisa TIC Empresas é um dos primeiros estudos desenvolvidos pelo CETIC.br (junto com a pesquisa TIC Domicílios) e tem como objetivo medir o acesso e o uso das Tecnologias da Informação e Comunicação (TIC) em empresas que possuem 10 ou mais funcionários, que pertençam ao setor organizado da economia no Brasil (CETIC, 2012).

A fim de mapear o impacto das TICs entre as crianças e adolescentes, o CETIC.br coordena dois estudos: as pesquisa TIC Crianças e TIC Kids Online. A Pesquisa TIC Crianças, realizada a primeira vez em 2009 tem como foco medir o uso das TICs pelas crianças na faixa etária entre 5 e 9 anos. Neste estudo são avaliados questões, referentes ao: (i) acesso individual a computadores e à Internet; (ii) atividades desenvolvidas na rede; (iii) habilidades para o uso do computador, Internet e acesso sem fio. Recém criada em 2012, a Pesquisa TIC Kids Online tem como objetivo medir o uso das TIC pelas crianças e adolescentes com faixa etária entre 9 e 16 anos. O foco desta pesquisa recai nas oportunidades e riscos relacionados ao uso da Internet (CETIC, 2012). 
Além das pesquisas supracitadas, o Centro de Estudos sobre as Tecnologias da Informação e Comunicação (CETIC.br) é responsável pela realização dos seguintes estudos: (i) Pesquisa TIC Governo Eletrônico, (ii) TIC Educação, (iii) TIC Provedores, (iv) TIC Lan Houses e Telecentros e (v) TIC Organizações sem fins lucrativos cujas características são descritas em seguida:

- A Pesquisa TIC Governo Eletrônico tem como escopo identificar as necessidades dos cidadãos e empresas com relação a serviços públicos de governo eletrônico (CETIC, 2012);

- A Pesquisa TIC Educação tem como objetivo identificar os diferentes tipos de usos e apropriações da Internet banda larga na rotina escolar das escolas públicas, a partir da prática docente e gestão administrativa;

- A Pesquisa TIC Provedores visa fomentar a expansão do setor de provedores de Internet, apresentando um panorama completo deste mercado no Brasil, a partir da construção de um Cadastro Nacional de Provedores de acesso à Internet;

- A pesquisa TIC Telencentros e Lan Houses. Ambas pesquisas foram criadas em 2010, no intuito de compreender a realidade dos centros de acesso público no Brasil. Na pesquisa TIC Lan House são explorados aspectos relacionados à gestão deste tipo de negócio, além dos tipos de serviços prestados, preços práticos e o perfil do consumidor. Em contrapartida, a pesquisa TIC Telecentro avalia as características e amplitude destes ambientes de acesso no país;

- A Pesquisa TIC Organização Sem Fins Lucrativos busca compreender o uso das Tecnologias da Informação e Comunicação em organizações do terceiro setor, no intuito de avaliar o impacto entre as instituições deste setor e a comunidade de atuação; 
- A Pesquisa TIC Saúde visa gerar dados quer permitam melhor compreender a adoção das Tecnologias da Informação e Comunicação (TIC) nos estabelecimentos de saúde e o uso destes artefatos tecnológicos pelos profissionais da área. Trata-se de uma iniciativa inovadora no Brasil, no intuito de se medir e observar de maneira sistemática o uso das TICs na área de saúde (CGI, 2013).

\subsubsection{Histórico da Pesquisa TIC Domicílios}

O Centro de Estudos sobre as Tecnologias da Informação (CETIC.br) se destaca nacionalmente na produção de indicadores e estatísticas referente a sociedade de informação no Brasil. Porém, segundo CGI (2010, p.16), o pensamento de desenvolver e conduzir pesquisas especializadas para mensurar o nível da posse e uso das TICs no país iniciou em 2004, especificamente durante um evento regional realizado em São Paulo, denominado NAPLA (Network Access Point Latin America). No referido evento, o Comitê Gestor da Internet no Brasil realizou a apresentação de um antigo projeto que visava produzir informação sistemática sobre o crescimento do acesso e do uso da internet no país. Na referida apresentação foram utilizados alguns instrumentos de coleta de dados (por exemplo: questionários estruturados), foi definida uma lista preliminar de indicadores e desenhou-se uma proposta de projeto de pesquisa. Tal projeto impulsionou a criação do que futuramente viria ser conhecido com o projeto de Pesquisa TIC (CGI, 2010, p.16).

Após a realização desse evento, o CGI.br foi convidado a participar da primeira reunião realizada pelo Observatório da Sociedade da Informação na América Latina e Caribe (OSILAC), um projeto específico da Comissão Econômica para América Latina e Caribe (CEPAL). O foco desta reunião foi realizar um acordo entre os países, no sentido de definir um conjunto de indicadores-chave sobre as TICs, no intuito de produzir informações comparáveis sobre a apropriação dos recursos tecnológicos pela população da América Latina e Caribe. Tal acordo possibilitou a criação e fortalecimento de uma rede de centros e institutos nacionais de estatística. 
Em seguida, o Comitê Gestor da Internet no Brasil tratou de realizar uma parceria com o Instituto Brasileiro de Geografia e Estatística (IBGE), a fim de criar um módulo de questões sobre o uso das TICs dentro da pesquisa do PNAD 2005. Todavia, embora essa parceria tenha sido um avanço considerável notava-se ainda existir a necessidade de se aprofundar a investigação sobre o impacto das TICs em cenários específicos, por exemplo: governo eletrônico, comércio eletrônico, habilidades do internauta entre outras. A partir dessa demanda foi desenvolvida a primeira edição da Pesquisa TIC Domicílios, cujas características são descritas na próxima seção (CGI, 2010).

\subsubsection{Caracterização da Pesquisa TIC Domicílios}

A Pesquisa sobre o Uso das Tecnologias da Informação e Comunicação no Brasil, conhecida como Pesquisa TIC Domicílios, consiste de um estudo, do tipo Survey (cf. FOWLER, 2009), que busca mapear a disponibilidade e uso dos recursos de TIC entre a população brasileira na faixa etária a partir dos 10 anos. Tendo sua primeira edição publicada em 2005, atualmente a pesquisa se encontra em sua sétima edição (Pesquisa TIC Domicílios 2011).

No decorrer destes sete anos, a Pesquisa TIC Domicílios buscou sempre se manter em conformidade com os padrões metodológicos desenvolvidos pela OCDE (Organização para Cooperação e Desenvolvimento Econômico) e da Eurostat (Instituto de Estatísticas da Comissão Europeia). Além disso, foram consideradas as orientações contidas na documentação metodológica produzida pelo Observatório para Sociedade da Informação na América Latina e Caribe (OSILAC), da Comissão Econômica para a América Latina e Caribe nas Nações Unidas (CEPAL). Tal conformidade metodológica com os padrões internacionais dá maior credibilidade e consistência à pesquisa realizada pelo CETIC.br, além possibilitar a comparabilidade entre a realidade brasileira com a de outros países.

Vale ressaltar que na construção do plano amostral da Pesquisa TIC Domicílios (todas as edições) são consideradas as informações provenientes do Censo Demográfico Brasileiro, referente ao ano de 2000 (todas as edições) e da Pesquisa 
Nacional por Amostra de Domicílios (PNAD), a fim de produzir um retrato representativo da população brasileira. A Figura 5 ilustra o plano amostral da Pesquisa TIC Domicílios 2010, no intuito de sintetizar cada um dos componentes considerados na composição do plano amostral do estudo.

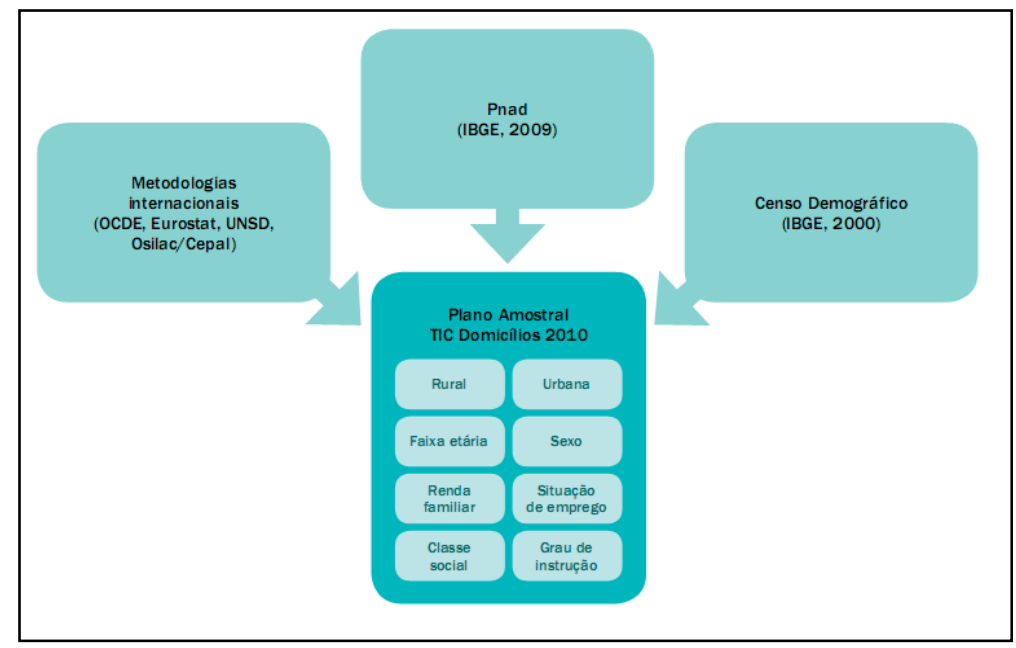

Figura 5- Procedimento do Desenho Amostral da Pesquisa TIC Domicílios 2010

Fonte: CGI (2011, p.118)

Visando garantir a representatividade da população brasileira, buscou-se incorporar ao desenho amostral da Pesquisa TIC Domicílios toda a diversidade regional, econômica e social do país. Para tanto, o processo de amostragem adotado pela pesquisa, pode ser classificado como amostragem sistemática, estratificada por conglomerados com cotas no último estágio (CGI, 2010b). O processo de amostragem adotado na pesquisa é composto por três etapas: (i) seleção dos municípios; (2) dos municípios escolhidos na etapa anterior é realizado um sorteio dos setores censitários; (3) escolha dos domicílios e dos respondentes finais, utilizando-se de cotas baseadas em estudos oficiais como PNAD e Censo 2000 (ambos os documentos produzidos pelo IBGE). Apesar da utilização das cotas, a amostra resultante pode ser classificada como probabilística e as cotas são utilizadas, no intuito de garantir que na amostra resultante todos os distintos grupos que compõem a população brasileira estejam devidamente representados.

Convém ressaltar que durante as edições da Pesquisa TIC Domicílios referente aos anos de 2005 a 2010, utilizou-se de uma amostra extra (oversample), composta apenas pelos usuários de Internet, no intuito de assegurar a leitura dos indicadores de uso da internet, cuja população de respondentes ainda era pequena para se obtivesse a 
precisão desejada (CGI, 2011). Na edição de 2011 da pesquisa TIC Domicílios ocorreu uma alteração no processo de amostragem, que ao invés de uma abordagem em três etapas - conforme supracitado - adotou-se uma abordagem de amostragem mista, na qual metade da amostra de domicílios e moradores foi selecionada de maneira probabilística (amostra probabilística), enquanto que a outra metade adotou procedimento de amostragem por cotas de perfil populacional (amostra por cotas) (CGI, 2012). Vale ressaltar que na edição de 2011 não houve a necessidade de se utilizar uma amostra extra de internautas (oversample).

\begin{tabular}{|l|c|c|c|}
\multicolumn{4}{|c|}{ Pesquisa TIC Domicílios (2005-2011): Precisão do Estudo } \\
\hline Ano & Tamanho da Amostra & Erro Amostral (nacional) & Erro Amostral (Regional) \\
\hline $\mathbf{2 0 0 5}$ & 8540 & $1,5 \%$ & $5 \%$ \\
\hline $\mathbf{2 0 0 6}$ & 10510 & $1,5 \%$ & $5 \%$ \\
\hline $\mathbf{2 0 0 7}$ & 17000 & $0,8 \%$ & $2 \%$ \\
\hline $\mathbf{2 0 0 8}$ & 21520 & $0,7 \%$ & $2 \%$ \\
\hline $\mathbf{2 0 0 9}$ & 19998 & $0,7 \%$ & $2 \%$ \\
\hline $\mathbf{2 0 1 0}$ & 23107 & $0,6 \%$ & $2 \%$ \\
\hline $\mathbf{2 0 1 1}$ & 25000 & $1,5 \%$ & $4 \%$ \\
\hline
\end{tabular}

Quadro 4 - Precisão Amostral da Pesquisa TIC Domicílios

Fonte: desenvolvido pelo autor

Analisando sob uma perspectiva histórica é possível evidenciar uma evolução nos procedimentos adotados pelo CETIC.br, a fim de aumentar a precisão da investigação. O Quadro 4 sintetiza as informações referentes: ao (i) tamanho da amostra, o (ii) erro amostral (considerando o âmbito nacional) e a (iii) maior taxa de erro amostral, por região (i.e Norte, Nordeste, Sul, Sudeste). Em todos os anos a pesquisa foi projetada visando manter o nível de confiabilidade de 95\%. Dessa forma, os dados gerados permitem calcular indicadores que refletem tanto a realidade nacional (total Brasil), quanto os indicadores para realidade urbana e rural. Porém, convém ressaltar que entre os anos de 2005 e 2007 o desenho amostral da pesquisa TIC Domicílios era composto apenas pelos cidadãos residentes em regiões urbanas e a partir da edição de 2008 adicionou-se a amostra os indivíduos provenientes de áreas rurais do país.

No que se refere à estrutura do estudo e as temáticas abordadas, o questionário da Pesquisa TIC Domicílios, pode ser dividido em duas grandes seções. A primeira parte do questionário visa capturar as características socioeconômicas dos respondentes. Assim, nesta seção são captados os dados referentes às seguintes variáveis: (i) Área; 
(ii) Região; (iii) Sexo; (iv) Grau de Instrução; (v) Situação do Emprego; (vi) Faixa Etária; (vii) Renda Familiar; (viii) Classe Social.

A segunda parte do questionário é composta pelas questões que visam mapear os aspectos relacionados à disponibilidade e ao uso dos recursos tecnológicos e da internet e tais variáveis são agrupadas nos seguintes módulos: (i) Acesso às Tecnologias da Informação e Comunicação; (ii) Uso do Computador; (iii) Uso da Internet; (iv) Uso de Serviços de Governo Eletrônico; (iv) Habilidades com o Computador e Internet; (v) Acesso sem Fio (uso do celular); (vi) Intenção de aquisição de equipamentos e serviços de TIC. Em consonância à temática desta investigação, explorou-se os atributos do bloco temático "uso de serviços de governo eletrônico".

\subsection{Modelo de Referência}

A presente investigação adota como principal eixo teórico a abordagem das Capacidades desenvolvida pelo economista Amartya Sen (2000). Segundo este autor, a simples disponibilização de um bem ou recurso, não implica diretamente em um aumento do bem estar de uma sociedade, em virtude da diversidade de maneiras com que este recurso pode ser utilizado (capacidades ou capabilities) e os resultados obtidos por meio do uso efetivo deste bem (funcionamento ou functioning).

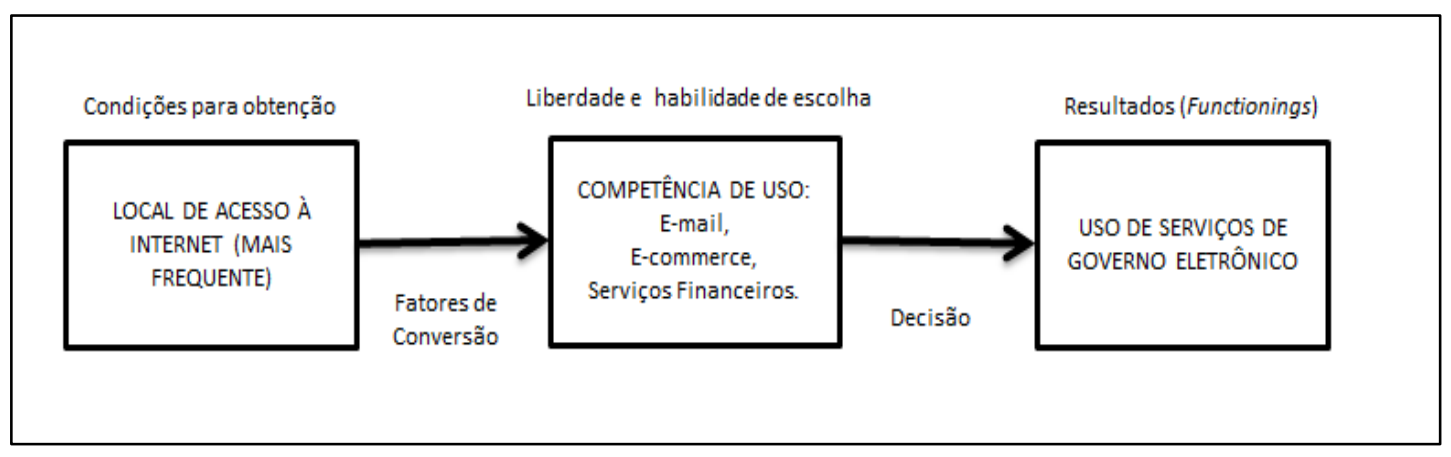

Figura 6- Modelo de Referência: Abordagem das Capacidades de Amartya Sen.

Fonte: adaptado de Reinhard (2010); Robeyns (2005). 
No intuito de manter a conformidade da Teoria das Capacidades aos pressupostos subjacentes desta investigação, foi desenvolvido o modelo de referência ilustrado na Figura 6. O referido modelo visa demonstrar a partir da disponibilização do acesso à internet, quais os fatores que compelem o indivíduo a se utilizar dos serviços de governo eletrônico. Em consonância à Figura 6, o modelo é composto de três construtos principais: (i) condições para obtenção (ou acesso) ao recurso; (ii) liberdade e habilidade de escolha (capacidades); (iii) resultados (functionings).

A fim de operacionalizar os princípios inerentes ao primeiro construto utilizou-se da variável "Local de Acesso à Internet (mais frequente)". Optou-se por considerar apenas o local de acesso mais frequente ou preferencial, por entender que este seria o ambiente em que o usuário se sentiria mais confortável na realização de atividades de e-gov.

O segundo construto visa sintetizar as diferentes capacidades (capabilities) deste internauta, isto é, os diferentes tipos de competências de uso de internet que este usuário possui. Para operacionalizar o referido construto, foram estipuladas as seguintes varáveis como proxies de competência de uso: (i) Uso de e-mail; (ii) Uso de Ecommerce (apenas atividades relacionadas à busca de produtos ou serviços na internet); (iii) Uso de Serviços Financeiros (atividades de consultas à conta corrente, cartão de crédito ou poupança). A escolha da variável uso de e-mail foi definida como proxy, por se entender que esta seja uma competência básica de comunicação, logo, sendo um requisito na utilização de alguns serviços de e-gov (e.g. fazer boletim de ocorrência). A escolha da proxy e-commerce, está alinhada à discussão realizada por Barbosa et al. (2009) que evidenciam que no Brasil os serviços de governo eletrônico passaram a se expandir, após a consolidação do fenômeno de comércio eletrônico. Portanto, fundamentando a conjectura de que o uso de e-commerce é uma competência prévia na utilização de e-gov. Definiu-se a variável de serviços financeiros como uma proxy de competência, pela conjectura de que esta atividade acaba sendo utilizada direta ou indiretamente na utilização dos diversos tipos de serviços de e-gov.

Conforme será detalhado na Seção 3.3, as variáveis de e-commerce e serviços financeiros visam avaliar se o internauta, respectivamente, já realizou atividades de "busca e produtos ou serviços na internet" e "consultas à conta corrente, cartão de crédito ou poupança (na internet)". Em ambos os casos, as referidas variáveis não 
representam efetivamente a transação de compras on-line (no caso de e-commerce) ou transação bancária por meio do internet banking (no caso de serviços financeiros). Visto que determinados grupos de usuários podem ter a competência de realizar as transações supracitadas (e-commerce e serviços financeiros), porém possam se sintam inibidos de realizá-las em virtude de aspectos relacionados à segurança da informação ou de ordem de preferência pessoal, optou-se por não representar as proxies de comércio eletrônico e serviços financeiros, por meio de suas transações.

Por fim, o último construto sintetiza o fenômeno alvo desta investigação, isto é, o uso de serviços de governo eletrônico. Para tanto, este conceito foi operacionalizado de duas maneiras: (i) inicialmente ele foi medido por meio de uma primitiva que considera apenas o uso/não uso de e-gov. Em seguida, a fim de qualificar o tipo de uso, foram exploradas as diferentes categorias de serviços de e-gov (e.g. pagamento de impostos, solicitar matrícula em escolas etc.).

A literatura da área de Sistemas de Informação possui uma série de modelos, no intuito de compreender o uso e a adoção dos recursos tecnológicos. Tradicionalmente, tais estudos podem ser categorizados em duas grandes correntes teóricas. A primeira delas congrega os seguintes modelos de adoção de TIC: Difusão da Inovação (ROGERS, 1995; 2004); TAM (DAVIS , 1989); TAM 2 (VENKATESH; DAVIS, 2000); UTAUT (VENKATESH et al., 2003). Segundo Saccol (2005) os trabalhos desta corrente teórica analisam o processo de adoção dos recursos tecnológicos sob a ótica de fatores, isto é, aspectos (ou variáveis) que influem na utilização do artefato de TIC. Tais trabalhos se fundamentam em um paradigma positivista funcionalista.

Em contrapartida, a segunda corrente de estudos congregam algumas das seguintes abordagens teóricas: Modelo Estruturacional da Tecnologia (ORLIKOWSKI, 1992; ORLIKOWSK; ROBEY, 1991; ORLIKOWSKI, 2000); Teoria da Domesticação; Teoria da Hospitalidade (CIBORRA, 1996; SACCOL; REINHARD, 2005). Tais autores e abordagens analisam o uso e adoção das TICs, sob a ótica do processo de adoção dos artefatos tecnológicos. Diferindo-se da primeira corrente, tais autores se posicionam em um paradigma interpretativista (WALSHAM, 1995) considerando aspectos sociais envolvidos neste processo de adoção e uso das TICs. 
Em conformidade as características desta investigação (explicitadas nas seções introdutórias), este trabalho se situa nos estudos da primeira corrente teórica, isto é, investigando os fatores que impelem ao uso dos recursos tecnológicos. Contudo, os modelos desta corrente teórica (TAM, TAM 2, UTAUT) acabam avaliando as crenças e atitudes dos usuários em relação aos recursos tecnológicos (e.g. percepção de utilidade e facilidade), características estas que não são mensuradas pela pesquisa TIC Domicílios, portanto inviabilizando a utilização de alguns destes célebres modelos e justificando o uso da abordagem das Capacidades (SEN, 2000) como eixo teórico desta dissertação.

\section{METODOLOGIA}

O presente capítulo visa apresentar a abordagem científico-metodológica adotada nesta dissertação. Para tanto, na Seção 3.1 é realiza uma descrição da estratégia metodológica empreendida nesta investigação. Em seguida, na Seção 3.2 são explicitados os procedimentos adotados para análise dos dados. A Seção 3.3 apresenta as variáveis que serão alvo desta investigação. Por fim, na Seção 3.4 é realizado o delineamento da amostra base deste trabalho.

\subsection{Estrutura metodológica}

A presente dissertação tem como escopo compreender, sob uma perspectiva histórica referente aos anos de 2007, 2009 e 2011 (últimos cinco anos) - a dinâmica referente aos aspectos que influenciam a adoção de serviços de e-gov no Brasil. Para tanto, esta investigação se baseia no seguinte problema de pesquisa, a saber: Como o uso de serviços de governo eletrônico é influenciado pelos diferentes locais de acesso à internet e pelas competências de uso do internauta?

A fim de responder a referida indagação foram explorados os microdados (dados secundários) gerados pela pesquisa TIC Domicílios - Survey anual coordenado pelo Centro de Estudos sobre as Tecnologias da Informação e Comunicação (CETIC.br) referente aos anos de 2007, 2009 e 2011, se configurando uma série histórica. No 
intuito de se operacionalizar as análises, trabalhou-se com dados em intervalos de dois anos, a fim de evidenciar a evolução dos fatores que influenciam o uso dos serviços de e-gov. Dessa forma, visto que o escopo desta investigação recai em analisar fenômenos intrinsecamente mensuráveis sob uma perspectiva longitudinal, adotou-se uma estratégia metodológica de cunho quantitativo dedutivo, do tipo exploratório-descritivo (SAMPIERI et al., 2008; MARTINS; THEÓPHILO, 2007).

Visando explicitar cada um dos aspectos da abordagem metodológica de um estudo científico, optou-se pelo uso do framework teórico apresentado em Diniz et al. (2006) baseado no trabalho de Myers (1997) e Creswell (2009) - que considera os seguintes aspectos que devem ser esclarecidos em uma investigação: (1) perspectiva filosófica/epistemológica; (2) método de pesquisa; (3) técnica para coleta de dados; (4) instrumentos de análise e interpretação dos resultados.

A postura filosófica ou epistemológica consiste dos princípios que norteiam "como" o pesquisador irá aprender e "o que" ele irá aprender com o projeto (DINIZ et al., 2006). Relaciona-se com a maneira como o conhecimento científico pode ser obtido. Hirschheim (1992) ressalta três tipos de abordagens filosóficas: (i) positivismo; (ii) interpretativismo; (iii) abordagem crítica. Em uma investigação de cunho positivista, o pesquisador assume que a realidade é dada (ou existente) e esta pode ser descrita pelas suas características mensuráveis que são independentes do observador (pesquisador) e de seus instrumentos (MYERS, 1997). Em contrapartida, em um estudo interpretativo o conhecimento da realidade estudada (fenômeno) ocorre de maneira relativa, isto é, ele é obtido por meio da percepção dos indivíduos (ou atores sociais) que vivenciam a realidade (cf. WALSHAM, 1995; MYERS, 1997). Em contrapartida, a abordagem crítica assume que a realidade é historicamente construída e que esta é produzida e reproduzida por pessoas, embora essas possam conscientemente atuar para mudar suas condições (circunstâncias) sociais e econômicas. Pesquisadores críticos reconhecem que essa habilidade é restringida de várias formas, por dominação política, social e cultural (MYERS, 1997).

A partir dessas considerações, neste trabalho optou-se pela adoção do positivismo como orientação epistemológica. Afinal, conforme supracitado os fenômenos avaliados (por meio da análise de dados proposta) neste estudo são objetivos e passíveis de serem 
mensurados, portanto, justificando a adoção dessa perspectiva filosófica (DINIZ et al., 2006).

O método de pesquisa, basicamente, consiste das estratégias de investigação, que estabelecem direções específicas para os procedimentos em um projeto de pesquisa (DINIZ et al., 2006). Neste trabalho, optou-se por uma abordagem em dados secundários como método de pesquisa, isto é, os dados analisados nesta dissertação foram coletados por meio de uma Survey (cf. FOWLER, 2009;) coordenada pelo Centro de Estudos sobre as Tecnologias da Informação e Comunicação, referente aos anos de 2007, 2009 e 2011. Convém ressaltar que por se tratar de uma pesquisa com base em dados secundários, o terceiro item do framework teórico utilizado (técnica para coleta de dados), não será contemplado, sendo que este aspecto é descrito detalhadamente em CGI (2008; 2010b; 2012b).

O último aspecto deste framework teórico refere-se às técnicas para análise e intepretação dos resultados, cujos detalhes serão descritos na seção 3.2. Basicamente, para análise dos dados foram exploradas técnicas estatísticas, tanto de cunho (i) descritivo: mediana, análise de frequência univariada, bivariada e teste Qui-Quadrado; quanto de natureza (ii) multivariada: Análise de Correspondência (ANACOR); Análise Fatorial Binária (AFB); Regressão Logística Binária (RLB). A execução dos procedimentos estatísticos se deu com o suporte das seguintes ferramentas de software: SPSS (Statistical Package for the Social Sciences) e Stata. Os resultados destas análises dialogam com a abordagem teórica das capacidades (SEN, 2000), por meio do modelo de referência construído, conforme explicitado na Seção 2.6.

\subsection{Procedimentos para Análise dos dados}

Esta seção tem como objetivo descrever os procedimentos de análise de dados aplicados. Em virtude das premissas subjacentes de cada técnica estatística e a necessidade de manter a conformidade ao escopo desta dissertação, optou-se por descrever cada um dos objetivos propostos na Seção 1.2 e, a partir deles, delinear a técnica estatística e a estratégia mais adequada para atendê-lo. 
O primeiro objetivo proposto visa: "Mapear a evolução do uso da internet em relação aos diferentes locais de acesso e como esses se diferenciam, em relação à classe socioeconômica do internauta". Para atingir o referido objetivo, inicialmente foi realizada uma análise descritiva bivariada cruzando os diferentes locais de acesso à internet com a classe social. Em seguida, foi aplicado o teste Qui-Quadrado no intuito de verificar a existência de associação entre os atributos "local de acesso à internet mais frequente" e "classe social". Por fim, foi aplicada a técnica de Análise de Correspondência (ANACOR), a fim verificar como os diferentes locais de acesso (e.g. Casa, Trabalho, Lan House etc.) se associam com cada uma das classes socioeconômicas ( $\mathrm{AB}, \mathrm{C}$ e $\mathrm{DE})$.

A ANACOR consiste em uma técnica multivariada que permite melhor explorar associações entre duas variáveis não métricas, por meio de um mapa perceptual, possibilitando visualizar padrões na estrutura dos dados (FÁVERO et al., 2009; HAIR et al., 2009).

O segundo objetivo específico busca: "Analisar de que maneira os diferentes locais de acesso à internet e as competências de uso (uso de e-mail; e-commerce e serviços financeiros) impactam na utilização de serviços de governo eletrônico no Brasil". No intuito de atender a esse objetivo, utilizou-se da técnica de Regressão Logística Binária, a fim de avaliar o impacto de cada um dos locais de acesso e das competências de uso (conjunto de variáveis dependentes) na utilização dos serviços de e-gov (atributo dependente). A Regressão Logística Binária trata-se de uma técnica que visa investigar a relação entre variáveis explicativas (ou independentes), métricas e não métricas e uma variável dependente binária (FÁVERO et al., 2009, p.441).

O terceiro objetivo dessa dissertação se propõe a: "Categorizar os diferentes tipos de serviços de governo eletrônico (e-gov) explorados na pesquisa TIC Domicílios". No intuito de desenvolver a referida classificação aplicou-se a técnica multivariada de Análise Fatorial para dados binários (BARTHOLOMEW et al., 2002). A Análise Fatorial (AF) consiste em uma técnica multivariada cujo objetivo é identificar um número relativamente pequeno de fatores comuns (variáveis latentes) que podem ser utilizados para representar relações entre um grande número de dados inter-relacionados (FÁVERO et al., 2009, p. 236). Em virtude da natureza dicotômica dos dados dessa 
dissertação foi aplicada uma variação da AF, conhecida como Análise Fatorial Binária (AFB).

Por fim, o último objetivo específico pode ser descrito pela seguinte proposição: "Avaliar de que maneira os diferentes locais de acesso à internet e as competências de uso impactam no grau de propensão de utilização de cada um dos tipos (categorias) de serviços de e-gov". Para tanto, utilizou-se dos "escores fatoriais" obtidos pela execução da Análise Fatorial Binária (realizada para atender ao objetivo anterior) como base para as categorias de serviços de e-gov. O escore fatorial consiste de uma variável que representa cada fator latente extraído por meio da Análise Fatorial. Assim, no caso desta análise, cada escore fatorial representa uma categoria serviço de e-gov distinta. Em seguida, cada um destes escores (de natureza quantitativa) foi transformado em uma variável qualitativa dicotômica. Para referida transformação adotou-se como critério a estatística descritiva mediana, isto é, aos escores com valor maior que a mediana, foi atribuído o valor igual a 1, enquanto que os escores com valor menor ou igual a mediana atribuiu-se o valor igual 0 .

Em seguida, foi aplicada a técnica de regressão logística binária, tendo como variável dependente os escores binários (que representam cada um dos tipos de serviços de egov) e as demais variáveis: "local de acesso à internet mais frequente" e "competências de uso", como conjunto de atributos explicativos ou independentes.

Por fim, visto que as variáveis utilizadas nesta investigação são de cunho de não métrica e categóricas, para operacionalizar as técnicas estatísticas supracitadas, utilizou-se de variáveis dummies, ou seja, cada uma das categorias das referidas variáveis foi representada por uma variável binária.

\subsection{Variáveis do estudo}

O foco desta seção recai em circunscrever o conjunto de variáveis que serão utilizados para a realização da investigação proposta nesta dissertação. O Quadro 5 sintetiza as categorias dos atributos utilizados neste estudo. Em complemento, nas publicações da pesquisa TIC Domicílios 2007, 2009 e 2011 (CGI, 2008; 2009; 2012) são evidenciadas 
as questões que operacionalizam as referidas variáveis. Convém ressaltar que a escolha destas variáveis está em conformidade ao modelo de referência de pesquisa (Seção 2.6).

\begin{tabular}{|c|c|}
\hline Variável & Categoria \\
\hline Classe Social & AB (combinada); C; DE (combinada) \\
\hline $\begin{array}{c}\text { Uso de E-commerce (pesquisa de preço de } \\
\text { produtos ou serviços na internet) }\end{array}$ & Sim/Não \\
\hline Uso de E-mail & Sim/Não \\
\hline Uso de Serviços Financeiros (consultas) & Sim/Não \\
\hline Uso de Serviços de E-gov & Sim/Não \\
\hline Tipos de Serviços de Governo Eletrônico & Vários \\
\hline Local de Acesso à Internet mais frequente & $\begin{array}{c}\text { Casa; Trabalho; Na casa de outra pessoa; Escola; } \\
\text { Centro Público de Acesso Gratuito (Telecentro }{ }^{1} \text { ); Centro } \\
\text { Público de Acesso Pago (Lan House }{ }^{2} \text { ); Outro Local }\end{array}$ \\
\hline
\end{tabular}

Quadro 5 - Conjunto de variáveis da dissertação

Em conformidade ao Quadro 5, o primeiro atributo analisado consiste da Classe Social (ou classe socioeconômica). Segundo CGI (2012) a categorização desta variável se baseia no Critério de Classificação Econômica Brasil (CCEB) em consonância com os princípios definidos pela Associação Brasileira de Empresas de Pesquisa (Abep). O referido atributo (Classe Social) não é questionado diretamente ao respondente, mas é definido por meio de uma classificação que considera a posse de alguns itens duráveis de consumo doméstico, mais o grau de instrução do chefe da família (cf. CGI (2012)). Tradicionalmente na publicação da Pesquisa TIC Domicílios, o referido atributo é categorizado nas seguintes classes: A, B, C, DE. Todavia, para fins desta dissertação as classes A e B foram agregadas em uma única classe, representando os internautas com maior poder econômico, seguidos dos internautas da classe C (classe média) e da classe DE, o grupo menos favorecido.

A variável dicotômica "Uso de E-commerce", visa identificar se o respondente utilizou a internet para a busca de produtos ou serviços nos últimos doze meses. A variável "Uso de e-mail", mapeia se o internauta utilizou-se o serviço de correio eletrônico pelo menos um a vez nos últimos três meses. A variável "Uso de serviços financeiros (consulta)" indica a proporção dos respondentes que utilizaram a internet para realizar a consulta de serviços financeiros (e.g. conta corrente, poupança, cartão de crédito) nos últimos três meses. A variável "Uso de Serviços de Governo Eletrônico" mapeia os internautas que

\footnotetext{
${ }^{1}$ Por questões de facilidade, os Centros Públicos de Acesso Gratuito serão denominados de "Telecentro" nas demais seções desta investigação.

${ }^{2}$ Por questões de facilidade, os Centros Públicos de Acesso Pago serão denominados de "Lan House" nas demais seções desta investigação.
} 
se utilizaram de alguns dos serviços de e-gov nos últimos 12 meses. A variável "Tipos de Serviços de Governo Eletrônico" visa representar cada um dos tipos de serviços de egov explorados pela pesquisa TIC Domicílios (Consultar CPF; Fazer Declaração de Imposto de Renda; Fazer boletim de ocorrência etc.). Visto que são diversos tipos de serviços de e-gov explorados (em torno de 20 tipos), estes serão mais bem detalhados na Seção 4 desta dissertação.

Em relação ao "local de acesso à internet mais frequente", esta variável é composta de sete categorias, as quais mapeiam os diferentes locais em que o respondente acessa a internet com maior frequência (acesso preferencial) nos últimos três meses.

Para efeitos de sistematização todas as variáveis apresentadas no Quadro 5 são qualitativas, com escala nominal (local de acesso à internet mais frequente), ordinal (classe social) e binária (uso de e-commerce, uso de e-mail, uso de serviços financeiros, uso de serviços de e-gov, tipos de serviços de governo eletrônico). Para operacionalização das análises estatísticas realizadas no contexto desta dissertação, as variáveis "classe social" e "local de acesso à internet mais frequente" tiveram suas categorias transformadas em dummies, isto é, variáveis dicotômicas.

\subsection{Caracterização da Amostra}

A pesquisa TIC Domicílios tem como objetivo mapear a disponibilidade e os padrões de uso das Tecnologias da Informação e Comunicação pela população brasileira com idade a partir dos 10 anos. Todavia, em virtude do escopo dessa investigação, foram considerados na amostra, apenas os respondentes classificados como internautas (aqueles que utilizaram a internet pelo menos uma vez nos últimos três meses), que residem em região urbana (em conformidade com a definição do Censo IBGE) e com idade a partir dos 16 anos. A referida amostra é caracterizada na Tabela 1. 
Tabela 1 - Caracterização da amostra para Análise de Dados

\begin{tabular}{|c|l|l|l|}
\hline Pesquisa TIC Domicilios (total) & $\mathbf{2 0 0 7}$ & $\mathbf{2 0 0 9}$ & $\mathbf{2 0 1 1}$ \\
\hline Internautas & 17000 & 19998 & 25000 \\
\hline Internautas Urbanos & 7062 & 9747 & 11136 \\
\hline Internautas Urbanos com idade a partir dos 16 anos (amostra) & 7062 & 9058 & 10635 \\
\hline Classe AB & 5638 & 7158 & 8661 \\
\hline Classe C & 2231 & 2992 & 4099 \\
\hline Classe DE & 2751 & 3556 & 4022 \\
\hline
\end{tabular}

Fonte: Desenvolvido pelo autor

Os dados apresentados na Tabela 1 evidenciam a quantidade de respondentes considerados em cada um dos anos da Pesquisa TIC Domicílios. Convém ressaltar que para as análises empreendidas no contexto desta dissertação, utilizou-se do fator de ponderação desenvolvido pelo CETIC.br - cujos detalhes pode ser verificados em CGI (2008; 2010; 2012). A fim de captar as diferenças entre internautas, as análises empreendidas foram realizadas buscando segmentar as diferentes classes sociais. Assim, a Tabela 1 ilustra a quantidade de internautas de cada classe no decorrer dos anos.

\section{ANÁLISE DE DADOS}

\subsection{Evolução dos locais de acesso à internet}

Uma dos objetivos deste trabalho (explicitado na seção 1.2) é compreender como se dá a dinâmica em relação aos diferentes locais utilizados pelos usuários, a fim de ter acesso à internet. Neste sentido, a Tabela 2 demostra a evolução dos diferentes locais de acesso no período entre 2007 a 2011.

Tabela 2 - Distribuição do local de acesso à internet mais frequente

\begin{tabular}{|c|c|c|c|}
\hline Casa & $\mathbf{2 0 0 7}$ & $\mathbf{2 0 0 9}$ & $\mathbf{2 0 1 1}$ \\
\hline Trabalho & 33,7 & 44,8 & 62,4 \\
\hline Escola & 19,8 & 17,1 & 15,4 \\
\hline Casa de outra pessoa & 3,5 & 2,5 & 1,1 \\
\hline Telecentro & 1,6 & 9,4 & 6,1 \\
\hline Lan House & 31,0 & 0,9 & 0,4 \\
\hline Outro Local & 1,1 & 0,6 & 12,7 \\
\hline
\end{tabular}

Fonte: desenvolvido pelo autor 
A série histórica apresentada na Tabela 2 evidencia uma tendência de aumento na proporção de indivíduos que acessam a internet, preferencialmente (ou mais frequente) de suas residências. O percentual de internautas com acesso no domicílio aumentou de 33,7\% (em 2007) para 62,4\% (em 2011). Em contrapartida, embora no Brasil tenha ocorrido um grande crescimento no uso dos Centros Públicos de Acesso Pago (Lan House), nota-se uma tendência de queda na utilização do referido local, o qual em 2007 era utilizado preferencialmente por $31 \%$ dos internautas, caindo para $24,8 \%$ em 2009 e $12,7 \%$ em 2011.

Em relação aos Centros Públicos de Acesso Gratuito (Telecentros) - alvo de diversas políticas públicas de inclusão digital no país (cf. MADON et al., 2008; MACADAR; REINHARD, 2004) - nota-se que este local apresentou, no decorrer da série histórica, uma taxa de utilização muito baixa. Afinal em 2007, o Telecentro era utilizado como principal local de acesso à internet por (apenas) 1,4\% dos internautas, percentual este que chega a $0,4 \%$ em 2011 . Visto que a variação na taxa de utilização deste centro público de acesso à internet no decorrer dos anos é inferior ao erro amostral (Quadro 4), pode-se afirmar que no referido intervalo de cinco anos houve certa estabilidade na utilização da internet neste local de acesso. Todavia, mesmo com a referida estabilidade, vale destacar que o uso da internet (preferencialmente) nos telecentros é pouco explorado pelos usuários brasileiros.

A série histórica ilustrada na Tabela 2 demonstra que os principais locais de acesso, em termo de seus respectivos percentuais são: (i) Casa; (ii) Trabalho; (iii) Centro Público de Acesso Pago (Lan House).

A fim de captar as diferenças entre internautas de grupos sociais distintos, avaliou-se a dinâmica dos diferentes locais de acesso, todavia, segmentando os usuários de classes socioeconômicos distintas. A Tabela 3 descreve essa distribuição entre os membros da classe AB. 
Tabela 3 - Distribuição do local de acesso à internet mais frequente (classe $A B$ )

\begin{tabular}{|c|c|c|c|}
\hline Casa & $\mathbf{2 0 0 7}$ & $\mathbf{2 0 0 9}$ & $\mathbf{2 0 1 1}$ \\
\hline Trabalho & 51,2 & 62,3 & 73,3 \\
\hline Escola & 24,9 & 22,3 & 18,6 \\
\hline Casa de outra pessoa & 2,9 & 1,2 & 0,6 \\
\hline Telecentro & 0,7 & 5,3 & 2,2 \\
\hline Lan House & 14,5 & 0,6 & 0,2 \\
\hline Outro Local & 0,0 & 0,1 & 4,0 \\
\hline
\end{tabular}

Fonte: desenvolvido pelo autor

O cenário na classe $\mathrm{AB}$ sofreu poucas mudanças, no que se refere à distribuição dos locais de acesso à internet. Conforme os dados da Tabela 3 os principais locais de acesso desta classe são: Casa e o Trabalho. A proporção de internautas que acessam a rede mundial de computadores em suas residências subiu de 51,2\% em 2007, para 73,3\% em 2011. O considerável crescimento no acesso domiciliar, se refletiu na queda nos percentuais dos demais ambientes de acesso.

Tabela 4 - Distribuição do local de acesso à internet mais frequente (classe C)

\begin{tabular}{|c|c|c|c|}
\hline & 2007 & 2009 & 2011 \\
\hline Casa & 26,1 & 35,2 & 56,7 \\
\hline Trabalho & 18,6 & 14,9 & 13,1 \\
\hline Escola & 3,3 & 3,1 & 1,5 \\
\hline Casa de outra pessoa & 12,0 & 11,9 & 8,2 \\
\hline Telecentro & 1,5 & 1,0 & 0,4 \\
\hline Lan House & 36,8 & 33,1 & 17,7 \\
\hline Outro Local & 1,6 & 0,8 & 2,2 \\
\hline
\end{tabular}

Fonte: desenvolvido pelo autor

No cenário da classe média, os dados da Tabela 4 evidenciam uma expansão da residência, como local de acesso preferencial à internet e um declínio das Lan Houses. Em 2007, o percentual de internautas que acessavam a internet preferencialmente de "Casa" era de 26,1\%, passando para 35,2\% em 2009 e alcançando o patamar de 56,7\% em 2011. Em contrapartida, as Lan Houses passaram por uma queda expressiva no percentual de acessos, que em 2007 era de 36,8\%, caindo para 33,1\% em 2009; alcançando a taxa de 17,7\% em 2011. 
Tabela 5 - Distribuição do local de acesso à internet mais frequente (Classe DE)

\begin{tabular}{|c|c|c|c|}
\hline Casa & $\mathbf{2 0 0 7}$ & $\mathbf{2 0 0 9}$ & $\mathbf{2 0 1 1}$ \\
\hline Trabalho & 6,4 & 15,1 & 22,0 \\
\hline Escola & 7,4 & 4,3 & 8,1 \\
\hline Casa de outra pessoa & 6,2 & 5,2 & 2,8 \\
\hline Telecentro & 12,5 & 14,4 & 20,2 \\
\hline Lan House & 62,7 & 1,5 & 1,5 \\
\hline Outro Local & 2,1 & 58,5 & 41,1 \\
\hline
\end{tabular}

Fonte: desenvolvido pelo autor

A Tabela 5 , assim como nas demais classes, demonstra uma tendência de aumento do acesso à internet na residência na classe DE. Em 2007, apenas 6,4\% dos internautas dessa classe acessavam preferencialmente em "Casa", tal proporção mais que dobrou em 2009 chegando a 15,1\% e crescendo para 22\% em 2011. Todavia, embora tenha ocorrido um crescimento expressivo do acesso domiciliar, a casa ainda não representa o principal ambiente de acesso à internet neste grupo social.

Embora os dados da Tabela 5 reforcem uma tendência de queda do acesso à internet nas Lan Houses (Centro Público de Acesso Pago), o referido ambiente ainda concentra a maior parte dos internautas da classe DE. Em 2007, a proporção de internautas com acesso preferencial nas Lan Houses era de 62,6\%, caindo para 58,5\% em 2009 e 41,1\% em 2011. A referida queda está em consonância ao aumento na proporção de internautas com acesso à internet preferencialmente no domicílio. Uma peculiaridade evidenciada na classe DE refere-se ao aumento da proporção de internautas que acessam a Internet na "Casa de outra pessoa", que em 2007 era de $12,5 \%$ e subiu para 20,2\% em 2011. Esse comportamento acaba evidenciando como os internautas desta classe exploram sua rede de contatos, visando ter acesso à rede mundial de computadores.

Uma análise conjunta dos dados apresentados nas Tabelas 2, 3, 4 e 5 reforça a tendência de crescimento na proporção do acesso à internet em "Casa", em todos os extratos sociais. $\mathrm{O}$ referido aumento nas classes sociais menos favorecidas (classe $\mathrm{C}$ e DE), possivelmente está relacionado com o desenvolvimento de políticas públicas de inclusão digital que favorecem o acesso individual. Exemplos destas inciativas são as 
políticas que promovem a desoneração de impostos na compra de equipamentos de informática e financiamento de computadores a juros baixos. Tais medidas, consequentemente, implicam em uma redução nos custos para aquisição de computadores e serviços de acesso à internet, portanto, favorecendo o acesso preferencialmente do ambiente domiciliar.

Em consonância a este movimento de expansão do acesso residencial, nota-se uma redução na importância dos centros públicos de acesso à internet (telecentros e lan houses). Analisando especificamente a utilização dos telecentros, é possível identificar que, embora haja (no decorrer da série histórica) certa estabilidade no percentual de internautas que os utilizem, estes locais de acesso são muito pouco utilizados, mesmo nas classes mais pobres (classe DE). Portanto, indicando uma possível inadequação destes centros públicos de acesso gratuito, como instrumento de promoção da inclusão digital.

Em contrapartida, em relação às Lan House os dados históricos demonstram uma clara tendência de redução no percentual de usuários que utilizam as lan houses como local de acesso à internet (mais frequente). Porém, mesmo com a supracitada tendência de queda, os centros públicos de acesso pago representam o local de acesso com maior percentual de internautas da classe DE. Logo, demonstrando que as Lan Houses ainda possuem um importante papel no provimento de acesso à internet nas classes sociais com menor poder aquisitivo, embora haja a tendência de que este percentual de acesso continue decaindo.

\subsection{Local de Acesso à Internet versus Classe Social}

A seção anterior evidenciou a evolução do acesso à internet em relação aos diferentes locais de acesso em um intervalo de cinco anos (2007-2011). Nesta linha de raciocínio, a fim de explorar como os diferentes locais de acesso à internet se diferenciam em relação à classe social dos internautas, aplicou-se o ferramental estatístico da Análise de Correspondência (ANACOR). 
A ANACOR consiste de uma técnica multivariada de caráter exploratório que exibe a associação entre duas variáveis não métricas (qualitativas) por meio de um mapa perceptual, permitindo ao pesquisador realizar um exame visual, a fim de identificar algum tipo de padrão existente na estrutura dos dados (FÁVERO et al., 2009). Logo, a escolha dessa técnica se baseou no fato de que as variáveis analisadas neste estudo são de caráter não métrico (qualitativo) e há o interesse em avaliar como se dá a associação entre os diferentes locais de acesso à internet e as classes socioeconômicas dos internautas.

Segundo Fávero et al. (2009) o processo de execução da ANACOR é composto de duas etapas básicas. O primeiro consiste do cálculo de associação entre as variáveis, no intuito de verificar se há uma relação de associação entre os atributos analisados. O segundo passo, trata da criação do mapa perceptual, para que sejam exploradas as relações entre as categorias das variáveis.

Dessa forma, a fim de atender as premissas da primeira etapa da ANACOR, por meio do software SPSS, foram calculadas as Tabelas de Contingência - cruzando os atributos "local de acesso mais frequente" e "classe social" - e realizado o Teste QuiQuadrado, a fim de testar a associação entre as variáveis. Para efeitos de sistematização, o referido teste se baseia nas seguintes hipóteses:

- Hipótese Nula (H0): Os atributos analisados se associam de maneira aleatória;

- Hipótese Alternativa (H1): Há associação entre os atributos avaliados;

Em seguida, foram executados os procedimentos referentes à Análise de Correspondência, para gerar o mapa perceptual. Basicamente o referido mapa consiste de uma ferramenta visual que possibilita ao pesquisador, por meio do posicionamento dos objetos, identificar determinados padrões de similaridade ou preferência na estrutura dos dados (HAIR et al., 2009; FÁVERO et al., 2009).

As Tabelas 6, 7 e 8 consistem das tabelas de contingência referentes aos anos de 2007, 2009 e 2011. Ao invés de apresentar os valores absolutos do cruzamento entre local de acesso e classe social, optou-se por demonstrar o percentual em relação ao 
total de internautas de cada classe socioeconômica. Por exemplo, a Tabela 6 demonstra que $51,2 \%$ dos membros da classe $\mathrm{AB}$ acessam a internet de suas residências, contra $26,1 \%$ do total da classe $\mathrm{C}$ e $6,4 \%$ da classe DE.

Tabela 6 - Tabela de Contingência: Local de Acesso versus Classe Social (2007)

\begin{tabular}{|c|c|c|c|}
\hline \multicolumn{4}{|c|}{ Local de Acesso versus Classe Social } \\
\hline & Classe AB & Classe C & Classe DE \\
\hline Casa & 51,2 & 26,1 & 6,4 \\
\hline Trabalho & 24,9 & 18,6 & 7,4 \\
\hline Escola & 2,9 & 3,3 & 6,2 \\
\hline Casa de outra pessoa & 5,7 & 12,0 & 12,5 \\
\hline Telecentro & 0,8 & 1,5 & 2,7 \\
\hline Lan House & 14,5 & 36,8 & 62,6 \\
\hline Outro Local & 0,0 & 1,6 & 2,1 \\
\hline
\end{tabular}

Fonte: desenvolvido pelo autor

Tabela 7 - Tabela de Contingência: Local de Acesso versus Classe Social (2009)

\begin{tabular}{|l|r|r|r|}
\hline \multicolumn{5}{|c|}{ Local de Acesso versus Classe Social } \\
\hline Casa & Classe AB & Classe C & Classe DE \\
\hline Trabalho & 62,3 & 35,2 & 15,1 \\
\hline Escola & 22,3 & 14,9 & 4,3 \\
\hline Casa de outra pessoa & 1,2 & 3,1 & 5,2 \\
\hline Telecentro & 5,3 & 11,9 & 14,4 \\
\hline Lan House & 0,6 & 1,0 & 1,5 \\
\hline Outro Local & 8,1 & 33,1 & 1,0 \\
\hline Valor do Qui-Quadrado: 1382,$484 ;$ Graus de Liberdade: $12 ;$ Nivel de Significância: $0,000$. \\
\hline
\end{tabular}

Fonte: desenvolvido pelo autor

Tabela 8 - Tabela de Contingência: Local de Acesso versus Classe Social (2011)

\begin{tabular}{|l|r|r|r|}
\hline \multicolumn{4}{|c|}{ Local de Acesso versus Classe Social } \\
\hline & Classe AB & Classe C & Classe DE \\
\hline Casa & 73,3 & 56,7 & 22,0 \\
\hline Trabalho & 18,6 & 13,1 & 8,1 \\
\hline Escola & 0,6 & 1,5 & 2,8 \\
\hline Casa de outra pessoa & 2,2 & 8,2 & 1,5 \\
\hline Telecentro & 0,2 & 0,4 & 41,1 \\
\hline Lan House & 4,0 & 17,7 & 4,3 \\
\hline Outro Local & 1,2 & 2,2 & $0,00$. \\
\hline Valor do Qui-Quadrado: 1351,$359 ;$ Graus de Liberdade: $12 ;$ Nivel de Significância: 0,000
\end{tabular}

Fonte: desenvolvido pelo autor

Os dados apresentados nas Tabelas 6, 7 e 8 apresentam os seguintes valores para o teste Qui-Quadrado (com 95\% de confiança): 1042,246 (2007); 1382,484 (2009) e 
1351,359 (2011), todos esses apresentaram nível de significância ( $p$-value) igual a 0,000. Os referidos resultados permitem rejeitar a hipótese nula de independência dos atributos analisados. Portanto, oferecendo indícios da existência de associação entre as variáveis "classe social" e "local de acesso" e possibilitando a aplicação da ANACOR.

As Figuras 7, 8 e 9 ilustram os mapas perceptuais, resultado da aplicação da Análise de Correspondência referente aos anos analisados nesta investigação. Ressalta-se que todos os mapas foram construídos utilizando normalização simétrica, a fim de identificar as diferenças e similaridades entre as categorias analisadas.

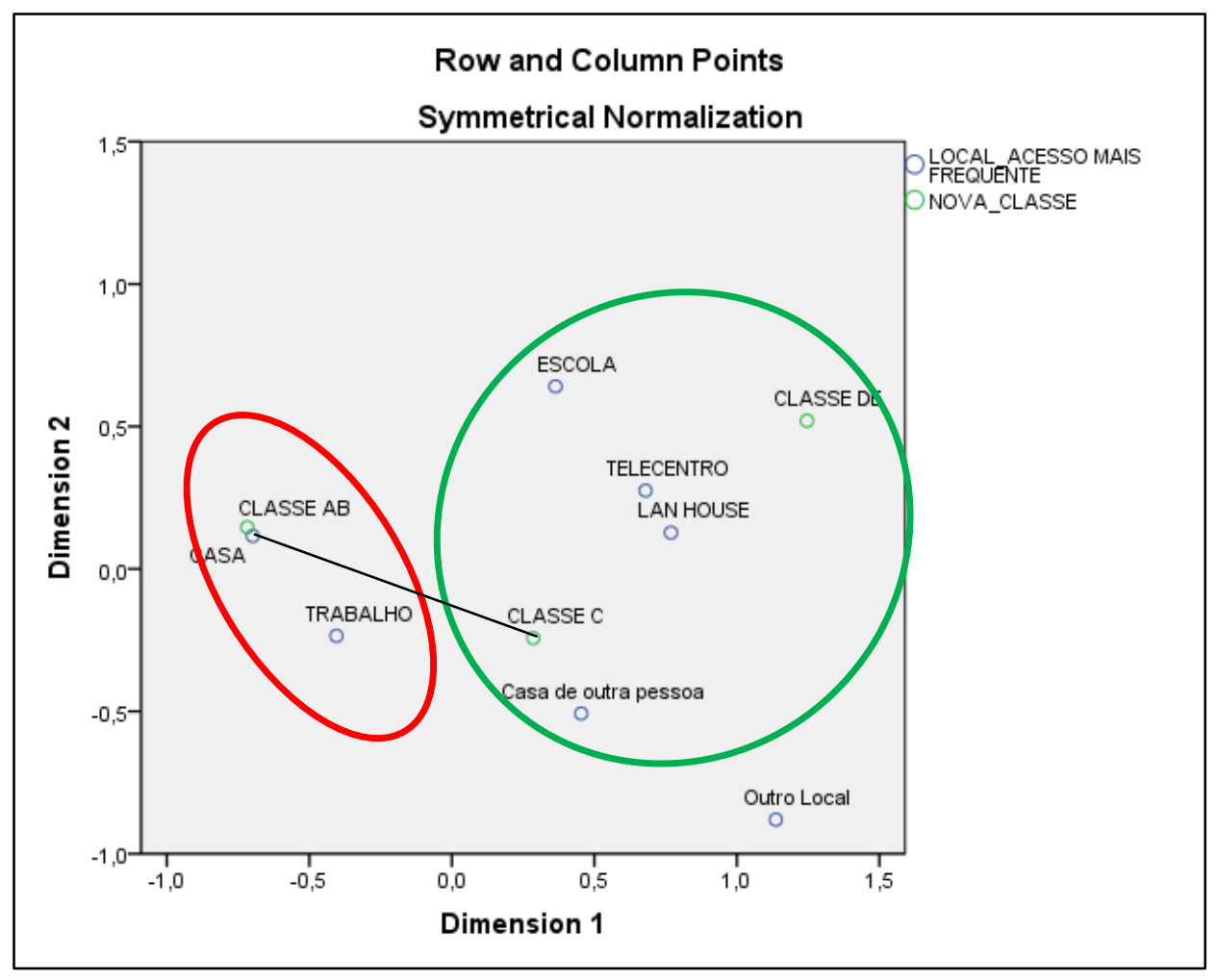

Figura 7- Mapa Perceptual do "Local de Acesso" versus "Classe Social" (2007)

O mapa perceptual demonstrado na Figura 7 foi gerado por meio do software SPSS. As dimensões 1 (linha) e 2 (coluna) do mapa explicam, respectivamente, 97,4\% e 2,6\% da inércia total dos dados. Portanto, demostrando que a dimensão 1 é muito mais relevante para explicar o comportamento dos dados. 
No mapa perceptual, quanto mais próximo estão as categorias de variáveis distintas, maior é o grau de associação entre elas. Uma análise gráfica da Figura 7 demonstra o alto grau de associação entre os internautas da classe $\mathrm{AB}$ com a residência, indicando que esse é o ambiente de acesso preferencial dos integrantes deste grupo social mais abastado. O local de acesso "Trabalho" apresentou uma posição próxima das classes $\mathrm{AB}$ e $\mathrm{C}$, porém se posicionando mais próxima da primeira. Tal comportamento oferece indícios que membros, tanto da classe $\mathrm{AB}$, quanto da classe $\mathrm{C}$ exercem atividades profissionais que exigem o uso da internet, embora essa proporção seja maior entre os internautas da classe $\mathrm{AB}$, conforme pode ser ilustrado na Tabela 6 .

Os locais de acesso: "Escola", "Telecentro" e "Lan House" acabam se situando em uma posição intermediária entre as classes $\mathrm{C}$ e DE, fato este que corrobora com os dados da Tabela de Contingência (Tabela 6) que demonstram a grande proporção de internautas que acessam a internet desses locais. A Figura 7 também evidencia que o uso da internet na "Casa de outra pessoa" está fortemente relacionado com os internautas da classe C.

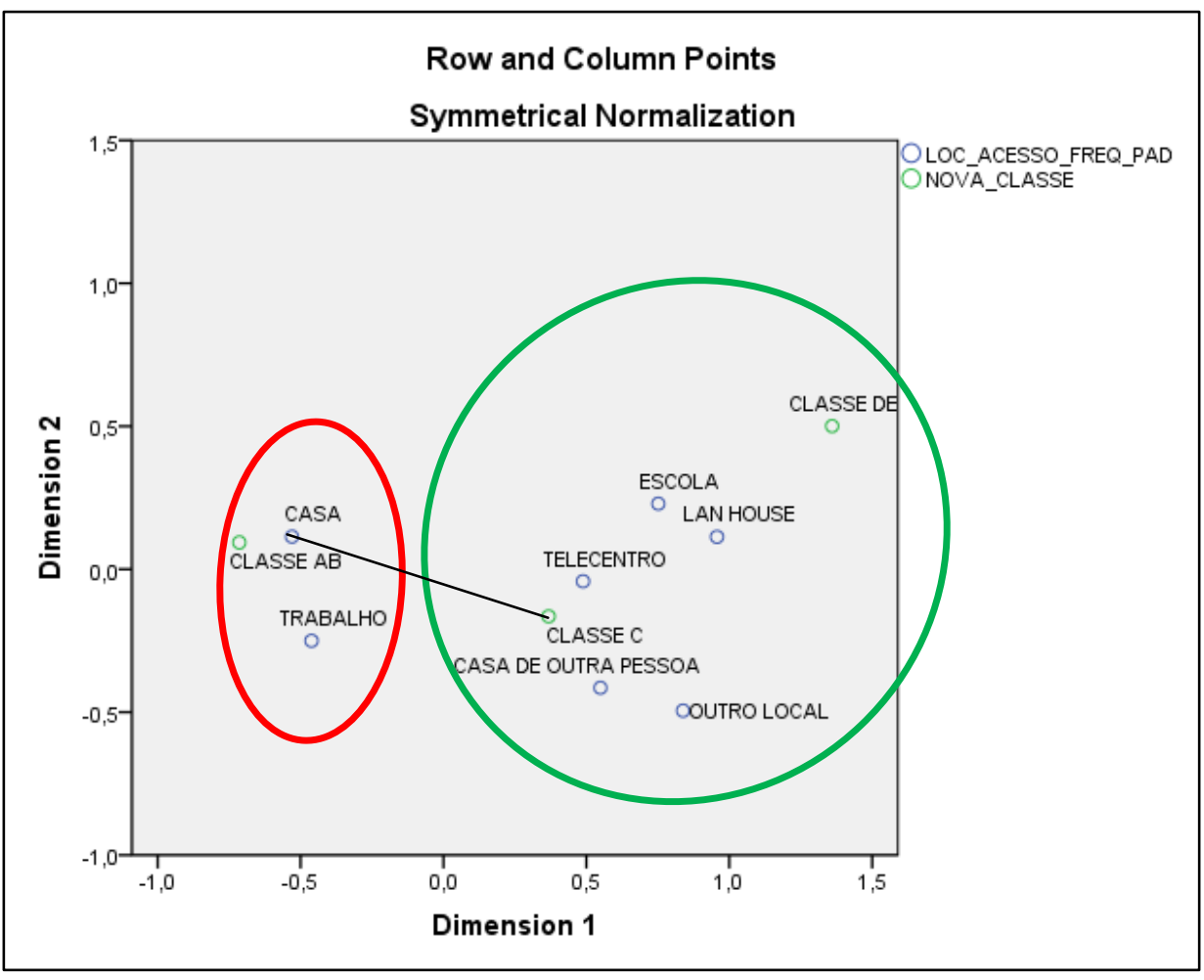

Figura 8 - Mapa Perceptual do "Local de Acesso" versus "Classe Social” (2009) 
A Figura 8 ilustra o mapa perceptual referente aos dados da pesquisa TIC Domicílios 2009. Nele, as dimensões 1 (linha) e 2 (coluna) são responsáveis por 99,2\% e 0,8\% da inércia total, evidenciando que a dimensão 1 é a mais relevante para explicar a variância original dos dados.

O referido mapa perceptual demonstra uma maior proximidade dos locais de acesso "Casa" e "Trabalho" dos internautas da classe AB, indicando uma clara preferência dos usuários dessa classe pelos referidos locais de acesso. Em conformidade a esses dados, a Tabela 7 demonstra a predominância do acesso mais frequente na residência e no trabalho, juntos os referidos locais representam aproximadamente $84 \%$ dos internautas da classe.

A Figura 8 demonstra que os locais "Escola" e "Lan House" acabam ficando muito mais próximos da classe DE, indicando uma preferência dos membros dessa classe em obter acesso à internet desses locais. Em contrapartida, o mapa evidencia uma maior associação entre os ambientes: "Telecentro" e "Casa de outra pessoa" com os integrantes da classe $\mathrm{C}$.

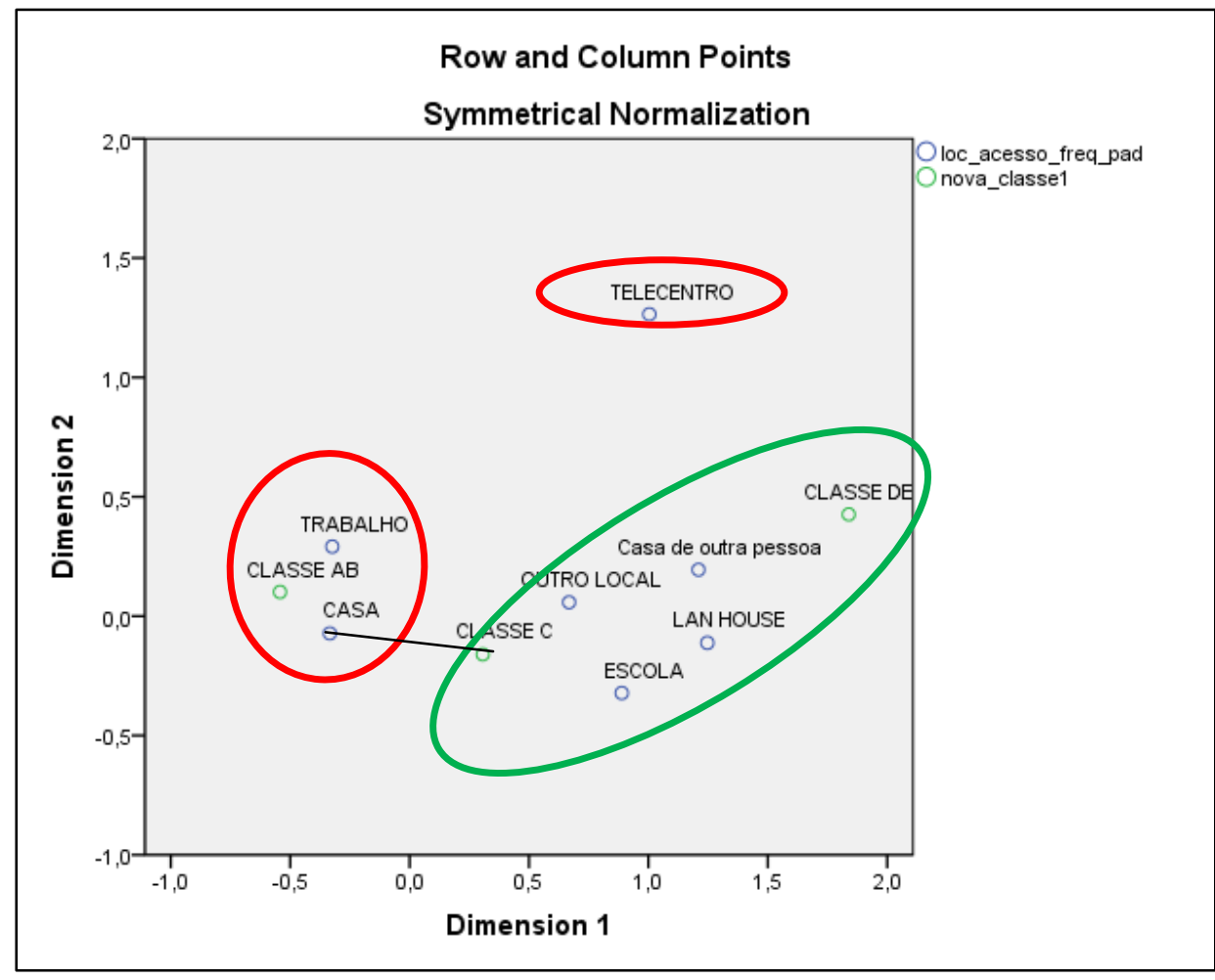

Figura 9 - Mapa Perceptual do "Local de Acesso" versus "Classe Social" (2011) 
Na Figura 9, a dimensão 1 (linha) representa 99,5\% da inércia total dos dados, enquanto que a dimensão 2 (coluna) corresponde à $0,5 \%$, portando indicando que a primeira dimensão é mais importante para explicar o comportamento dos dados. O mapa perceptual dos dados de 2011 evidencia uma clara preferência pelo acesso à internet em "Casa" e no "Trabalho" entre os membros da classe AB. Em contrapartida, a classe C acaba tendo uma posição intermediária, tendo maior associação com os referidos locais: (i) Outro Local; (ii) Lan House; (iii) Escola e (iv) Casa de outra pessoa. Além disso, convém ressaltar a proximidade da Classe C com o local de acesso: "Casa", indicando a tendência de expansão de internautas da classe média que acessam a internet preferencialmente de suas residências.

A Figura 9 também demonstra que a classe DE, apresenta maior associação com o acesso na "Casa de outra pessoa", indicando a preferência deste grupo de internautas. Uma peculiaridade evidenciada pelo mapa perceptual refere-se à posição periférica do "Telecentro" (Centro Público de Acesso Gratuito), apresentando fraca associação deste ambiente de acesso com todas as classes socioeconômicas. Esse comportamento evidencia a baixa preferência deste local de acesso à internet.

Analisando conjuntamente dos três mapas perceptuais é possível notar uma tendência de redução da importância dos Centros Públicos de Acesso Gratuito (Telecentros). Embora nos anos de 2007 e 2009, o referido local ainda estivesse mais associado às classes C e DE, é possível notar que em 2011, este local passou a ocupar uma posição marginal no mapa perceptual, ou seja, apresentando baixa associação com as demais classes socioeconômicas. Tais evidências reforçam a baixa utilização dos Telecentros demonstrada nas Tabelas 2 a 5. Porém, os mapas perceptuais (Figuras 7, 8 e 9) evidenciam a queda na associação dos Centros Públicos de Acesso Gratuito com as classes sociais mais pobres. Assim, tais resultados apontam para uma redução da importância dos Telecentros, portanto, indicando uma potencial inadequação dos atuais telecentros, como instrumento de inclusão digital na classe $\mathrm{C}$ e DE.

Em contrapartida, as informações dos mapas perceptuais estão em consonância aos resultados apresentados na Seção 4.1, os quais apontam para uma tendência de aumento no crescimento do acesso à internet preferencialmente da residência, inclusive nas classes mais baixas. Tal tendência é reforçada pelo aumento na associação entre o 
acesso à internet em casa com as classes $\mathrm{C}$ e $\mathrm{DE}$ (redução na distância entre as referidas categorias no mapa). Assim como discutido na Seção 4.1, os referidos resultados (expansão do acesso à internet domiciliar nos extratos sociais menos favorecidas) provavelmente estão relacionados com o desenvolvimento de políticas públicas de inclusão digital que visem o acesso individual (e.g. redução de impostos na aquisição de equipamentos de informática).

\subsection{Explorando as Competências e Uso de Serviços de Governo Eletrônico}

Nesta seção serão exploradas as distribuições referentes à evolução das diferentes proxies de competências de uso: (i) uso de e-commerce (busca de serviços e produtos); (ii) uso de e-mail; (iii) uso de serviços de financeiros e a utilização de serviços de e-gov.

Os dados da Figura 10 evidenciam uma tendência de aumento na proporção de internautas que realizaram as atividades relacionadas às proxies de competência de uso. Comparativamente, o uso de e-commerce, apresentou maior crescimento, iniciando a série com $57,5 \%$ dos internautas que realizavam a busca de produtos e serviços na internet, tal percentual subiu para 65,1\% em 2009, atingindo 70,9\% em 2011. O uso do e-mail é a competência mais difundida pelos internautas, sendo utilizada por mais de $80 \%$ destes. Em contrapartida, o uso de serviços financeiros possui um menor número de usuários, embora haja forte tendência de crescimento.

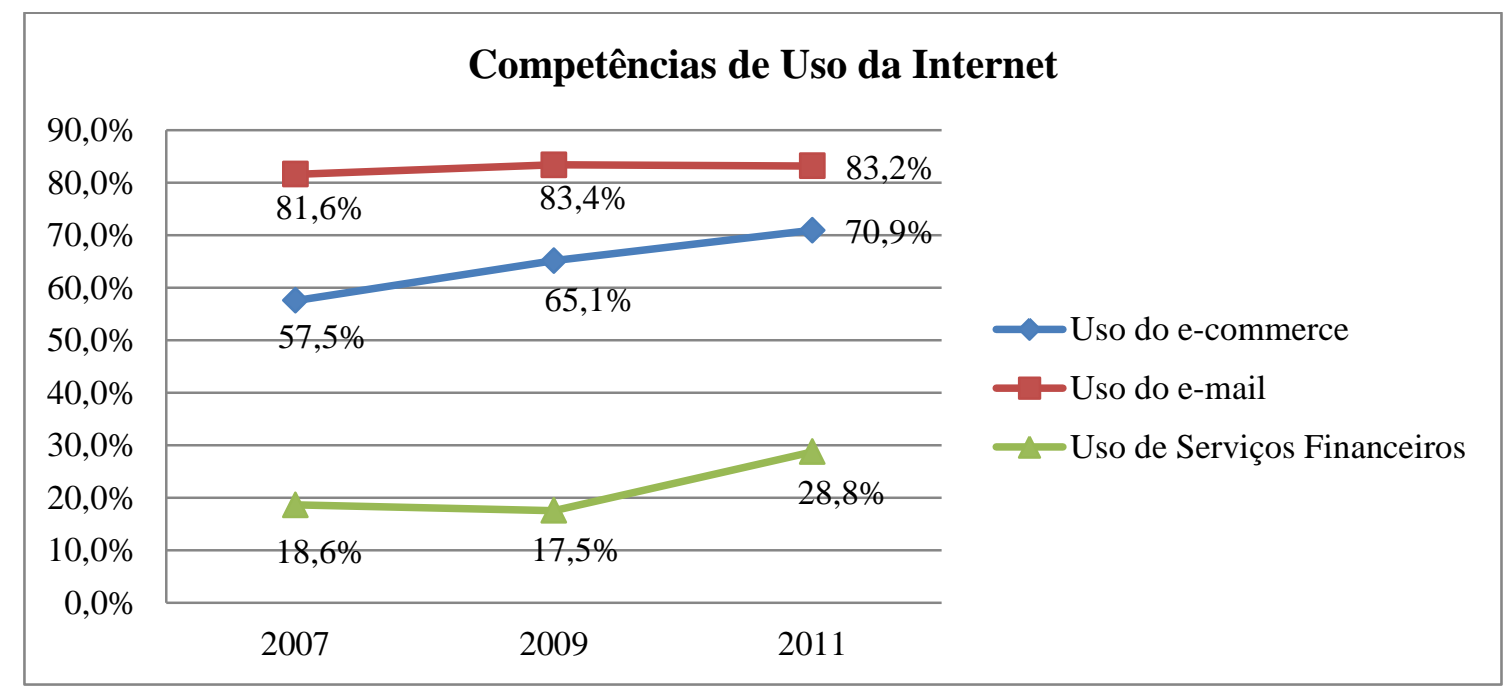

Figura 10 - Evolução das competências de uso (classes agregadas) 
Perante as distinções entre os usuários de internet provenientes de diversas classes, buscou-se segmentar as análises, a fim de capturar as peculiaridades intrínsecas a cada grupo social.

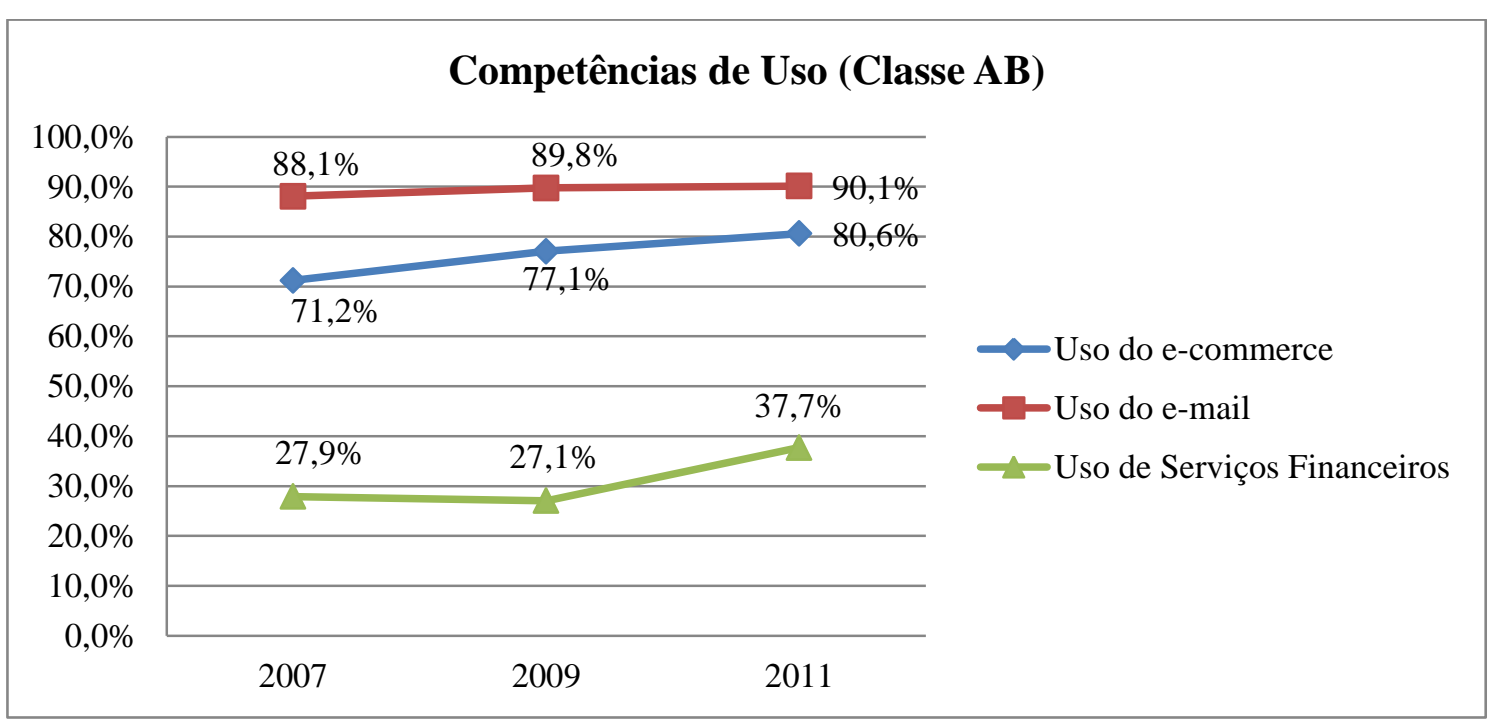

Figura 11 - Evolução das competências de uso (classe AB).

A Figura 11 descreve o cenário entre os internautas da classe AB. Os referidos dados apresentam uma tendência de crescimento no uso de todas as proxies de competências. Nota-se que o uso de serviços de correio eletrônico e comércio eletrônico são utilizados, respectivamente, por $90 \%$ e $80 \%$ dos usuários de internet, sendo, portanto as competências mais amplamente difundidas. Convém salientar o crescimento na utilização de serviços financeiros para consulta, percentual este que em 2007 era de 27,9\%, aumentando para 37,7\% (2011) dos membros deste grupo social mais abastado. 


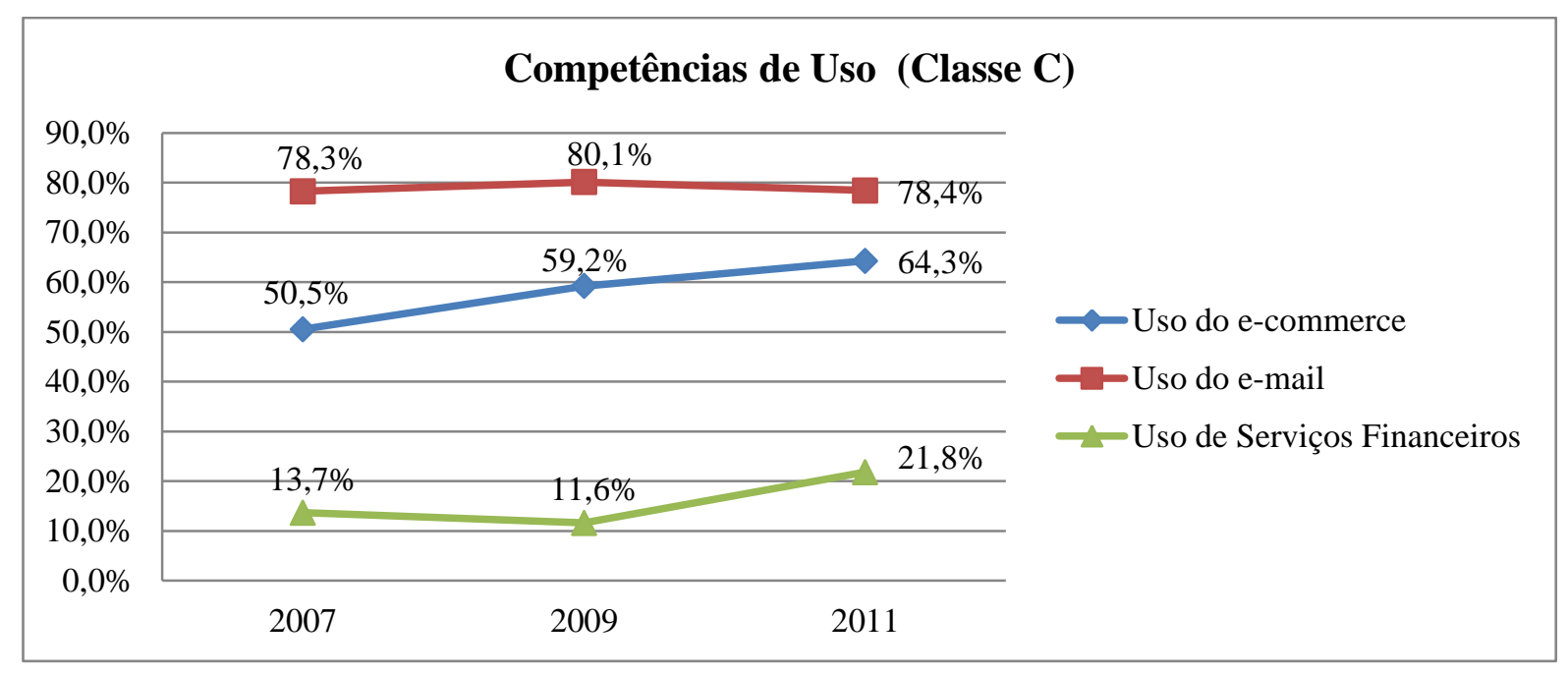

Figura 12 - Evolução das competências de uso (classe C) .

A Figura 12 apresenta o cenário em relação aos internautas da classe média (classe C), seus dados evidenciam uma tendência de crescimento nas competências de uso da internet. Nota-se que o uso de e-mail é a proxy de competência mais difundida representando aproximadamente $80 \%$ dos internautas. Além disso, há uma tendência crescimento no uso das demais competências, com o destaque para o forte crescimento na utilização de serviços financeiros entre 2009 (11,6\%) e 2011(21,8\%).

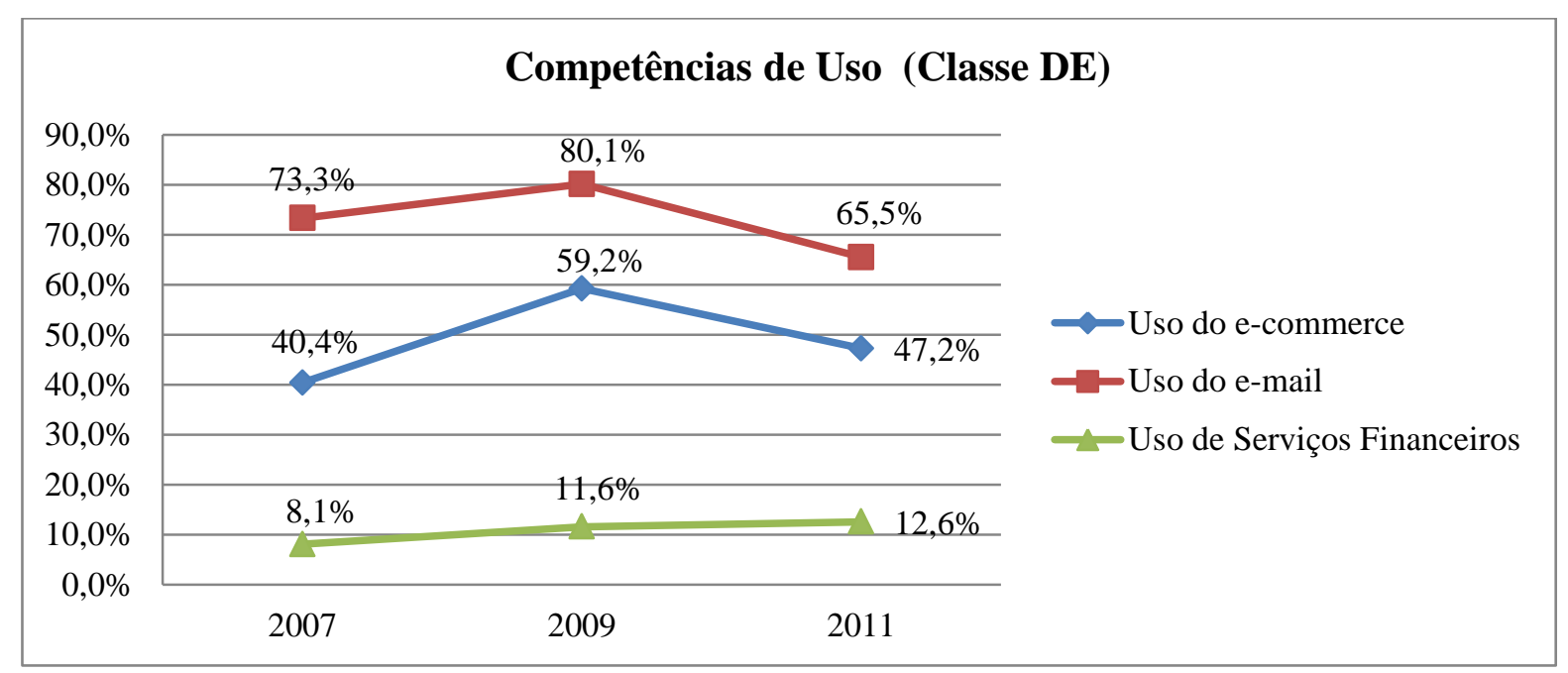

Figura 13 - Evolução das competências de uso (classe DE).

A Figura 13 apresenta o cenário no grupo social menos abastado. Em conformidade aos referidos dados, nota-se uma tendência de queda na proporção de internautas que utilizaram serviços de e-commerce e e-mail (as competências mais difundidas). Todavia, essa redução não foi evidenciada na utilização de serviços financeiros, o 
qual representava 8,1\% em 2007, subindo para 11,6\% em 2009 e alcançando a margem de 12,6\% em 2011. Portanto, indicando certa estabilidade proporção de usuários de serviços financeiros na classe DE.

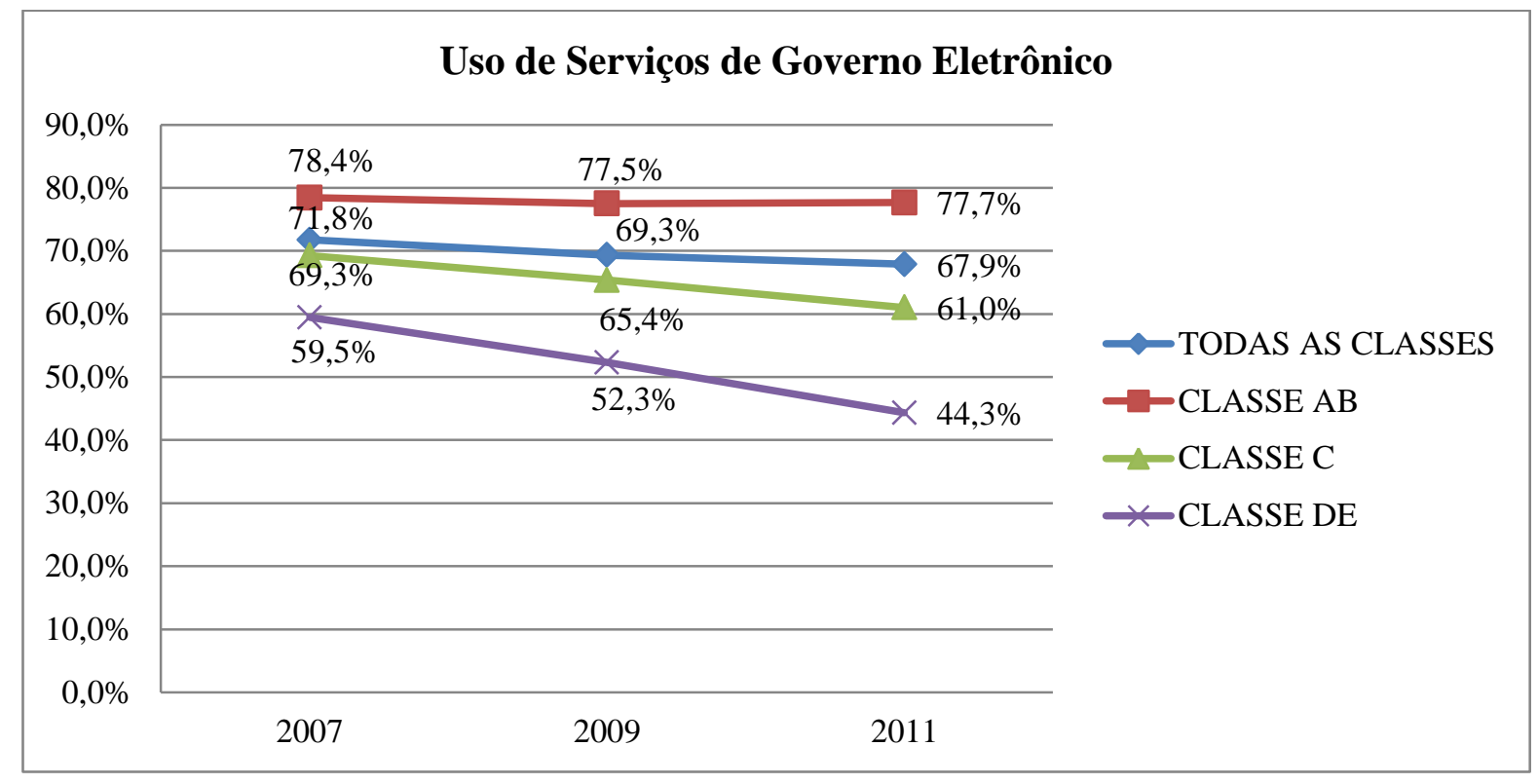

Figura 14 - Evolução da utilização de serviços de governo eletrônico (e-gov)

O último construto do modelo de pesquisa (Figura 14) refere-se aos usuários que utilizam a internet para realizar atividades relacionadas com os serviços de governo eletrônico (e-gov). A Figura 14 demonstra a evolução na taxa de uso do e-gov no Brasil, no intervalo dos últimos cinco anos (2007-2011), tanto com todas as classes agregadas, quanto com as mesmas separadas.

Os dados agregados demonstram uma queda na proporção do uso de e-gov, em 2007 este percentual era de 71,8\%, passando para 69,3\% em 2009, atingindo 67,9\% em 2011. Analisando individualmente a distribuição das demais classes, nota-se que a referida queda foi influenciada pela redução no percentual de usuário de e-gov nas classes menos favorecidas (classe C e DE). Todavia, a referida queda não foi observada entre os internautas da classe AB, cujo percentual em 2007 era de 78,4\%, mantendo 77,5\% em 2009 e atingindo $77,7 \%$ em 2011.

Analisando o padrão de uso de governo eletrônico explicitado no gráfico da Figura 14, é possível notar que o uso de serviços de governo eletrônico consiste de uma competência amplamente disseminada entre os internautas da classe $\mathrm{AB}$ (mais de $70 \%$ em todos os anos). Em contrapartida a essa tendência, os dados apresentam uma tendência de queda 
na proporção de internautas que utilizaram e-gov nas classes $\mathrm{C}$ e DE. A referida proporção provavelmente esteja relacionada ao crescimento destas classes menos favorecidas que, consequentemente passou por um aumento número de internautas (usuários recentes), os quais ainda não se utilizam das competências de uso (evidenciada pela queda no uso das proxies de competência na classe DE) e dos serviços de governo eletrônico (Figura 14).

\subsection{Fatores que influenciam a adoção dos serviços de e-gov}

O modelo de referência apresentado na Seção 3.4, sistematiza como a decisão de uso de serviços de governo eletrônico, pode ser mediada pelos diferentes locais de acesso à internet e as competências de uso. As seções anteriores exploraram os construtos do modelo de pesquisa individualmente, evidenciando a evolução do uso dos diferentes locais de acesso à internet, das competências de uso da internet e da utilização dos serviços de e-gov.

O foco desta seção recai em analisar como a decisão de uso de serviços de governo eletrônico pode ser mediada, tanto pelas competências de uso da internet (e-mail; ecommerce e serviços financeiros), quanto pelos ambientes de acesso. Para tanto, foi aplicada a Regressão Logística Binária (FÁVERO et al., 2009; HAIR et al., 2009; HAMILTON, 2009).

A Regressão Logística Binária (RLB) consiste de uma técnica estatística multivariada utilizada para descrever o comportamento entre uma variável dependente binária e um conjunto de variáveis métricas e/ou não métricas (FÁVERO et al., 2009). Em conformidade ao modelo de pesquisa (Figura 6), foram executadas RLBs visando avaliar o impacto dos diferentes locais de acesso à internet (mais frequente) no domínio de cada uma das três competências de uso avaliadas: (i) uso de e-commerce (atividades de busca de produtos e serviços); (ii) uso de e-mail; (iii) uso de serviços financeiros (consulta). A fim de operacionalizar a referida regressão, o atributo local de acesso foi transformado em variáveis dummies (i.e. cada categoria foi representada por uma variável binária). Em seguida, foi avaliado como as três competências de uso influenciavam no uso de e-gov (binário). Por fim, analisou-se como cada um dos locais de acesso à internet influenciava individualmente no uso de serviços de governo 
eletrônico. Convém ressaltar que os procedimentos referentes à regressão logística foram realizados com o suporte do software estatístico Stata.

Antes da aplicação da Regressão Logística Binária foram realizados testes, no intuito de identificar problemas de multicolinearidade. Segundo Hair et al. (2009), a multicolinearidade consiste em um problema inerente aos dados (e não do modelo), quando há alta correlação entre as variáveis explicativas (ou independentes) da regressão. A fim de diagnosticar o referido problema, foram realizados diagnósticos por meio das estatísticas: Tolerância e VIF (Variance Inflation Factor).

A Tolerância (Tolerance) consiste de uma medida que indica a proporção da variação de uma variável explicativa que independe dos demais atributos explicativos. Em outras palavras, uma Tolerância baixa indica que a variável explicativa compartilhará um alto percentual de sua variância com os outros atributos explicativos. Em contrapartida, a estatística VIF mensura o quanto a variância de cada coeficiente da regressão estimado aumenta devido à multicolinearidade. Em geral, quando o valor da estatística VIF for acima de 10, há indícios de alta relação linear e problemas graves de multicolinearidade (FÁVERO et al, 2009, p.359).

Na execução da regressão logística optou-se por agrupar os locais de acesso: "Casa" e "Trabalho" em uma única categoria dicotômica, a fim de avaliar o impacto desses locais conjuntamente na decisão de uso de e-gov e das competências de e-mail, e-commerce e serviços financeiros, em relação aos demais locais de acesso. Devido a baixa frequência de internautas no local "Escola" e "Outro local", optou-se por excluir esses dois locais das regressões empreendidas.

A Tabela 9 sintetiza os resultados das estatísticas VIF e Tolerância realizada com o conjunto de variáveis independentes. Nas regressões realizadas, há dois grupos de variáveis dependentes: (i) locais de acesso; (ii) competências de uso. Visto que são dois grupos distintos os valores de VIF e Tolerância foram calculados separadamente, embora seus valores estejam apresentados juntos na Tabela 9. 
Tabela 9 - Diagnóstico para multicolinearidade.

\begin{tabular}{|l|r|r|r|r|r|r|}
\hline & \multicolumn{3}{|c|}{ VIF } & \multicolumn{3}{c|}{ Tolerância } \\
\hline & $\mathbf{2 0 0 7}$ & $\mathbf{2 0 0 9}$ & $\mathbf{2 0 1 1}$ & $\mathbf{2 0 0 7}$ & $\mathbf{2 0 0 9}$ & $\mathbf{2 0 1 1}$ \\
\hline Casa ou Trabalho & 6,1 & 7,5 & 6,3 & 0,2 & 0,1 & 0,2 \\
\hline Casa de outra pessoa & 3,0 & 3,3 & 3,0 & 0,3 & 0,3 & 0,3 \\
\hline Telecentro & 1,3 & 1,2 & 1,2 & 0,8 & 0,8 & 0,9 \\
\hline Lan House & 5,7 & 6,6 & 4,7 & 0,2 & 0,2 & 0,2 \\
\hline Uso de E-commerce & 1,1 & 1,1 & 1,1 & 0,9 & 0,9 & 0,9 \\
\hline Uso de E-mail & 1,1 & 1,1 & 1,1 & 0,9 & 0,9 & 0,9 \\
\hline Uso de Serviços Financeiros & 1,1 & 1,1 & 1,1 & 0,9 & 0,9 & 0,9 \\
\hline
\end{tabular}

Fonte: desenvolvido pelo autor

Os resultados apresentados na Tabela 9 demonstram que todos os valores de VIF são menores que 10 indicando não haver graves problemas de multicolinearidade, consequentemente, possibilitando executar os procedimentos referentes à regressão logística.

Em conformidade ao escopo desta dissertação, optou-se por analisar apenas os valores de odds ratio dos atributos estatisticamente significantes, no intuito de compreender a contribuição de individual os diferentes locais de acesso à internet e das competências de uso. Visto que o foco da análise recai na verificação do impacto individual das variáveis supracitadas e não na geração de um modelo de predição, não foram realizadas análises das medidas de adequação do modelo logístico (e.g. Curva ROC, HosmerLemeshow Goodness-of-fit, tabelas de classificação, medidas de sensitividade e especificidade).

A medida odds ratio, indica o quanto - mantida as demais condições constantes (ceteris paribus) - cada uma das variáveis explicativas aumenta na chance de ocorrência (ou na probabilidade) do fenômeno estudado. Para exemplificar, na Tabela 10 o valor de odds ratio é igual a 2,5 (referente ao local de acesso: "Casa e Trabalho", na classe C em 2007) indicando que o uso da internet preferencialmente em casa ou no trabalho aumenta a chance (ou probabilidade) de usar de e-commerce 2,5 vezes mais em relação a quem utiliza a internet preferencialmente em outro local. Em contrapartida, quando o valor do odds ratio for menor 1, a interpretação será que o atributo explicativo implicará numa redução da chance do evento analisado. Na Tabela 10, o coeficiente (odds ratio) 
referente à contribuição do "lan house" no uso de e-commerce é igual a 0,3. Portanto, o uso da internet no referido local implica em uma redução na probabilidade de usar ecommerce, quando comparado aos demais locais de acesso.

As Tabelas 10, 11 e 12 representam os resultados da regressão logística, cujo foco foi avaliar o impacto dos diferentes locais de acesso (variáveis explicativas) na utilização (ou conhecimento) das competências de uso da internet. Convém ressaltar que as células em branco, referem-se aos atributos cujas estimativas não foram estatisticamente significantes com $95 \%$ de confiança.

Tabela 10 - Contribuição do local de acesso no uso de e-commerce (odds ratio)

\begin{tabular}{|l|c|c|c|c|c|c|c|c|c|}
\hline & \multicolumn{3}{|c|}{ Classe AB } & \multicolumn{3}{c|}{ Classe C } & \multicolumn{3}{c|}{ Classe DE } \\
\hline & $\mathbf{2 0 0 7}$ & $\mathbf{2 0 0 9}$ & $\mathbf{2 0 1 1}$ & $\mathbf{2 0 0 7}$ & $\mathbf{2 0 0 9}$ & $\mathbf{2 0 1 1}$ & $\mathbf{2 0 0 7}$ & $\mathbf{2 0 0 9}$ & $\mathbf{2 0 1 1}$ \\
\hline Casa ou Trabalho & 3,2 & 2,3 & & 2,5 & 2,5 & 2,1 & 5,3 & 2,8 & 3,4 \\
\hline Casa de outra pessoa & & & 0,3 & & & & 1,9 & & \\
\hline Telecentro & & & & & & & 4,9 & & \\
\hline Lan House & 1,7 & & 0,3 & 0,7 & & & & & \\
\hline
\end{tabular}

Fonte: desenvolvido pelo autor

Analisando mais especificamente os membros da Classe C e DE - alvo das políticas públicas de inclusão digital - é possível perceber que acesso preferencial à internet na residência e no local de trabalho, aumentam significativamente as chances de uso de ecommerce para busca de produtos e serviços, em relação aos demais locais de acesso.

Tabela 11 - Contribuição do local de acesso no uso de e-mail (odds ratio)

\begin{tabular}{|l|c|c|c|c|c|c|c|c|c|}
\hline & \multicolumn{3}{|c|}{ Classe AB } & \multicolumn{3}{c|}{ Classe C } & \multicolumn{3}{c|}{ Classe DE } \\
\hline & $\mathbf{2 0 0 7}$ & $\mathbf{2 0 0 9}$ & $\mathbf{2 0 1 1}$ & $\mathbf{2 0 0 7}$ & $\mathbf{2 0 0 9}$ & $\mathbf{2 0 1 1}$ & $\mathbf{2 0 0 7}$ & $\mathbf{2 0 0 9}$ & $\mathbf{2 0 1 1}$ \\
\hline Casa ou Trabalho & & 2,5 & & 3,4 & 4,7 & 2,8 & 7,1 & 3,8 & \\
\hline Casa de outra pessoa & 0,5 & & 0,2 & & 1,8 & 1,6 & 5,7 & & 0,5 \\
\hline Telecentro & 0,2 & & & 3,2 & 0,5 & & & & \\
\hline Lan House & 0,3 & & 0,3 & 1,8 & 2,5 & & 3,8 & & \\
\hline
\end{tabular}

Fonte: desenvolvido pelo autor

A Tabela 11 evidencia a contribuição dos diferentes locais de acesso no uso de e-mail. Conforme os dados apresentados na referida Tabela, tanto na classe $\mathrm{C}$, quanto na classe DE o uso preferencial em "Casa ou Trabalho" favorecem positivamente o uso do serviço de correio eletrônico. No que se refere a essa competência, convém destacar que na Classe C, os locais de acesso: "Casa de outra pessoa" e "Lan House" também contribuíram positivamente na chance de usar e-mail. Todavia, tais coeficientes de odds 
ratio se mostraram inferiores aos de "Casa ou Trabalho", além de apresentarem uma tendência de redução no decorrer do tempo.

Tabela 12 - Contribuição do local de acesso no uso de serviços financeiros (odds ratio)

\begin{tabular}{|l|c|c|c|c|c|c|c|c|c|}
\hline & \multicolumn{3}{|c|}{ Classe AB } & \multicolumn{3}{c|}{ Classe C } & \multicolumn{3}{c|}{ Classe DE } \\
\hline & $\mathbf{2 0 0 7}$ & $\mathbf{2 0 0 9}$ & $\mathbf{2 0 1 1}$ & $\mathbf{2 0 0 7}$ & $\mathbf{2 0 0 9}$ & $\mathbf{2 0 1 1}$ & $\mathbf{2 0 0 7}$ & $\mathbf{2 0 0 9}$ & $\mathbf{2 0 1 1}$ \\
\hline Casa ou Trabalho & 3,9 & 3,1 & 3,1 & 2,3 & 3,8 & 2,2 & 2,2 & 3,3 & 4,0 \\
\hline Casa de outra pessoa & & 1,8 & & & 2,7 & & & & \\
\hline Telecentro & & & & & & & & & \\
\hline Lan House & & & & & & 0,7 & & & \\
\hline
\end{tabular}

Fonte: desenvolvido pelo autor

A Tabela 12 demonstra a contribuição dos diversos locais de acesso preferencial no uso de serviços financeiros. Os dados da Tabela 12 demonstram que em todas as classes socioeconômicas, o acesso preferencial em casa ou no trabalho implica em um aumento considerável (todos os valores de odds ratio maiores que 1) na probabilidade de realizar consulta de serviços financeiros.

Os resultados apresentados nas Tabelas 10, 11 e 12 evidenciam que o local de acesso preferencial: "Casa ou Trabalho" favorece significativamente mais em relação aos demais ambientes de acesso, o uso das seguintes proxies de competências de uso da internet: (i) uso de e-commerce para busca de produtos e serviços; (ii) uso de e-mail; (iii) uso de serviços financeiros. Convém ressaltar que nos demais locais de acesso, é possível notar uma tendência de queda no valor de odds ratio, apontando para uma redução da importância dos demais ambientes de acesso à internet. Por fim, as referidas análises suportam as proposições apresentadas no modelo de referência, isto é, que os locais de acesso à internet - mais especificamente o ambiente de casa ou do trabalho favorecem o domínio das competências (ou capabilities dentro da abordagem das capacidades), sendo, portanto, fatores de conversão (SEN, 2000) na aquisição das capacidades propostas.

A segunda proposição do modelo de pesquisa demonstra o impacto das capacidades, representadas por meio das proxies de competências de uso, na adoção de serviços de governo eletrônico. 
Tabela 13- Contribuição das competências no uso de governo eletrônico (odds ratio)

\begin{tabular}{|l|l|l|l|l|c|c|c|c|c|}
\hline & \multicolumn{3}{|c|}{ Classe AB } & \multicolumn{3}{c|}{ Classe C } & \multicolumn{3}{c|}{ Classe DE } \\
\hline & $\mathbf{2 0 0 7}$ & $\mathbf{2 0 0 9}$ & $\mathbf{2 0 1 1}$ & $\mathbf{2 0 0 7}$ & $\mathbf{2 0 0 9}$ & $\mathbf{2 0 1 1}$ & $\mathbf{2 0 0 7}$ & $\mathbf{2 0 0 9}$ & $\mathbf{2 0 1 1}$ \\
\hline Uso de E-commerce & 2,0 & 3,1 & 2,1 & 3,3 & 2,0 & 2,2 & 2,4 & 1,9 & 1,9 \\
\hline Uso de E-mail & 1,5 & 1,9 & 2,5 & 2,0 & 1,4 & 2,7 & & 3,1 & 7,1 \\
\hline Uso de Serviços Financeiros & 5,2 & 2,7 & 4,1 & 5,2 & 4,1 & 3,2 & 3,1 & & 5,9 \\
\hline
\end{tabular}

Fonte: desenvolvido pelo autor

A Tabela 13 sintetiza os resultados da regressão logística, demonstrando a contribuição (odds ratio) de cada uma das proxies de competência de uso da internet na utilização dos serviços de e-gov. Uma análise dos valores de odds ratio demonstra que o uso de serviços financeiros é a competência que mais contribui no uso de e-gov, em relação às demais proxies avaliadas.

Os referidos resultados suportam a segunda proposição evidenciada no modelo de referência (Seção 2.6), no qual o desenvolvimento das competências influenciará na escolha dos funcionamentos. Em outras palavras, o uso das proxies de competência de uso impacta positivamente no grau de propensão de uso dos serviços de e-gov.

Tabela 14 - Contribuição dos locais de acesso à internet no uso de e-gov (odds ratio)

\begin{tabular}{|l|l|l|r|r|r|r|r|r|r|}
\hline & \multicolumn{3}{|c|}{ Classe AB } & \multicolumn{3}{c|}{ Classe C } & \multicolumn{3}{c|}{ Classe DE } \\
\hline & $\mathbf{2 0 0 7}$ & $\mathbf{2 0 0 9}$ & $\mathbf{2 0 1 1}$ & $\mathbf{2 0 0 7}$ & $\mathbf{2 0 0 9}$ & $\mathbf{2 0 1 1}$ & $\mathbf{2 0 0 7}$ & $\mathbf{2 0 0 9}$ & $\mathbf{2 0 1 1}$ \\
\hline Casa ou Trabalho & 2,2 & & & 3,5 & 1,7 & 1,8 & 3,4 & 2,0 & \\
\hline Casa de outra pessoa & 0,5 & 0,6 & 0,4 & 1,7 & & & 2,4 & 2,4 & 0,4 \\
\hline Telecentro & & & & 3,4 & 2,9 & & 0,3 & & \\
\hline Lan House & & 0,6 & 0,5 & & & & & & 0,5 \\
\hline
\end{tabular}

Fonte: desenvolvido pelo autor

Os resultados apresentados na Tabela 14 demonstram individualmente o impacto dos diferentes locais de acesso à internet na adoção de serviços de e-gov. Embora, os dados da Tabela 14 tenham consistência em relação aos demais resultados, eles indicam que o local de acesso à internet sozinho é um previsor (predictor) muito mais fraco do uso de serviços de e-gov, do que todo o processo mediado pelas competências de uso, indicando a contribuição da cadeia de mediação (mediating chain) proposta na abordagem das capacidades que fundamenta o modelo de referência desta pesquisa (Seção 2.6).

Assim, as análises empreendidas demonstram a adequação da abordagem das capacidades (SEN, 2000) ao problema analisado. Afinal, individualmente o local de acesso à internet (infraestrutura) se mostrou um fator fraco na avaliação da propensão 
ao uso de e-gov, consequentemente, demonstrando que a simples disponibilização do recurso, pouco influi nos resultados (functionings) alcançados pelo uso do mesmo. Todavia, os dados reforçam a utilidade do modelo de adoção em cadeia, isto é, "local de acesso" contribui positivamente no domínio das proxies de competências (capacidades) e essas por sua vez aumentam a propensão ao uso de e-gov. Analisando os resultados das regressões empreendidas à luz do referencial teórico das capacidades (SEN, 2000) é possível compreender o ambiente de acesso "Casa ou Trabalho" atuam como fatores de conversão para a aquisição das capacidades propostas (e-mail, e-commerce e serviços financeiros) e as referidas competências (com maior impacto devido ao uso de serviços financeiros) influem positivamente na decisão de utilização de e-gov.

\subsection{Categorizando os diferentes tipos de serviços de e-gov}

Nas seções anteriores o fenômeno referente ao uso dos serviços de governo eletrônico foi avaliado por meio de uma única primitiva binária que indicava se o internauta tinha utilizado dos serviços de e-gov. No intuito de superar essa limitação, nesta seção buscou-se explorar os diferentes tipos de atividades de e-gov abordados na pesquisa TIC Domicílios e, consequentemente, categorizá-los. Para tanto, aplicou-se a técnica estatística multivariada de Análise Fatorial Binária (AFB).

Segundo Hair et al. (2009) a Análise Fatorial consiste de um técnica de interdependência cujo objetivo é definir a estrutura latente entre as variáveis da análise. A premissa subjacente a esta técnica é que seja possível representar um conjunto de variáveis observadas, por meio de número menor de fatores intrínsecos. Portanto, um dos objetivos da Análise Fatorial é a simplificação ou redução de um grande número de variáveis (FÁ VERO et al., 2009, p.235).

Convém ressaltar que em virtude da natureza dicotômica dos dados analisados, não foi possível aplicar a abordagem tradicional da Análise Fatorial (AF), pois essa foi projetada para lidar com dados quantitativos, isto é, o modelo da AF assume que as variáveis observadas são métricas e não binárias. Portanto, em conformidade à natureza booleana dos dados analisados, nesta dissertação foi empreendida uma variação da AF, específica para lidar com dados dicotômicos, isto é a Análise Fatorial Binária (AFB). 
Bartholomew et al. (2002) apresentam duas abordagens distintas para adaptar o modelo da Análise Fatorial para lidar com dados binários. O primeiro deles consiste da utilização de um modelo logístico, no intuito de se estimar as variáveis latentes (latent variables model). E a segunda abordagem denominada de "variáveis subjacentes" (underlying variables approach) se utiliza dos coeficientes de correlação tetracórica (tetrachoric correlations) para estimar os fatores. Para fins desta investigação, adotouse a segunda abordagem, pois esta mantém os principais procedimentos da abordagem clássica da Análise Fatorial (AF exploratória).

Segundo Bartholomew et al. (2002) para execução da Análise Fatorial Binária utilizando da abordagem de variáveis subjacentes (underlying variables) é necessário inicialmente calcular a matriz de correlações tetracóricas e utilizá-la como entrada para o algoritmo da Análise Fatorial tradicional (exploratória). A AF tradicional, diferentemente da sua vertente binária, se fundamenta nas correlações de Pearson específicas para dados métricos (BARTHOLOMEW, 2002).

Para execução da Análise Fatorial Binária (de cunho exploratório) utilizou-se dos diferentes tipos de serviços de governo eletrônico explorados na pesquisa TIC Domicílios. Visto que o conjunto de serviços de e-gov questionados, sofre pequenas variações entre os anos analisados os Quadros 6, 7 e 8 evidenciam as atividades de egov consideradas em cada um dos anos. Em virtude de inadequação teórica aos construtos analisados, foram excluídos das análises os atributos relacionados a serviços de saúde. Além disso, nos anos de 2009 e 2011 a variável binária que mapeava se o internauta já havia utilizado e-gov para "para participar de fóruns chats, votações etc. relacionadas ao governo?" foi excluída, por entender que tal variável configura um tipo de interação de feedback do cidadão ao governo, diferindo-se dos demais serviços e-gov listados que estabelecem uma clara relação do serviço prestado do governo ao cidadão (G2C). Variáveis com o rótulo "outros tipos de serviço", isto é, aquelas que não representavam os serviços previamente especificados no questionário da pesquisa TIC Domicílios também foram desconsideradas das análises. As variáveis efetivamente utilizadas nesta investigação estão apresentadas nos quadros 6,7 e 8 e possuem uma codificação respectiva, a fim de facilitar a apresentação dos resultados nas matrizes de correlações. 


\begin{tabular}{|c|l|}
\hline Código & \multicolumn{1}{|c|}{ Tipos de Serviços de Governo eletrônico } \\
\hline G1 & $\begin{array}{l}\text { Buscar informações sobre como emitir documentos (carteira de identidade, carteira de trabalho, } \\
\text { CPF). }\end{array}$ \\
\hline G2 & Obter certidões negativas. \\
\hline G3 & Consultar o CPF - Cadastro de Pessoa Física. \\
\hline G4 & Obter licenças e permissões. \\
\hline G5 & Fazer declaração de imposto de renda. \\
\hline G6 & Fazer pagamento de IPVA, multas, licenciamento de veículos. \\
\hline G7 & Fazer pagamento de IPTU e outros impostos municipais \\
\hline G8 & Fazer pagamento de taxas de serviços públicos (água, luz, gás, iluminação, lixo, etc.) \\
\hline G9 & $\begin{array}{l}\text { Buscar informações sobre previdência social (auxílio-doença, salário-maternidade, benefício de } \\
\text { aposentadoria). }\end{array}$ \\
\hline G10 & Solicitar salário-maternidade e auxílio doença. \\
\hline G11 & Fazer inscrição na previdência social. \\
\hline G12 & Buscar informações sobre benefícios sociais (bolsa-família, bolsa-escola, auxílio-gás e outros). \\
\hline G13 & Fazer boletim de ocorrência. \\
\hline G14 & Consultar andamento de atos processuais na justiça. \\
\hline G15 & Buscar informações sobre direito do consumidor. \\
\hline G16 & Buscar informações sobre veículos roubados (registro de roubo e furto de veículos). \\
\hline G17 & Consultar pontos na carteira de habilitação e multas. \\
\hline G18 & $\begin{array}{l}\text { Buscar informações sobre serviços públicos de educação (instituições de ensino, livros } \\
\text { didáticos, FIES, PROUNI, vestibular). }\end{array}$ \\
\hline G19 & $\begin{array}{l}\text { Buscar informações sobre direitos do trabalhador (seguro-desemprego, FGTS, primeiro } \\
\text { emprego). }\end{array}$ \\
\hline G20 & Fazer inscrição em concursos públicos (polícia militar, etc.). \\
\hline
\end{tabular}

Quadro 6 - Tipos de serviços de e-gov abordados na pesquisa TIC Domicílios 2007.

\begin{tabular}{|c|l|}
\hline Código & \multicolumn{1}{|c|}{ Tipos de Serviços de Governo eletrônico } \\
\hline G1 & Buscar Informações sobre como emitir documentos. \\
\hline G2 & Obter certidões negativas, licenças e permissões. \\
\hline G3 & Consultar o CPF - Cadastro de Pessoa Física. \\
\hline G4 & Emissão de Documentos (certificados, atestados, comprovantes etc.). \\
\hline G5 & Obter informações sobre impostos e taxas em sites de governo. \\
\hline G6 & Fazer Declaração de Imposto de Renda (incluindo declaração de isento). \\
\hline G7 & Fazer Pagamento impostos, multas e taxas (água, luz, gás, iluminação, lixo etc.). \\
\hline G8 & $\begin{array}{l}\text { Buscar informações sobre previdência social e benefícios sociais (auxílio-doença, salário- } \\
\text { maternidade, benefício de aposentadoria, bolsa-família, bolsa-escola, auxílio-gás e outros). }\end{array}$ \\
\hline G9 & Fazer inscrição/cadastro na Previdência Social. \\
\hline G10 & $\begin{array}{l}\text { Solicitar serviços junto à previdência social (salário-maternidade, auxílio doença, benefícios de } \\
\text { aposentadoria etc.). }\end{array}$ \\
\hline G11 & Fazer boletim de ocorrência. \\
\hline G12 & Consultar andamento de atos processuais na justiça. \\
\hline G13 & Buscar informações sobre direito do consumidor. \\
\hline G14 & Buscar informações sobre veículos roubados (Registro de roubo e furto de veículos). \\
\hline G15 & Consultar pontos na carteira de habilitação e multas. \\
\hline G16 & Buscar informações sobre serviços públicos de educação. \\
\hline G17 & Fazer matrículas em escolas públicas ou instituições de ensino público \\
\hline G18 & $\begin{array}{l}\text { Buscar Informações sobre direitos do trabalhador (seguro-desemprego, FGTS, primeiro } \\
\text { emprego, PIS, PASEP, abono salarial). }\end{array}$ \\
\hline G19 & Fazer Inscrição em concursos públicos. \\
\hline G20 & $\begin{array}{l}\text { Buscar informações sobre empregos (vagas, contratações etc.) em algum canal de comunicação } \\
\text { do governo pela Internet. }\end{array}$ \\
\hline
\end{tabular}

Quadro 7 - Tipos de serviços de e-gov abordados na pesquisa TIC Domicílios 2009 


\begin{tabular}{|c|l|}
\hline Código & \multicolumn{1}{|c|}{ Tipos de Serviços de Governo eletrônico } \\
\hline G1 & Buscar Informações sobre como emitir documentos \\
\hline G2 & Obter certidões negativas, licenças e permissões. \\
\hline G3 & Consultar o CPF - Cadastro de Pessoa Física \\
\hline G4 & Emissão de Documentos \\
\hline G5 & Obter informações sobre impostos e taxas em sites de governo \\
\hline G6 & Fazer Declaração de Imposto de Renda (incluindo declaração de isento) \\
\hline G7 & Fazer Pagamento impostos, multas e taxas (IPVA, IPTU, multas etc.) \\
\hline G8 & Buscar informações sobre previdência social e benefícios sociais. \\
\hline G9 & Solicitar serviços junto à previdência social (salário-maternidade, auxílio doença etc.) \\
\hline G10 & Fazer boletim de ocorrência \\
\hline G11 & Consultar andamento de atos processuais na justiça \\
\hline G12 & Buscar informações sobre direito do consumidor \\
\hline G13 & Buscar informações sobre veículos roubados (Registro de roubo e furto de veículos) \\
\hline G14 & Consultar pontos na carteira de habilitação e multas \\
\hline G15 & Buscar informações sobre serviços públicos de educação. \\
\hline G16 & Fazer matrículas em escolas públicas ou instituições de ensino público \\
\hline G17 & Buscar Informações sobre direitos do trabalhador. \\
\hline G18 & Fazer Inscrição em concursos públicos \\
\hline G19 & Buscar informações sobre empregos em algum canal de comunicação do governo pela Internet \\
\hline
\end{tabular}

Quadro 8 - Tipos de serviços de e-gov abordados na pesquisa TIC Domicílios 2011.

Em conformidade aos princípios discutidos em Fávero et al. (2009), Hair et al. (2009) e Bartholomew et al. (2002), a seguinte sequência foi adotada para execução da Análise Fatorial Binária (AFB): (i) Análise da matriz de correlação; (ii) Seleção do método fatorial; (iii) Extração e determinação do número de fatores; (iv) Rotação dos fatores; (v) Interpretação dos mesmos e (vi) Computação dos escores fatorial.

As matrizes de correlação tetracórica - base para a Análise Fatorial Binária - foram calculadas por meio de uma biblioteca específica compatível com o software estatístico Stata (versão 11). Tal biblioteca foi desenvolvida pelo Institute for Digital Research and Education (IDRE), centro de pesquisa da Universidade da Califórnia em Los Angeles (cf. UCLA, 2013). 
Tabela 15- Matriz de correlação tetracórica dos serviços de governo eletrônico (2007)

\begin{tabular}{|c|c|c|c|c|c|c|c|c|c|c|c|c|c|c|c|c|c|c|c|c|}
\hline & G1 & G2 & G3 & G4 & G5 & G6 & G7 & G8 & G9 & G10 & G11 & G12 & G13 & G14 & G15 & G16 & G17 & G18 & G19 & G20 \\
\hline G1 & 1,00 & & & & & & & & & & & & & & & & & & & \\
\hline G2 & 0,64 & 1,00 & & & & & & & & & & & & & & & & & & \\
\hline G3 & 0,71 & 0,61 & 1,00 & & & & & & & & & & & & & & & & & \\
\hline G4 & 0,56 & 0,72 & 0,56 & 1,00 & & & & & & & & & & & & & & & & \\
\hline G5 & 0,53 & 0,62 & 0,60 & 0,53 & 1,00 & & & & & & & & & & & & & & & \\
\hline G6 & 0,44 & 0,61 & 0,43 & 0,52 & 0,67 & 1,00 & & & & & & & & & & & & & & \\
\hline G7 & 0,49 & 0,61 & 0,51 & 0,57 & 0,73 & 0,93 & 1,00 & & & & & & & & & & & & & \\
\hline G8 & 0,43 & 0,53 & 0,40 & 0,52 & 0,57 & 0,74 & 0,80 & 1,00 & & & & & & & & & & & & \\
\hline G9 & 0,44 & 0,56 & 0,45 & 0,49 & 0,56 & 0,46 & 0,48 & 0,50 & 1,00 & & & & & & & & & & & \\
\hline G10 & 0,40 & 0,47 & 0,41 & 0,52 & 0,45 & 0,43 & 0,44 & 0,37 & 0,84 & 1,00 & & & & & & & & & & \\
\hline G11 & 0,48 & 0,59 & 0,53 & 0,54 & 0,57 & 0,53 & 0,53 & 0,42 & 0,81 & 0,78 & 1,00 & & & & & & & & & \\
\hline G12 & 0,51 & 0,53 & 0,49 & 0,54 & 0,42 & 0,39 & \begin{tabular}{|l|}
0,39 \\
\end{tabular} & 0,43 & 0,70 & 0,65 & 0,71 & 1,00 & & & & & & & & \\
\hline G13 & 0,46 & 0,59 & 0,51 & 0,53 & 0,49 & 0,43 & 0,52 & 0,50 & 0,46 & 0,49 & 0,54 & 0,56 & 1,00 & & & & & & & \\
\hline G14 & 0,52 & 0,68 & 0,52 & 0,53 & 0,61 & 0,55 & 0,56 & 0,58 & 0,64 & 0,50 & 0,61 & 0,54 & 0,71 & 1,00 & & & & & & \\
\hline G15 & 0,57 & 0,63 & 0,58 & 0,62 & 0,58 & 0,55 & 0,58 & 0,55 & 0,63 & 0,49 & 0,48 & 0,59 & 0,61 & 0,71 & 1,00 & & & & & \\
\hline G16 & 0,45 & 0,46 & 0,50 & 0,54 & 0,55 & 0,49 & \begin{tabular}{|l|}
0,49 \\
\end{tabular} & 0,46 & 0,40 & 0,41 & 0,33 & 0,35 & 0,58 & 0,56 & 0,62 & 1,00 & & & & \\
\hline G17 & 0,47 & 0,57 & 0,55 & 0,57 & 0,60 & 0,68 & 0,60 & 0,56 & 0,52 & 0,47 & 0,47 & 0,49 & 0,60 & 0,67 & 0,65 & 0,76 & 1,00 & & & \\
\hline G18 & 0,46 & 0,45 & 0,43 & 0,43 & 0,45 & 0,36 & 0,41 & 0,46 & 0,51 & 0,43 & 0,38 & 0,48 & 0,41 & 0,47 & 0,59 & 0,40 & 0,39 & 1,00 & & \\
\hline G19 & 0,51 & 0,54 & 0,52 & 0,56 & 0,54 & 0,44 & 0,47 & 0,49 & 0,57 & 0,57 & 0,56 & 0,64 & 0,47 & 0,56 & 0,68 & 0,42 & 0,50 & 0,69 & 1,00 & \\
\hline G20 & 0,40 & 0,47 & 0,44 & 0,38 & 0,45 & 0,33 & 0,31 & 0,40 & 0,40 & 0,32 & 0,42 & 0,44 & 0,34 & 0,46 & 0,46 & 0,37 & 0,32 & 0,65 & 0,59 & 1,00 \\
\hline
\end{tabular}

Fonte: desenvolvido pelo autor

A Tabela 15 demonstra a matriz de correlação tetracórica entre os 21 tipos de serviços de governo eletrônico explorado na edição de 2007 da pesquisa TIC Domicílios. Para fins de visualização, optou-se por apresentar as referidas variáveis de acordo com a sua codificação apresentada nos Quadro 5.

Uma premissa essencial para aplicação Análise Fatorial é que os atributos analisados sejam correlacionados, afinal a variável latente (fator) representa um conjunto de variáveis altamente correlacionadas entre si e pouco correlacionadas aos atributos de diferentes fatores.

Uma análise visual da matriz tetracórica (Tabela 15) demonstra haver considerável número de correlações com coeficientes maiores que 0,3 . Portanto, oferecendo indícios iniciais de ajuste das variáveis para aplicação da Análise Fatorial Binária. 
Tabela 16- Matriz de correlação tetracórica dos serviços de governo eletrônico (2009)

\begin{tabular}{|c|c|c|c|c|c|c|c|c|c|c|c|c|c|c|c|c|c|c|c|c|}
\hline & G1 & G2 & G3 & G4 & G5 & G6 & G7 & G8 & G9 & G10 & G11 & G12 & G13 & G14 & G15 & G16 & G17 & G18 & G19 & G20 \\
\hline G1 & 1,00 & & & & & & & & & & & & & & & & & & & \\
\hline G2 & 0,71 & 1,00 & & & & & & & & & & & & & & & & & & \\
\hline G3 & 0,71 & 0,64 & 1,00 & & & & & & & & & & & & & & & & & \\
\hline G4 & 0,68 & 0,75 & 0,65 & 1,00 & & & & & & & & & & & & & & & & \\
\hline G5 & 0,63 & 0,64 & 0,60 & 0,63 & 1,00 & & & & & & & & & & & & & & & \\
\hline G6 & 0,46 & 0,48 & 0,53 & 0,53 & 0,70 & 1,00 & & & & & & & & & & & & & & \\
\hline G7 & 0,45 & 0,50 & 0,51 & 0,56 & 0,68 & 0,60 & 1,00 & & & & & & & & & & & & & \\
\hline G8 & 0,44 & 0,49 & 0,46 & 0,47 & 0,54 & 0,46 & 0,43 & 1,00 & & & & & & & & & & & & \\
\hline G9 & 0,48 & 0,47 & 0,46 & 0,48 & 0,42 & 0,42 & 0,45 & 0,79 & 1,00 & & & & & & & & & & & \\
\hline G10 & 0,47 & 0,48 & 0,47 & 0,45 & 0,45 & 0,41 & 0,45 & 0,84 & 0,86 & 1,00 & & & & & & & & & & \\
\hline G11 & 0,32 & 0,36 & 0,32 & 0,45 & 0,34 & 0,36 & 0,36 & 0,31 & 0,47 & 0,38 & 1,00 & & & & & & & & & \\
\hline G12 & 0,40 & 0,57 & 0,43 & 0,52 & 0,49 & 0,50 & 0,46 & 0,49 & 0,49 & 0,46 & 0,53 & 1,00 & & & & & & & & \\
\hline G13 & 0,47 & 0,49 & 0,51 & 0,50 & 0,59 & 0,50 & 0,41 & 0,53 & 0,48 & 0,44 & 0,47 & 0,61 & 1,00 & & & & & & & \\
\hline G14 & 0,38 & 0,47 & 0,43 & 0,51 & 0,49 & 0,47 & 0,43 & 0,38 & 0,45 & 0,41 & 0,48 & 0,56 & 0,61 & 1,00 & & & & & & \\
\hline G15 & 0,37 & 0,50 & 0,43 & 0,45 & 0,54 & 0,48 & 0,47 & 0,44 & 0,42 & 0,39 & 0,36 & 0,48 & 0,49 & 0,78 & 1,00 & & & & & \\
\hline G16 & 0,39 & 0,42 & 0,41 & 0,44 & 0,44 & 0,34 & 0,28 & 0,49 & 0,38 & 0,41 & 0,26 & 0,32 & 0,56 & 0,32 & 0,30 & 1,00 & & & & \\
\hline G17 & 0,34 & 0,34 & 0,36 & 0,39 & 0,36 & 0,30 & 0,30 & 0,39 & 0,35 & 0,36 & 0,29 & 0,33 & 0,43 & 0,27 & 0,23 & 0,67 & 1,00 & & & \\
\hline G18 & 0,51 & 0,56 & 0,55 & 0,52 & 0,51 & 0,43 & 0,44 & 0,63 & 0,60 & 0,63 & 0,41 & 0,47 & 0,68 & 0,50 & 0,52 & 0,59 & 0,52 & 1,00 & & \\
\hline G19 & 0,39 & 0,42 & 0,46 & 0,43 & 0,50 & 0,44 & 0,34 & 0,43 & 0,39 & 0,34 & 0,40 & 0,43 & 0,56 & 0,35 & 0,35 & 0,65 & 0,60 & 0,59 & 1,00 & \\
\hline G20 & 0,50 & 0,46 & 0,46 & 0,49 & 0,53 & 0,37 & 0,34 & 0,50 & 0,47 & 0,45 & 0,43 & 0,39 & 0,51 & 0,40 & 0,38 & 0,62 & 0,48 & 0,65 & 0,71 & 1,00 \\
\hline
\end{tabular}

Fonte: desenvolvido pelo autor

A Tabela 16 apresenta a matriz de correlação tetracórica entre os diferentes serviços de e-gov explorados na pesquisa TIC Domicílios 2009. Por meio de uma inspeção visual da referida matriz, nota-se que haver considerável número de coeficientes com valores superiores a 0,3. Tal característica, segundo Hair et al. (2009) indicam que os referidos dados atendem a premissa básica para aplicação da Análise Fatorial Binária. 
Tabela 17 - Matriz de correlação tetracórica dos serviços de governo eletrônico (2011)

\begin{tabular}{|c|c|c|c|c|c|c|c|c|c|c|c|c|c|c|c|c|c|c|c|}
\hline & G1 & G2 & G3 & G4 & G5 & G6 & G7 & G8 & G9 & G10 & G11 & G12 & G13 & G14 & G15 & G16 & G17 & G18 & G19 \\
\hline G1 & 1,00 & & & & & & & & & & & & & & & & & & \\
\hline G2 & 0,74 & 1,00 & & & & & & & & & & & & & & & & & \\
\hline G3 & 0,73 & 0,70 & 1,00 & & & & & & & & & & & & & & & & \\
\hline G4 & 0,77 & 0,81 & 0,70 & 1,00 & & & & & & & & & & & & & & & \\
\hline G5 & 0,58 & 0,67 & 0,55 & 0,65 & 1,00 & & & & & & & & & & & & & & \\
\hline G6 & 0,48 & 0,58 & 0,55 & 0,57 & 0,76 & 1,00 & & & & & & & & & & & & & \\
\hline G7 & 0,45 & 0,57 & 0,47 & 0,55 & 0,69 & 0,73 & 1,00 & & & & & & & & & & & & \\
\hline G8 & 0,50 & 0,45 & 0,46 & 0,52 & 0,54 & 0,48 & 0,41 & 1,00 & & & & & & & & & & & \\
\hline G9 & 0,48 & 0,43 & 0,44 & 0,50 & 0,46 & 0,49 & 0,43 & 0,89 & 1,00 & & & & & & & & & & \\
\hline G10 & 0,48 & 0,46 & 0,47 & 0,47 & 0,50 & 0,43 & 0,43 & 0,37 & 0,36 & 1,00 & & & & & & & & & \\
\hline G11 & 0,46 & 0,56 & 0,42 & 0,52 & 0,55 & 0,55 & 0,48 & 0,52 & 0,47 & 0,55 & 1,00 & & & & & & & & \\
\hline G12 & 0,53 & 0,50 & 0,54 & 0,55 & 0,61 & 0,54 & 0,44 & 0,58 & 0,57 & 0,49 & 0,64 & 1,00 & & & & & & & \\
\hline G13 & 0,46 & 0,54 & 0,50 & 0,50 & 0,51 & 0,49 & 0,49 & 0,46 & 0,45 & 0,63 & 0,55 & 0,62 & 1,00 & & & & & & \\
\hline G14 & 0,43 & 0,48 & 0,46 & 0,51 & 0,56 & 0,51 & 0,59 & 0,41 & 0,42 & 0,47 & 0,52 & 0,55 & 0,72 & 1,00 & & & & & \\
\hline G15 & 0,44 & 0,37 & 0,39 & 0,47 & 0,44 & 0,37 & 0,30 & 0,46 & 0,47 & 0,32 & 0,33 & 0,52 & 0,36 & 0,32 & 1,00 & & & & \\
\hline G16 & 0,39 & 0,33 & 0,36 & 0,42 & 0,32 & 0,27 & 0,25 & 0,43 & 0,47 & 0,29 & 0,29 & 0,41 & 0,37 & 0,26 & 0,63 & 1,00 & & & \\
\hline G17 & 0,49 & 0,45 & 0,52 & 0,53 & 0,51 & 0,46 & 0,39 & 0,63 & 0,55 & 0,34 & 0,43 & 0,64 & 0,46 & 0,45 & 0,56 & 0,47 & 1,00 & & \\
\hline G18 & 0,40 & 0,42 & 0,41 & 0,47 & 0,42 & 0,34 & 0,30 & 0,40 & 0,42 & 0,34 & 0,34 & 0,51 & 0,38 & 0,39 & 0,64 & 0,50 & 0,54 & 1,00 & \\
\hline G19 & 0,42 & 0,38 & 0,41 & 0,45 & 0,43 & 0,32 & 0,26 & 0,43 & 0,43 & 0,32 & 0,33 & 0,52 & 0,33 & 0,35 & 0,57 & 0,47 & 0,58 & 0,68 & 1,00 \\
\hline
\end{tabular}

Fonte: desenvolvido pelo autor

Por fim, a Tabela 17 sintetiza a matriz de correlação tetracórica referente aos diferentes tipos de serviços de governo eletrônico explorados na pesquisa TIC Domicílios 2011. A inspeção visual da referida matriz demonstra a adequação dos dados de 2011 - assim como dos demais anos - à aplicação da Análise Fatorial Binária.

Além da inspeção da matriz de correlações foi calculada a estatística KMO (KaiserMeyer-Olkin), no intuito de avaliar a adequação da amostra à AFB. Os valores de KMO variam de 0 a 1 , quanto mais próximo a 1, maior será a correlação entre as variáveis indicando adequação da amostra à Análise Fatorial. O cálculo da estatística KMO apresentou os seguintes resultados: (i) em 2007: 0,82; (ii) em 2009: 0,90; (iii) em 2011: 0,90. De acordo com a classificação apresentada em Hair et al. (2009), as amostras analisadas podem ser classificadas como "Boas" e "Muito Boas", portanto, indicando a adequação dos dados para aplicação da técnica de Análise Fatorial Binária (AFB). 
Para aplicação da AFB utilizou-se da Análise de Componentes Principais (ACP) como método de extração dos fatores. A referida abordagem de extração de variáveis latentes (fatores) considera a variância total dos dados. Segundo Fávero et al. (2009, p. 243) a ACP busca maximizar a variância total explicada, por meio da combinação linear das variáveis observadas. Assim, escolheu-se a ACP como método de extração em virtude do objetivo de redução dimensional dos dados, no intuito de se obter um agrupamento de variáveis que representem os diferentes tipos de serviços de governo eletrônico.

Após a definição do método de extração, o próximo passo consiste na definição do critério para escolha do número de fatores. Para fins desta dissertação optou-se pela escolha do critério a priori, no qual o pesquisador já possui indícios sobre o número de fatores que devem ser extraídos. Em conformidade a uma categorização dos serviços de e-gov apresentadas nas edições da pesquisa TIC Domicílios 2007, 2009 e 2011, optouse por executar a AFB retendo cinco fatores. A referida classificação agrupa os serviços de e-gov em cinco categorias: (1) obtenção de documentos; (2) pagamento de taxas e impostos; (3) previdência e assistência social; (4) justiça e segurança e (5) outros serviços. Embora nas publicações da pesquisa TIC Domicílios (CGI, 2008; 2010; 2012) não esteja explicito os fundamentos desta categorização, conjectura-se que tal agrupamento se deu com base na similaridade conceitual dos diversos tipos de serviços de e-gov. Diferindo-se da categorização proposta nesta dissertação que se fundamenta na técnica de Análise Fatorial Binária.

Em seguida, no intuito de facilitar a interpretação dos fatores extraídos, aplicou-se o método de rotação ortogonal Varimax. Os métodos de rotação ortogonal visam produzir fatores que não estejam correlacionados entre si, sendo estes interpretados a partir de suas cargas. Em particular o método Varimax visa minimizar o número de variáveis que tem altas cargas em um fator (FÁVERO et al., 2009, p.245). Para execução dos procedimentos referentes à Análise Fatorial Binária (AFB) utilizou-se do software estatístico Stata.

As Tabelas 18, 19 e 20 apresentam os resultados da execução da AFB (após a rotação Varimax) referente aos anos de 2007, 2009 e 2011. Nestas tabelas são apresentadas todas as variáveis consideradas na análise, junto com as cargas fatoriais do fator a qual ela pertence e sua comunalidade. Visto que após a execução da Análise Fatorial Binária 
sempre há uma perda de variância original dos atributos, a comunalidade é uma medida que visa indicar o quanto da variância original é explicada por meio dos fatores extraídos.

Tabela 18- Resultados da Análise Fatorial (2007)

\begin{tabular}{|c|c|c|c|c|c|c|}
\hline & 1 & 2 & 3 & 4 & 5 & Comunalidade \\
\hline Buscar informações sobre como emitir documentos & 0,7774 & & & & & 0,7893 \\
\hline Obter certidões negativas & 0,5854 & & & & & 0,7368 \\
\hline Consultar o CPF. & 0,7586 & & & & & 0,7883 \\
\hline Obter licenças e permissões & 0,5146 & & & & & 0,6332 \\
\hline Fazer declaração de imposto de renda. & & 0,599 & & & & 0,6817 \\
\hline Fazer pagamento de IPVA, multas, licenc. de veículos. & & 0,8847 & & & & 0,9112 \\
\hline Fazer pagamento de IPTU e outros impostos municipais. & & 0,8874 & & & & 0,9404 \\
\hline Fazer pagamento de taxas de serviços públicos. & & 0,7726 & & & & 0,7805 \\
\hline Buscar informações sobre previdência social. & & & 0,8289 & & & 0,8668 \\
\hline Solicitar salário-maternidade e auxílio doença. & & & 0,8619 & & & 0,844 \\
\hline Fazer inscrição na previdência social. & & & 0,8244 & & & 0,873 \\
\hline Buscar informações sobre benefícios sociais. & & & 0,7104 & & & 0,7351 \\
\hline Fazer boletim de ocorrência. & & & & 0,6472 & & 0,8668 \\
\hline Consultar andamento de atos processuais na justiça. & & & & 0,5469 & & 0,844 \\
\hline Buscar informações sobre direito do consumidor. & & & & 0,5433 & & 0,873 \\
\hline Buscar informações sobre veículos roubados. & & & & 0,8114 & & 0,7351 \\
\hline Consultar pontos na carteira de habilitação e multas. & & & & 0,7097 & & 0,8091 \\
\hline Buscar informações sobre serviços públicos de educação. & & & & & 0,8198 & 0,8145 \\
\hline Buscar informações sobre direitos do trabalhador. & & & & & 0,6463 & 0,7556 \\
\hline Fazer inscrição em concursos públicos. & & & & & 0,8035 & 0,7556 \\
\hline Variância Explicada do fator & 0,1931 & 0,1831 & 0,1453 & 0,1307 & 0,1281 & \\
\hline $\begin{array}{l}\text { Método de Extração: Principal Components (PCA) } \\
\text { Rotação: Varimax. } \\
\text { Variância Total Explicada: } 78,32 \% \\
\text { Total de observações: } 5638 \text {. }\end{array}$ & & & & & & \\
\hline
\end{tabular}

Fonte: desenvolvido pelo autor

A Tabela 18 sintetiza os principais resultados da AFB referente aos dados de 2007, que indicam a extração de cinco dimensões latentes, as quais explicam 78,32\% da variância original dos dados (isto é, uma perda de 21,77\%). Analisando individualmente cada uma das variáveis latentes, pode-se afirmar que o primeiro fator possui maior poder explicativo, respondendo por $19,31 \%$ da variância original.

Para definição dos atributos que compuseram cada um dos fatores gerados, foi realizada uma análise das cargas fatoriais (loadings) após o método de rotação Varimax. A carga fatorial é uma medida da correlação entre os fatores extraídos e a variável analisada. Portanto, tal medida possibilita explicar qual fator melhor explica a variável original (FÁVERO et al, 2009, p. 256). Logo, uma variável analisada pertencerá ao fator com a qual ela tiver maior valor de carga fatorial. A fim de facilitar a visualização dos 
resultados optou-se por apresentar apenas as cargas das variáveis referentes ao fator ao qual ela pertence.

A partir dos resultados da Tabela 18 foi confeccionado o Quadro 8 que caracteriza as dimensões latentes extraídas da $\mathrm{AFB}$, as variáveis que compõem cada fator e a nomeação destes.

\begin{tabular}{|l|}
\hline Fator 1 - Atividades relacionadas à Documentação \\
\hline Buscar informações sobre como emitir documentos \\
\hline Obter certidões negativas \\
\hline Consultar o CPF. \\
\hline Obter licenças e permissões \\
\hline Fator 2 - Atividades relacionadas ao Pagamento de Impostos e Taxas. \\
\hline Fazer declaração de imposto de renda. \\
\hline Fazer pagamento de IPVA, multas, licenciamento de veículos. \\
\hline Fazer pagamento de IPTU e outros impostos municipais. \\
\hline Fazer pagamento de taxas de serviços públicos. \\
\hline Fator 3 - Atividades relacionadas à Assistência Social \\
\hline Buscar informações sobre previdência social. \\
\hline Solicitar salário-maternidade e auxílio doença. \\
\hline Fazer inscrição na previdência social. \\
\hline Buscar informações sobre benefícios sociais. \\
\hline Fator 4 - Atividades relacionadas à Justiça e Trânsito. \\
\hline Fazer boletim de ocorrência. \\
\hline Consultar andamento de atos processuais na justiça. \\
\hline Buscar informações sobre direito do consumidor. \\
\hline Buscar informações sobre veículos roubados. \\
\hline Consultar pontos na carteira de habilitação e multas. \\
\hline Fator 5 - Atividades relacionadas à Educação e Trabalho. \\
\hline Buscar informações sobre serviços públicos de educação. \\
\hline Buscar informações sobre direitos do trabalhador. \\
\hline Fazer inscrição em concursos públicos. \\
\hline
\end{tabular}

Quadro 9 - Composição e Nomeação dos Fatores (2007)

O primeiro fator extraído visa sintetizar as variáveis relacionadas às tarefas para obtenção de documentos (CPF, RG etc.) certidões negativas, licenças e permissões. Em virtude dessas características este fator nomeado como "Atividades relacionadas à Documentação". O fator seguinte refere-se às tarefas empreendidas pelo cidadão no intuito de realizar o pagamento de diversos tipos de taxas e impostos (e.g. IPVA, IPTU, imposto de renda e etc.). O terceiro fator congrega as atividades de e-gov relacionadas à previdência social e demais benefícios (auxílio doença, salário maternidade etc.). A quarta dimensão latente refere-se ao grupo de tarefas referentes à Segurança e/ou Justiça (e.g. boletim de ocorrência, consulta de processos judiciais) e Trânsito (e.g. consulta de multas e pontos na carteira). Por fim, o último construto latente congrega os serviços de 
e-gov, tanto relacionados à educação, quanto ao trabalho (aquisição de emprego e direito do trabalhador).

Tabela 19 - Resultados da Análise Fatorial (2009)

\begin{tabular}{|c|c|c|c|c|c|c|}
\hline & 1 & 2 & 3 & 4 & 5 & Comunalidade \\
\hline Buscar Informações sobre como emitir documentos. & 0,8225 & & & & & 0,8135 \\
\hline Obter certidões negativas, licenças e permissões. & 0,7518 & & & & & 0,7773 \\
\hline Consultar o CPF - Cadastro de Pessoa Física & 0,6982 & & & & & 0,7089 \\
\hline Emissão de Documentos & 0,7374 & & & & & 0,7732 \\
\hline $\begin{array}{l}\text { Obter informações sobre impostos e taxas em sites de } \\
\text { governo }\end{array}$ & & 0,6579 & & & & 0,8143 \\
\hline Fazer Declaração de Imposto de Renda & & 0,7021 & & & & 0,7047 \\
\hline Fazer Pagamento impostos, multas e taxas & & 0,6574 & & & & 0,671 \\
\hline $\begin{array}{l}\text { Buscar informações sobre previdência social e benefícios } \\
\text { sociais }\end{array}$ & & & 0,8385 & & & 0,878 \\
\hline Fazer inscrição/cadastro na Previdência Social & & & 0,8579 & & & 0,8824 \\
\hline Solicitar serviços junto à previdência social & & & 0,903 & & & 0,9236 \\
\hline Fazer boletim de ocorrência & & & & 0,7333 & & 0,6933 \\
\hline Consultar andamento de atos processuais na justiça & & & & 0,618 & & 0,6361 \\
\hline Buscar informaccões sobre direito do consumidor & & & & 0,501 & & 0,6761 \\
\hline Buscar informações sobre veículos roubados & & & & 0,7344 & & 0,788 \\
\hline Consultar pontos na carteira de habilitacão e multas & & & & 0,5704 & & 0,7188 \\
\hline Buscar informações sobre serviços públicos de educação & & & & & 0,8206 & 0,777 \\
\hline $\begin{array}{l}\text { Fazer matrículas em escolas públicas ou instituições de } \\
\text { ensino público }\end{array}$ & & & & & 0,7674 & 0.6573 \\
\hline Buscar Informações sobre direitos do trabalhador & & & & & 0,5362 & 0,7123 \\
\hline Fazer Inscrição em concursos públicos & & & & & 0,7908 & 0,7603 \\
\hline $\begin{array}{l}\text { Buscar informações sobre empregos em algum canal de } \\
\text { comunicação do governo pela Internet }\end{array}$ & & & & & 0,6776 & 0,6799 \\
\hline Variância Explicada do fator & 0,1700 & 0,1671 & 0,1669 & 0,1288 & 0,1195 & \\
\hline $\begin{array}{l}\text { Método de Extração: Principal Components (PCA) } \\
\text { Rotação: Varimax. } \\
\text { Variância Total Explicada: } 75,23 \% \\
\text { Total de observações: } 7158 \text {. }\end{array}$ & & & & & & \\
\hline
\end{tabular}

Fonte: desenvolvido pelo autor

As informações apresentadas na Tabela 19 sintetizam os resultados da aplicação da Análise Fatorial Binária, referente ao ano de 2009. A partir do conjunto original de 20 variáveis foram extraídos cinco fatores (por meio do método de componentes principais e critério a priori), que explicam em torno de $75,23 \%$ da variância original dos dados. A Tabela 19 também apresenta as cargas fatoriais referentes ao fator, ao qual cada variável pertence, permitindo visualizar a composição dos fatores.

O Quadro 9 descreve sucintamente cada um dos cinco fatores gerados, suas variáveis correspondentes e a nomeação atribuída para cada um dos referidos construtos latentes. 


\begin{tabular}{|l|}
\hline Fator 1 - Atividades relacionadas à Documentação \\
\hline Buscar Informações sobre como emitir documentos. \\
\hline Obter certidões negativas, licenças e permissões. \\
\hline Consultar o CPF - Cadastro de Pessoa Física \\
\hline Emissão de Documentos \\
\hline Fator 2 - Atividades relacionadas ao Pagamento de Impostos e Taxas. \\
\hline Obter informações sobre impostos e taxas em sites de governo \\
\hline Fazer Declaração de Imposto de Renda \\
\hline Fazer Pagamento impostos, multas e taxas. \\
\hline Fator 3 - Atividades relacionadas à Assistência Social \\
\hline Buscar informações sobre previdência social e benefícios sociais \\
\hline Fazer inscrição/cadastro na Previdência Social \\
\hline Solicitar serviços junto à previdência social \\
\hline Fator 4 - Atividades relacionadas à Justiça e Trânsito. \\
\hline Fazer boletim de ocorrência \\
\hline Consultar andamento de atos processuais na justiça \\
\hline Buscar informações sobre direito do consumidor \\
\hline Buscar informações sobre veículos roubados \\
\hline Consultar pontos na carteira de habilitação e multas \\
\hline Fator 5 - Atividades relacionadas à Educação e Trabalho. \\
\hline Buscar informações sobre serviços públicos de educação \\
\hline Fazer matrículas em escolas públicas ou instituições de ensino público \\
\hline Buscar Informações sobre direitos do trabalhador \\
\hline Fazer Inscrição em concursos públicos \\
\hline Buscar informações sobre empregos em algum canal de comunicação do governo pela Internet \\
\hline
\end{tabular}

Quadro 10 - Composição e Nomeação dos Fatores (2009)

O primeiro fator, denominado "Atividades relacionadas à Documentação" visa sintetizar cada um dos serviços de governo eletrônico que permitem ao cidadão obter ou retirar algum documento. $\mathrm{O}$ segundo construto representa as tarefas relacionadas ao pagamento de taxas e impostos ao governo (seja em sua esfera federal, municipal ou estadual). O fator seguinte congrega as atividades relacionadas tanto à previdência social, quanto aos diversos benefícios sociais disponíveis ao cidadão brasileiro (e.g. salário maternidade, auxílio doença etc.). A penúltima variável latente, denominada "Atividades relacionadas à Justiça e Trânsito", agrupa dois tipos tarefas, tanto aquelas diretamente relacionadas à segurança e justiça (e.g. Boletim de Ocorrência, Consulta a processos judiciais e direito do consumidor), quanto ao trânsito (e.g. consulta de multas e pontos na carteira). Por fim, o quinto fator representa as atividades de e-gov relacionadas à educação (matricula em escola pública) e ao trabalho (e.g. busca de empregos, concurso público, direitos do trabalhador). 
Tabela 20 - Resultados da Análise Fatorial (2011)

\begin{tabular}{|c|c|c|c|c|c|c|}
\hline & 1 & 2 & 3 & 4 & 5 & Comunalidade \\
\hline Buscar Informações sobre como emitir documentos. & 0,8258 & & & & & 0,8433 \\
\hline Obter certidões negativas, licenças e permissões. & 0,7687 & & & & & 0,8297 \\
\hline Consultar o CPF - Cadastro de Pessoa Física. & 0,7559 & & & & & 0,7529 \\
\hline Emissão de Documentos & 0,756 & & & & & 0,8273 \\
\hline $\begin{array}{l}\text { Obter informações sobre impostos e taxas em sites de } \\
\text { governo }\end{array}$ & & 0,6996 & & & & 0,7987 \\
\hline Fazer Declaração de Imposto de Renda & & 0,7866 & & & & 0,822 \\
\hline Fazer Pagamento impostos, multas e taxas. & & 0,8124 & & & & 0,8096 \\
\hline $\begin{array}{l}\text { Buscar informações sobre previdência social e benefícios } \\
\text { sociais }\end{array}$ & & & 0,8749 & & & 0,9243 \\
\hline Solicitar serviços junto à previdência social. & & & 0,8617 & & & 0,893 \\
\hline Fazer boletim de ocorrência & & & & 0,7322 & & 0,6966 \\
\hline Consultar andamento de atos processuais na justiça & & & & 0,5719 & & 0,6356 \\
\hline Buscar informações sobre direito do consumidor & & & & 0,4854 & & 0,6938 \\
\hline Buscar informações sobre veículos roubados & & & & 0,7829 & & 0,8031 \\
\hline Consultar pontos na carteira de habilitação e multas & & & & 0,6387 & & 0,7076 \\
\hline Buscar informações sobre serviços públicos de educação & & & & & 0,7674 & 0,7262 \\
\hline $\begin{array}{l}\text { Fazer matrículas em escolas públicas ou instituições de } \\
\text { ensino público }\end{array}$ & & & & & 0,6359 & 0,5806 \\
\hline Buscar Informações sobre direitos do trabalhador & & & & & 0,524 & 0,6477 \\
\hline Fazer Inscrição em concursos públicos & & & & & 0,8053 & 0,7582 \\
\hline $\begin{array}{l}\text { Buscar informações sobre empregos em algum canal de } \\
\text { comunicação do governo pela Internet }\end{array}$ & & & & & 0,7715 & 0,7027 \\
\hline Variância Explicada do fator & 0,1765 & 0,1631 & 0,1447 & 0,1395 & 0,1368 & \\
\hline $\begin{array}{l}\text { Método de Extração: Principal Components (PCA) } \\
\text { Rotação: Varimax. } \\
\text { Variância Total Explicada: } 76,07 \% \\
\text { Total de observaç̃es: } 8661 \text {. }\end{array}$ & & & & & & \\
\hline
\end{tabular}

Fonte: desenvolvido pelo autor

Os dados apresentados na Tabela 20 descrevem os principais resultados referentes a aplicação da AFB nos microdados de 2011 da pesquisa TIC Domicílios. As informações disponíveis na referida tabela demonstram que os cinco fatores extraídos conseguem explicar 76,07\% da variância original dos dados, portanto havendo uma pequena perda de variância de $24 \%$ por meio da redução de variáveis.

Além disso, a fim de evidenciar a composição dos fatores foram apresentados os valores de cargas fatoriais das variáveis referentes aos fatores, aos quais estas (variáveis originais) pertencem. Assim, a partir desses resultados foi desenvolvido o Quadro 10 que permite evidenciar cada um dos fatores e as variáveis que ele representa, além do nome que lhe foi atribuído. 


\begin{tabular}{|l|}
\hline Fator 1 - Atividades relacionadas à Documentação \\
\hline Buscar Informações sobre como emitir documentos. \\
\hline Obter certidões negativas, licenças e permissões. \\
\hline Consultar o CPF - Cadastro de Pessoa Física. \\
\hline Emissão de Documentos \\
\hline Fator 2 - Atividades relacionadas ao Pagamento de Impostos e Taxas. \\
\hline Obter informações sobre impostos e taxas em sites de governo \\
\hline Fazer Declaração de Imposto de Renda \\
\hline Fazer Pagamento impostos, multas e taxas. \\
\hline Fator 3 - Atividades relacionadas à Assistência Social \\
\hline Buscar informações sobre previdência social e benefícios sociais \\
\hline Solicitar serviços junto à previdência social. \\
\hline Fator 4 - Atividades relacionadas à Justiça e Trânsito. \\
\hline Fazer boletim de ocorrência \\
\hline Consultar andamento de atos processuais na justiça \\
\hline Buscar informações sobre direito do consumidor \\
\hline Buscar informações sobre veículos roubados \\
\hline Consultar pontos na carteira de habilitação e multas \\
\hline Fator $\mathbf{5}$ - Atividades relacionadas à Educação e Trabalho. \\
\hline Buscar informações sobre serviços públicos de educação \\
\hline Fazer matrículas em escolas públicas ou instituições de ensino público \\
\hline Buscar Informações sobre direitos do trabalhador \\
\hline Fazer Inscrição em concursos públicos \\
\hline Buscar informações sobre empregos em algum canal de comunicação do governo pela Internet \\
\hline
\end{tabular}

Quadro 11 - Composição e Nomeação dos Fatores (2007)

Uma análise do Quadro 10 demonstra que a configuração e nomeação dos fatores referente à pesquisa TIC Domicílios 2011 se manteve em conformidade aos resultados dos anos anteriores avaliados (2007 e 2011). O primeiro fator extraído sintetiza as tarefas relacionadas à obtenção de documentos (cadastro de pessoa física, certidões, licenças etc.). $\mathrm{O}$ fator seguinte representa as tarefas referentes ao pagamento de impostos e taxas. A terceira dimensão latente congrega as atividades relacionadas, tanto à previdência social, quanto a benefícios sociais. O quarto fator, intitulado "Atividades relacionadas à Justiça e Trânsito", assim como o próprio nome sugere congrega o conjunto de tarefas referentes a (i) segurança e justiça (e.g. realizar boletim de ocorrência, verificar o andamento de processos na justiça) e (ii) trânsito. Em conclusão, o último construto representa as atividades de educação (serviços públicos de educação, matrículas em escolas públicas etc.) e trabalho (emprego e direitos).

Embora, os serviços de governo eletrônico (e-gov) explorados pela pesquisa TIC Domicílios, tenham sofrido pequenas alterações em cada um dos anos analisados, notase que os fatores latentes extraídos, basicamente, se mantêm os mesmos no decorrer do período de cinco anos (2007-2011) avaliado. Respectivamente, os referidos fatores agrupam os serviços de e-gov em cinco grupos de atividades: (i) Documentação; (ii) 
Pagamento de Impostos e Taxas; (iii) Assistência Social; (iv) Justiça e Trânsito e (v) Educação e Trabalho. No intuito de representar os fatores acima discutidos foi realizado cálculo dos "escores fatoriais". Tal escore consiste de uma variável que representa cada um dos fatores extraídos por meio da aplicação da Análise Fatorial Binária. Portanto, para cada ano avaliado, foram gerados cinco escores fatoriais, isto é, variáveis que representam as seguintes categorias de serviços de e-gov: (i) Documentação; (ii) Pagamento de Impostos e Taxas; (iii) Assistência Social; (iv) Justiça e Trânsito; (v) Educação e Trabalho. A referida categorização será explorada na próxima seção, no intuito de avaliar como o local de acesso e as competências de uso influem em cada destas categorias de serviços de e-gov.

\subsection{Impacto dos diferentes tipos de serviços de e-gov}

Na Seção 4.5 buscou-se segmentar os diferentes tipos de serviços de governo eletrônico explorados na pesquisa TIC Domicílios. Para tanto, o foco desta seção recai em avaliar o impacto dos diferentes "locais de acesso à internet (mais frequente)" e das competências de uso (capabilities) em cada uma das categorias de serviços de e-gov apresentadas na seção anterior.

Para tratar os diferentes tipos de serviços de e-gov, utilizou-se dos escores fatoriais obtidos por meio da execução da Análise Fatorial Binária (AFB). Os referidos "escores" consistem de dados métricos que representam cada um dos fatores extraídos. Todavia, visto que o foco desta dissertação recai em avaliar o impacto das "competências de uso" (capabilities) e "locais de acesso" em cada uma das categorias de e-gov extraídos, optou-se (assim como na Seção 4.4) pela aplicação da Regressão Logística Binária.

No entanto, a fim de operacionalizar a execução desta técnica foi realizada a transformação dos escores fatoriais (variáveis quantitativas) em dados dicotômicos (variável qualitativa). Para tanto, utilizou-se da mediana de cada um dos escores, isto é, para os valores de "escore" com valor menor ou igual à sua mediana, atribuiu-se o valor 0 e aos valores acima da mediana atribuiu-se o valor 1. Assim, esses escores se tornaram uma variável qualitativa (não métrica) e binária. Os dados da Tabela 21 
sintetizam as medianas referentes aos cinco "escores fatoriais" nos anos de 2007, 2009 e 2011.

Tabela 21 - Mediana dos escores fatoriais

\begin{tabular}{|c|c|c|c|c|c|}
\hline & $\begin{array}{c}\text { Escore } \\
\text { do Fator 1 } \\
\text { (Documentação) }\end{array}$ & $\begin{array}{c}\text { Escore do Fator 2 } \\
\text { (Pagamento de } \\
\text { Impostos eTaxas) }\end{array}$ & $\begin{array}{c}\text { Escore do } \\
\text { Fator 3 } \\
\text { (Assistência } \\
\text { Social) }\end{array}$ & $\begin{array}{c}\text { Escore do } \\
\text { Fator 4 } \\
\text { (Justiça e } \\
\text { Trânsito) }\end{array}$ & $\begin{array}{c}\text { Escore do } \\
\text { Fator 5 } \\
\text { (Educação e } \\
\text { Trabalho) }\end{array}$ \\
\hline $\mathbf{2 0 0 7}$ & $-0,0476$ & 0,0000 & $-0,0378$ & 0,0000 & 0,0000 \\
\hline $\mathbf{2 0 0 9}$ & 0,0000 & 0,0000 & 0,0000 & 0,0000 & 0,0000 \\
\hline $\mathbf{2 0 1 1}$ & 0,0000 & 0,0000 & 0,0000 & 0,0000 & 0,0000 \\
\hline
\end{tabular}

Fonte: desenvolvido pelo autor

Em seguida, foram executadas as regressões logísticas tendo como atributo dependente os diferentes tipos de serviços de e-gov (escores transformados em dados binários) e as variáveis referentes à competência de uso (e-mail, e-commerce e serviços financeiros) e local de acesso à internet, como atributos independentes ou explicativos.

Para interpretação dos resultados da regressão logística, como na Seção 4.4, optou-se por avaliar os coeficientes de "odds ratio" dos atributos estatisticamente significantes a 95\% de confiança, a fim de evidenciar como as variáveis independentes impactam no uso de cada um dos tipos de serviços de e-gov.

Visto que o conjunto de atributos explicativos são os mesmos das regressões logísticas realizadas na Seção 4.4, não serão realizados testes para verificar a existência de problemas de multicolinearidade, pois estes já foram realizados indicando a ausência deste tipo de problema nos dados explicativos utilizados.

Os dados apresentados nas Tabelas 22 a 26 descrevem os coeficientes de "odds ratio" de cada uma das proxies de competência de uso em relação a cada uma das categorias de serviços de governo eletrônico. As células em branco indicam que o coeficiente referente ao atributo explicativo não é estatisticamente significante com $95 \%$ de confiança. 
Tabela 22 - Contribuição das “competências de uso" nas atividades relacionadas à Documentação.

\begin{tabular}{|c|r|r|r|r|r|r|r|r|r|}
\hline & \multicolumn{3}{|c|}{ AB } & \multicolumn{3}{|c|}{ C } & \multicolumn{3}{c|}{ DE } \\
\hline E-commerce (busca) & $\mathbf{2 0 0 7}$ & $\mathbf{2 0 0 9}$ & $\mathbf{2 0 1 1}$ & $\mathbf{2 0 0 7}$ & $\mathbf{2 0 0 9}$ & $\mathbf{2 0 1 1}$ & $\mathbf{2 0 0 7}$ & $\mathbf{2 0 0 9}$ & $\mathbf{2 0 1 1}$ \\
\hline E-mail & 0,7 & 2,3 & 1,7 & 0,5 & 1,9 & 2,4 & 0,5 & & 2,3 \\
\hline Serviços Financeiros (consulta) & & 2,9 & 2,7 & 0,5 & 1,7 & 2,3 & & 3,0 & \\
\hline
\end{tabular}

Fonte: desenvolvido pelo autor

Os resultados da Tabela 22 indicam que o impacto das proxies de competência de uso influi de maneira distinta no uso de serviços de e-gov para documentação. No grupo social de maior poder aquisitivo, o e-mail é a competência com maior coeficiente de odds ratio, portanto indicando que essa competência é que a mais influi no uso e-gov para obtenção de documentos entre os internautas deste estrato social. Em contrapartida, tanto na classe média, quanto na classe DE a utilização de serviços financeiros é a capacidade/competência (capability) que mais influi no grau de propensão ao uso de atividades de governo eletrônico relacionadas à documentação. Portanto, pode-se afirmar que os serviços financeiros impactam positivamente muito mais nas classes menos abastadas ( $\mathrm{C}$ e $\mathrm{DE})$ do que a classe social $\mathrm{AB}$.

Tabela 23 - Contribuição das "competências de uso" nas atividades relacionadas ao Pagamento de Impostos e Taxas

\begin{tabular}{|l|r|r|r|r|r|r|r|r|r|}
\hline & \multicolumn{3}{|c|}{ AB } & \multicolumn{3}{|c|}{ C } & \multicolumn{3}{|c|}{ DE } \\
\hline & $\mathbf{2 0 0 7}$ & $\mathbf{2 0 0 9}$ & $\mathbf{2 0 1 1}$ & $\mathbf{2 0 0 7}$ & $\mathbf{2 0 0 9}$ & $\mathbf{2 0 1 1}$ & $\mathbf{2 0 0 7}$ & $\mathbf{2 0 0 9}$ & $\mathbf{2 0 1 1}$ \\
\hline E-commerce (busca) & 1,6 & 1,8 & 1,8 & 2,1 & 2,0 & 1,7 & & 1,7 & 2,1 \\
\hline E-mail & & 2,2 & 2,4 & 1,8 & & 2,5 & & 2,1 & \\
\hline Serviços Financeiros (consulta) & 3,0 & 1,9 & 1,6 & 2,8 & 3,1 & 1,8 & 6,0 & & 3,8 \\
\hline
\end{tabular}

As informações apresentadas na Tabela 23 enfatizam a importância das proxies de competências de uso (capacidades) propostas no grau de propensão ao uso de atividades de e-gov para o pagamento de impostos e taxas. Uma análise dos coeficientes de "odds ratio" demonstra que o uso de serviços financeiros é a competência que mais contribui no uso desta categoria de serviços de governo eletrônico. Os referidos dados também evidenciam que o impacto da referida competência é maior nas classes DE e C (respectivamente), quando comparado à classe $\mathrm{AB}$. 
Tabela 24 - Contribuição das "competências de uso" nas atividades relacionadas à Assistência Social.

\begin{tabular}{|l|r|r|r|r|r|r|r|r|r|}
\hline & \multicolumn{3}{|c|}{ AB } & \multicolumn{3}{|c|}{ C } & \multicolumn{3}{c|}{ DE } \\
\hline & $\mathbf{2 0 0 7}$ & $\mathbf{2 0 0 9}$ & $\mathbf{2 0 1 1}$ & $\mathbf{2 0 0 7}$ & $\mathbf{2 0 0 9}$ & $\mathbf{2 0 1 1}$ & $\mathbf{2 0 0 7}$ & $\mathbf{2 0 0 9}$ & $\mathbf{2 0 1 1}$ \\
\hline E-commerce (busca) & & 1,8 & 1,9 & 0,6 & 1,8 & 1,6 & & & \\
\hline E-mail & & & 2,0 & 0,5 & 1,6 & 2,0 & & 2,4 & \\
\hline Serviços Financeiros (consulta) & & 2,3 & 2,9 & & 2,4 & 2,0 & & & 2,5 \\
\hline
\end{tabular}

Fonte: desenvolvido pelo autor

Os resultados da Tabela 24 sintetizam o impacto das proxies de competência de uso nas atividades de e-gov referentes à Assistência Social (previdência social, auxílio-doença, salário maternidade etc.). Embora haja considerável parte de coeficientes de odds ratio estatisticamente não significantes (principalmente na classe $\mathrm{DE}$ ), indicando uma possível inadequação das proxies propostas para explicar a propensão ao uso e-gov para atividades relacionadas à Assistência Social, nota-se que o uso de serviços financeiros acaba tendo maior impacto do que as demais variáveis explicativas para explicar o fenômeno analisado na Tabela 24 .

Tabela 25 - Contribuição das "competências de uso" nas atividades relacionadas aos serviços de Justiça e Trânsito.

\begin{tabular}{|l|r|r|r|r|r|r|r|r|r|}
\hline & \multicolumn{3}{|c|}{ AB } & \multicolumn{3}{c|}{ C } & \multicolumn{3}{c|}{ DE } \\
\hline & $\mathbf{2 0 0 7}$ & $\mathbf{2 0 0 9}$ & $\mathbf{2 0 1 1}$ & $\mathbf{2 0 0 7}$ & $\mathbf{2 0 0 9}$ & $\mathbf{2 0 1 1}$ & $\mathbf{2 0 0 7}$ & $\mathbf{2 0 0 9}$ & $\mathbf{2 0 1 1}$ \\
\hline E-commerce (busca) & 1,7 & 1,9 & & 2,1 & 1,6 & 2,0 & 2,4 & 10,1 & \\
\hline E-mail & & & 1,9 & 1,7 & & 1,7 & & & 3 \\
\hline Serviços Financeiros (consulta) & 2,2 & & 1,8 & 3,7 & 1,9 & 1,7 & 3,9 & & 5,5 \\
\hline
\end{tabular}

Fonte: desenvolvido pelo autor

As informações descritas na Tabela 25 evidenciam o grau de propensão de cada uma das competências de uso avaliadas nas atividades de e-gov relacionadas à Justiça e Trânsito. Os resultados da Tabela 25 - padrão repetido nos demais tipos de serviços de e-gov analisados - indicam que o uso de serviços financeiros é a competência que mais influi na propensão ao uso de serviços de governo eletrônico relacionados à Justiça e Trânsito. Além disso, os referidos dados evidenciam que essa contribuição é ainda maior nas classes $\mathrm{C}$ e DE, que apresentam maiores valores de odds ratio, quando comparada à classe $\mathrm{AB}$. 
Tabela 26 - Contribuição das "competências de uso" nas atividades relacionadas à Educação e Trabalho.

\begin{tabular}{|l|r|r|r|r|r|r|r|r|r|}
\hline & \multicolumn{3}{|c|}{ AB } & \multicolumn{3}{c|}{ C } & \multicolumn{3}{c|}{ DE } \\
\hline & $\mathbf{2 0 0 7}$ & $\mathbf{2 0 0 9}$ & $\mathbf{2 0 1 1}$ & $\mathbf{2 0 0 7}$ & $\mathbf{2 0 0 9}$ & $\mathbf{2 0 1 1}$ & $\mathbf{2 0 0 7}$ & $\mathbf{2 0 0 9}$ & $\mathbf{2 0 1 1}$ \\
\hline E-commerce (busca) & 1,6 & 2,0 & 1,5 & 2,7 & 1,9 & 2,0 & 1,8 & & \\
\hline E-mail & 1,8 & 1,7 & & 1,7 & 1,6 & 1,6 & & 2,0 & \\
\hline Serviços Financeiros (consulta) & 2,2 & 2,2 & 1,9 & 3,6 & 2,5 & 2,2 & 4,4 & 3,1 & 3,8 \\
\hline
\end{tabular}

Os dados da Tabela 26 descrevem a contribuição das competências de uso na utilização de e-gov em atividades relacionadas à educação e trabalho (fazer matrícula em escolas públicas, busca de empregos, direito do trabalhador etc.). Os resultados da referida tabela, enfatizam a tendência de que o uso de serviços financeiros é a competência que mais impacta positivamente na decisão de utilizar atividades de e-gov relacionadas à educação e trabalho. Esses dados, ainda reforçam que essa contribuição é maior nas classes menos abastadas (classe C e DE), tendência esta que se mostrou comum em todos os tipos de serviços de e-gov analisados nesta dissertação.

Em conformidade ao modelo de referência (Seção 2.6), avaliou-se o impacto individual dos diferentes "locais de acesso à internet (mais frequente)" na utilização dos diversos serviços de e-gov (documentação, pagamento de impostos e taxas, assistência social, justiça e segurança, educação e trabalho). As Tabelas 27 a 31 demonstram as contribuições dos referidos ambientes de acesso (odds ratio) no uso das categorias de governo eletrônico. As células em branco indicam que os coeficientes de odds ratio das variáveis explicativas não são estatisticamente significantes com 95\% de confiança.

Tabela 27 - Contribuição do "local de acesso à internet" nas atividades relacionada à Documentação

\begin{tabular}{|l|r|r|r|r|r|r|r|r|r|}
\hline & \multicolumn{4}{|c|}{ AB } & \multicolumn{3}{c|}{ C } & \multicolumn{3}{c|}{ DE } \\
\hline & $\mathbf{2 0 0 7}$ & $\mathbf{2 0 0 9}$ & $\mathbf{2 0 1 1}$ & $\mathbf{2 0 0 7}$ & $\mathbf{2 0 0 9}$ & $\mathbf{2 0 1 1}$ & $\mathbf{2 0 0 7}$ & $\mathbf{2 0 0 9}$ & $\mathbf{2 0 1 1}$ \\
\hline Casa ou Trabalho & & 0,4 & 0,4 & 0,4 & 0,6 & 1,6 & 0,5 & & 2,6 \\
\hline Casa de outra pessoa & & 0,3 & 0,3 & 0,5 & 0,5 & & & & \\
\hline Telecentro & & & & 0,3 & & & & & \\
\hline Lan House & & 0,2 & & & & & & & \\
\hline
\end{tabular}

Fonte: desenvolvido pelo autor 
Tabela 28 - Contribuição das “competências de uso" nas atividades relacionadas ao Pagamento de Impostos e Taxas

\begin{tabular}{|l|r|r|r|r|r|r|r|r|r|}
\hline & \multicolumn{3}{|c|}{ AB } & \multicolumn{3}{c|}{ C } & \multicolumn{3}{c|}{ DE } \\
\hline & $\mathbf{2 0 0 7}$ & $\mathbf{2 0 0 9}$ & $\mathbf{2 0 1 1}$ & $\mathbf{2 0 0 7}$ & $\mathbf{2 0 0 9}$ & $\mathbf{2 0 1 1}$ & $\mathbf{2 0 0 7}$ & $\mathbf{2 0 0 9}$ & $\mathbf{2 0 1 1}$ \\
\hline Casa ou Trabalho & 2,0 & & & 2,9 & 1,6 & & & 2,2 & 2,3 \\
\hline Casa de outra pessoa & & & 0,4 & & & & & & \\
\hline Telecentro & & & & & & & & & \\
\hline Lan House & & & & & & 0,7 & & & \\
\hline
\end{tabular}

Fonte: desenvolvido pelo autor

Tabela 29 - Contribuição das "competências de uso" nas atividades relacionadas à Assistência Social.

\begin{tabular}{|l|r|r|r|r|r|r|r|r|r|}
\hline & \multicolumn{3}{|c|}{ AB } & \multicolumn{3}{c|}{ C } & \multicolumn{3}{c|}{ DE } \\
\hline & $\mathbf{2 0 0 7}$ & $\mathbf{2 0 0 9}$ & $\mathbf{2 0 1 1}$ & $\mathbf{2 0 0 7}$ & $\mathbf{2 0 0 9}$ & $\mathbf{2 0 1 1}$ & $\mathbf{2 0 0 7}$ & $\mathbf{2 0 0 9}$ & $\mathbf{2 0 1 1}$ \\
\hline Casa ou Trabalho & & & 1,9 & 0,5 & & 1,9 & 0,2 & 2,7 & \\
\hline Casa de outra pessoa & & & & & & & 0,2 & & \\
\hline Telecentro & & & & 0,3 & & & & & \\
\hline Lan House & & & & & 0,5 & & 0,4 & & \\
\hline
\end{tabular}

Fonte: desenvolvido pelo autor

Tabela 30 - Contribuição das "competências de uso" nas atividades relacionadas aos serviços de Justiça e Trânsito.

\begin{tabular}{|l|r|r|r|r|r|r|r|r|r|}
\hline & \multicolumn{3}{|c|}{ AB } & \multicolumn{3}{c|}{ C } & \multicolumn{3}{c|}{ DE } \\
\hline & $\mathbf{2 0 0 7}$ & $\mathbf{2 0 0 9}$ & $\mathbf{2 0 1 1}$ & $\mathbf{2 0 0 7}$ & $\mathbf{2 0 0 9}$ & $\mathbf{2 0 1 1}$ & $\mathbf{2 0 0 7}$ & $\mathbf{2 0 0 9}$ & $\mathbf{2 0 1 1}$ \\
\hline Casa ou Trabalho & 2,4 & & 1,5 & 2,4 & 1,4 & 2 & 2,8 & 3,8 & \\
\hline Casa de outra pessoa & & & & 1,9 & & & 2,3 & & 0,3 \\
\hline Telecentro & & & 5,8 & & & & & & \\
\hline Lan House & & & & & & & & 3,0 & 0,4 \\
\hline
\end{tabular}

Fonte: desenvolvido pelo autor

Tabela 31 - Contribuição das "competências de uso" nas atividades relacionadas à Educação e Trabalho.

\begin{tabular}{|l|r|r|r|r|r|r|r|r|r|}
\hline & \multicolumn{3}{|c|}{ AB } & \multicolumn{3}{c|}{ C } & \multicolumn{3}{c|}{ DE } \\
\hline & $\mathbf{2 0 0 7}$ & $\mathbf{2 0 0 9}$ & $\mathbf{2 0 1 1}$ & $\mathbf{2 0 0 7}$ & $\mathbf{2 0 0 9}$ & $\mathbf{2 0 1 1}$ & $\mathbf{2 0 0 7}$ & $\mathbf{2 0 0 9}$ & $\mathbf{2 0 1 1}$ \\
\hline Casa ou Trabalho & 0,4 & & & 2,3 & 1,7 & & 2,6 & & \\
\hline Casa de outra pessoa & & & & & & & & & \\
\hline Telecentro & & 0,4 & 4,9 & & & & & 0,1 & \\
\hline Lan House & & & & & & 0,4 & & & \\
\hline
\end{tabular}

Fonte: desenvolvido pelo autor

Os resultados apresentados nas referidas tabelas demonstram que independentemente do tipo de serviço de governo eletrônico analisado, a maior parte dos coeficientes de "odds ratio" não foram estatisticamente significantes (células em branco) ou com valores menores que zero. Tal cenário reforça que apenas o local de acesso à internet é pouco efetivo na predição (ou grau de propensão) do uso dos diferentes tipos de serviços de egov analisados. 
Essa constatação está em consonância e reforça os princípios da abordagem das capacidades (SEN, 2000) que defende que a mera disponibilização de um recurso, não implica diretamente em um aumento do "bem estar" de uma comunidade. Portanto, sendo necessário explorar as diferentes maneiras que esses recursos podem ser usados (capacidades) para atingir diferentes resultados (functionings).

Os resultados expostos permitem enxergar o uso dos diferentes tipos de serviços de egov, por meio de uma cadeia de mediação, na qual o "local de acesso" influi na adoção das proxies de competência de uso (e-mail, serviços financeiros, e-commerce) capacidades - e essas por sua vez influenciam na utilização nas categorias de e-gov, conforme demonstrado nas Tabelas 22 a 26. Portanto, também mostrando a adequação da abordagem das capacidades (que fundamenta a avaliação do e-gov mediada, de maneira encadeada, pelas competências de uso e pelos locais de acesso à internet).

Os resultados apresentados ainda demonstram a importância da utilização dos serviços financeiros, nos grupos sociais menos abastados. Pois, os coeficientes de "odds ratio" referentes a serviços financeiros nas classes $C$ e $D E$ são maiores do que na classe $A B$, portanto, evidenciando que o domínio dessa competência influi muito mais positivamente na propensão de uso de e-gov (ou categorias de serviços de e-gov) nos grupos sociais com menos favorecidos.

Assim, a partir do referencial teórico proposto por Sen (2000), nota-se que o local de acesso residência ou no trabalho, acaba atuando como fator de conversão para o domínio das competências de uso (capacidades) propostas neste estudo e a utilização de serviços financeiros é a capacidade que mais influi no uso das categorias de e-gov, nas classes menos abastadas (C e DE). Esse processo de adoção em cadeia (mediating chain) apresenta indícios que o "acesso à internet na residência e no trabalho" em consonância à utilização de serviços financeiros (consulta) atuam como fortes fatores de inclusão (ou propensão) para o uso de e-gov, tanto na classe média, quanto na classe DE. 


\section{CONSIDERAÇÕES FINAIS}

A presente investigação teve como objetivo compreender de que maneira os diferentes locais de acesso à internet e o conjunto de competências de uso (uso do e-mail; ecommerce e serviços financeiros) impactam no grau de propensão ao uso serviços de governo eletrônico (e-gov). Para tanto, foram utilizados os microdados da pesquisa TIC Domicílios referentes aos anos de 2007, 2009 e 2011, configurando, portanto, um estudo longitudinal. A análise dos dados se deu por meio da aplicação de técnicas estatísticas descritivas (mediana, análise de frequência univariada e bivariada) e multivariadas (Análise de Correspondência, Análise Fatorial Binária e Regressão Logística Binária). A interpretação dos resultados dialoga com o referencial teórico da abordagem das Capacidades (SEN, 2000).

Os resultados apresentados nas seções 4.1 e 4.2 demonstram uma tendência (no intervalo de 5 anos analisado) de aumento na proporção de usuários que utilizam a internet preferencialmente no domicílio. Vale ressaltar que a referida tendência se repete mesmos nas classes de menor poder aquisitivo (classe $\mathrm{C}$ e DE). Em complemento a essa dinâmica, os resultados desta investigação apontam para uma redução da importância dos Centros Públicos de Acesso à Internet (i.e. Lan Houses e Telecentros). Em relação às Lan Houses, os dados da série histórica demostram uma queda na proporção de internautas que utilizam o referido ambiente, como local de acesso à internet mais frequente. Em contrapartida, embora os Telecentros tenham mantido certa estabilidade na proporção de internautas no decorrer dos anos avaliados (considerando o erro amostral), este local representa uma opção de acesso preferencial à internet apenas para pequena parte dos internautas brasileiros.

Ainda em relação aos Telecentros, os dados da Tabela 6, 7 e 8 apontam que tais locais de acesso (alvo de políticas públicas de inclusão digital) são muito pouco utilizados em todas as classes socioeconômicas, mesmo nos extratos sociais menos favorecidos. Os dados da classe DE, enfatizam essa baixa utilização dos Telecentros, pois em 2007 apenas de $2,7 \%$ destes internautas utilizavam este local de acesso à internet, como principal ambiente de acesso, e tal percentual chegou a 1,5\% em 2011. Em consonância com a redução da importância dos Telecentros, convém ressaltar as informações dos mapas perceptuais (Figuras 7, 8 e 9) que demonstram, que no decorrer do tempo houve 
uma redução da associação destes centros públicos de acesso gratuito com todas as classes sociais, principalmente na classe DE. Tais resultados oferecem indícios de potencial inadequação dos atuais Telecentros como instrumento de fomento à inclusão digital (considerando a dimensão de acesso às TICs) nas classes sociais menos favorecidas.

A utilização das Lan Houses apresentou forte queda no intervalo de cinco anos avaliados (2007, 2009 e 2011), afinal esse era o ambiente de acesso preferencial à internet para $31 \%$ dos usuários em 2007, caindo (mais que a metade) para $12,7 \%$ em 2011. A referida tendência de queda ocorreu em todos os grupos sociais, mesmo nas classes menos favorecidas em decorrência da expansão do acesso à internet no domicílio. Todavia, convém ressaltar que mesmo com essa tendência de redução, o referido local de acesso ainda é o principal ambiente de acesso de internautas da classe DE, sendo utilizado por $41 \%$ dos internautas (em 2011) dessa classe.

Assim, a partir dos resultados discutidos retoma-se o primeiro objetivo específico de pesquisa, que visava: Mapear a evolução do uso da internet em relação aos diferentes locais de acesso disponíveis e como estes se diferenciam em relação à classe socioeconômica do internauta. As análises empreendidas nesta dissertação demonstram que no decorrer da série histórica houve uma evolução do acesso à internet em casa, em todas as classes socioeconômicas, e uma redução na importância dos Telecentros e Lan Houses. A tendência de queda mais preponderante, em relação ao uso dos locais de acesso, se deu por conta das Lan Houses. Embora, este ainda seja o principal local de acesso na classe DE, demonstrando, portanto, que as Lan Houses ainda exercem um papel importante como instrumento de inclusão digital nos grupos sociais com menor poder aquisitivo.

O segundo objetivo específico desta dissertação buscava: Analisar de que maneira os diferentes locais de acesso à internet e as competências de uso do internauta (uso de email; e-commerce e serviços financeiros) impactam na utilização de serviços de governo eletrônico no Brasil.

Com base no modelo de referência (Seção 2.6) desenvolvido a partir da abordagem das Capacidades (SEN, 2000) avaliou-se como o uso de e-gov (medido por uma primitiva 
binária) é mediado pelos diferentes locais de acesso à internet e pelas seguintes competências de uso estipuladas: uso de e-commerce, e-mail e serviços financeiros. Os resultados demonstram que o acesso à internet preferencialmente de "Casa" ou do "Trabalho" impacta positivamente no domínio das competências de uso propostas. À luz da Teoria das Capacidades (SEN, 2000) pode-se afirmar que o acesso preferencial de casa ou do trabalho atuam como fatores de conversão para aquisição das capacidades (e-mail, e-commerce e serviços financeiros) analisadas. Estas capacidades, consequentemente, influem positivamente na propensão ao uso de e-gov (functioning). Em complemento aos referidos resultados, convém ressaltar que o local de acesso à internet, individualmente, não se demonstrou um bom preditor ao uso de e-gov. Enfatizando, portanto, a adequação da abordagem das capacidades que defende uma adoção em cadeia, no qual o local de acesso influi na utilização de um conjunto de competências (a capacidade) e estas, consequentemente, impactam positivamente no uso de e-gov. Logo, o uso de governo eletrônico é resultado da mediação entre os locais de acesso à internet e as proxies de competência de uso.

O terceiro objetivo específico desta dissertação visava: Categorizar os diferentes tipos de serviços de governo eletrônico explorados na pesquisa TIC Domicílios. Visto que o construto de e-gov foi mensurado, inicialmente, por meio de uma medida primitiva binária, optou-se por explorar as diferentes categorias de serviços de governo eletrônico. Para tanto, utilizou-se do ferramental estatístico da Análise Fatorial Binária (AFB) que resultou em cinco fatores que representam os seguintes grupos de atividades de e-gov: (i) documentação; (ii) pagamento de impostos e taxas; (iii) assistência social; (iv) justiça e trânsito; (v) educação e trabalho.

Por fim, o último objetivo específico proposto nesta dissertação tinha como foco: Avaliar como os diferentes locais de acesso à internet e as competências de uso impactam no grau de propensão de uso de cada uma das categorias dos serviços de governo eletrônico.

Para tanto, a partir das categorias de serviços de e-gov supracitadas (cinco fatores) foi reavaliado o impacto dos locais de acesso e das competências no uso de cada um dos fatores supracitados. Os resultados demonstraram que as referidas competências (capacidades) aumentam o grau de propensão ao uso de cada uma das categorias de e- 
gov analisadas. Visto que tais competências são impactadas positivamente pelos locais de acesso, esses resultados reforçam que a propensão ao uso das categorias de e-gov é influenciada tanto pelo "local de acesso", quanto pelas competências de uso, contudo não individualmente, mas de maneira encadeada, isto é, o local de acesso influi na competência que influi no uso das categorias de serviços de e-gov. Os resultados ainda apontam que o impacto da competência "uso de serviços financeiros" é maior nas classes $\mathrm{C}$ e $\mathrm{DE}$ (de menor poder aquisitivo), quando comparadas à classe $\mathrm{AB}$. Portanto, demonstrando que a utilização de serviços financeiros atua como fator de inclusão para o uso de e-gov tanto na classe média, quanto na classe DE.

À luz dos resultados apresentados retoma-se o problema de pesquisa que norteou esta investigação, expressa pela seguinte interrogativa: Como o uso de serviços de governo eletrônico é influenciado pelos diferentes locais de acesso à internet e pelas competências de uso? As análises empreendidas nesta dissertação demonstram que o local de acesso e as diferentes competências de uso da internet (para fins deste trabalho: e-commerce, e-mail e serviços financeiros) afetam de maneira encadeada o uso dos serviços de e-gov. Dessa forma, o local de acesso - e mais especificamente o acesso à internet de casa ou do trabalho - aumenta a propensão ao uso das competências e estas (sendo serviços financeiros a capacidade que mais contribui) impactam positivamente no uso do e-gov.

Em termos de implicação para a prática os resultados desta investigação oferecem indícios de que o acesso à internet preferencialmente de casa ou do trabalho, contribui positivamente no desenvolvimento de competências de uso da internet. Porém, deve-se salientar que a simples disponibilização do acesso nos referidos locais (medida de infraestrutura) são medidas insuficientes no sentido de promover a expansão do uso de serviços de governo eletrônico. Neste sentido, sugere-se que políticas públicas que visem o aumento do uso de serviços de e-gov devem não apenas se focar em iniciativas para disponibilizar o acesso à infraestrutura de TIC, mas também explorar ações que visem o desenvolvimento de competências de uso de internet.

No que se refere à avaliação de políticas públicas de inclusão digital, já existentes, os referidos dados oferecem indícios de que políticas públicas que promovam o acesso à internet individual (no ambiente residencial), por meio da redução de impostos na venda 
de computadores e nos serviços de provimento de acesso à internet, financiamento a juros baixos para computadores domésticos, podem ser mais eficazes como iniciativas de fomento e expansão ao uso de e-gov (em consonância com outras ações que visam o desenvolvimento de competências de uso), quando comparadas às iniciativas que visam reorientar as Lan Houses e os Telecentros para que se tornem pontos de acesso aos serviços de e-gov.

Além disso, as análises empreendidas nesta dissertação demonstram o impacto positivo causado pelo uso de serviços financeiros na probabilidade de utilizar e-gov, principalmente nas classes $\mathrm{C}$ e DE. Tais resultados apontam que políticas de bancarização (i.e. que visem ao aumento do acesso aos serviços financeiros bancários) podem atuar como instrumento para o aumento de e-gov, principalmente nas classes com menor poder aquisitivo.

Em termos de contribuição teórica, a referida investigação demonstrou a adequação e o desenvolvimento de uma abordagem metodológica, no intuito de operacionalizar os pressupostos da abordagem das capacidades (no contexto brasileiro), a fim de gerar conhecimentos que permitam melhor compreender os fatores que compelem ao uso de e-gov. Além disso, a contribuição do estudo se dá na análise do fenômeno da inclusão digital, todavia não explorando a dimensão dicotômica do acesso versus não acesso às TICs, mas se focando no universo dos internautas e de seus fatores condicionantes ao uso de e-gov.

A contribuição em termo de método desta investigação se dá na operacionalização da Análise Fatorial Binária (AFB), embora a Análise Fatorial seja um instrumento amplamente disseminado na área das Ciências Sociais e Aplicadas, a vertente binária ainda é pouco utilizada na área. Assim, esta contribuição pode auxiliar na aplicação da referida técnica em situações de fenômenos iminentemente binários.

Recomenda-se para estudos futuros: (i) replicar as análises empreendidas nesta dissertação, a fim de comparar com os resultados expostos. Além disso, recomenda-se (ii) analisar outros fatores de propensão ao uso de e-gov, todavia, não se focando simplesmente nas diferenças entre as classes, mas avaliando outras dimensões da divisão digital como faixa etária, gênero e etnia, possibilitando assim, realizar uma 
comparação dos internautas de grupos etários distintos e como os fatores de propensão ao e-gov são afetados em cada faixa etária. Além disso, recomenda-se a replicação das análises empreendidas nesta dissertação. 


\section{REFERÊNCIAS BIBLIOGRÁFICAS}

ABRAMSON, M.; MEANS, G. E. E-Government 2001 - IBM Endowment for The Business of Government. Rowman \& Littlefield Publishers, Inc. 2001.

ADACHI, T. Comitê Gestor da Internet no Brasil (CGI.br): uma evolução do sistema de informação nacional moldada socialmente. 2011. Tese (Doutorado em Administração) - Faculdade de Economia, Administração e Contabilidade, Universidade de São Paulo, 2011.

AFONSO, C. Internet no Brasil: o Acesso para todos é possível? Policy Paper, São Paulo: n.26, Friedrich Ebert Stfitung, set.2000.

AGUNE, R. M; CARLOS, J. A. Governo eletrônico e novos processos de trabalho. In: LEVY, Evelyn; DRAGO, Pedro Anibal. Gestão pública no Brasil contemporâneo. São Paulo: Edições Fundap, 2005.

ALAMPAY, E. Analysing Socio-Demographic Differences in the acess \& Use of ICTs in the Philippines using the capability approach. The Eletronic Journal on Information Systems in Developing Countries, v. 27, n. 5, p. 1-39, 2006

ASSUMPÇÃO, R. O. Além da Inclusão Digital: O Projeto sampa.org. 2002. 157 f. Dissertação (Mestrado em Ciências da Comunicação) - Escola de Comunicações e Artes, Universidade de São Paulo, São Paulo.

AVGEROU, Chrisanthi. The link between ICT and economic growth in the discourse of development. In: Korpela et al, Organizational Information Systems in the Context of Globalization, Boston, Kluwer, pp 373-386, 2003.

AVGEROU, C.; CIBORRA, C. Land, F. The Social Study of Information and Communicaton Technology Innovation, Actors, and Contexts. New York: Oxford University Press, 2004. 290p.

BARBOSA, A. F. Governo Eletrônico: Dimensões da avaliação de desempenho na perspectiva do cidadão. 2008. Tese (Doutorado em Administração de Empresas) Escola de Administração, Fundação Getúlio Vargas, 2008.

BARRETO, L. F. B. P. M. Uma análise da divisão digital no Brasil através da aplicação da aprendizagem de redes bayesianas. 2012. Dissertação (Mestrado em Administração) - Faculdade de Economia, Admnistração e Contabilidade, Universidade de São Paulo, São Paulo, 2012.

BARTHOLOMEW, D.; STEELE, F.; MOUSTAKI, I.; GALBRAITH, J. The Analysis and Interpretation of Multivariate Data for Social Scientists. 1st edition. London: Chapman and Hall/CRC Press, 2002.

BALBONI, Mariana Reis. Por detrás da inclusão digita: Uma reflexão sobre o consumo e a produção da informação em centros públicos de acesso à Internet no Brasil. 2007. Tese (Doutorado em Interfaces Sociais da Comunicação) - Escola de Comunicações e Artes, Universidade de São Paulo, São Paulo, 2007 
BORGES, J. Inclusão digital e governo eletrônico: conceitos ligados pelo acesso à informação. 2005. Dissertação (Mestrado em Ciência da Informação) - Instituto Ciência da Informação, Universidade Federal da Bahia, Salvador.

CASTELlS, M. A Sociedade em Rede: A era da informação da informação: economia, sociedade e cultura (Volume 1). 10.ed. São Paulo: Paz e Terra, 2007.

CASTELLS, M. A Galáxia da Internet: reflexões sobre a internet, os negócios e a sociedade. 1. ed. Rio de Janeiro: Jorge Zahar, 2003.

CETIC. Centro de Estudos sobre as Tecnologias da Informação e Comunicação. Disponível em: < http://www.cetic.br/sobre-ceticbr/>. Acesso em Out. 2012

CGI. Pesquisa sobre o uso das tecnologias da informação e da comunicação no Brasil 2005: TIC domicílios e TIC empresas. São Paulo: Comitê Gestor da Internet no Brasil, 2006.

CGI. Pesquisa sobre o uso das tecnologias da informação e da comunicação no Brasil 2006: TIC domicílios e TIC empresas. São Paulo: Comitê Gestor da Internet no Brasil, 2007.

CGI. Pesquisa sobre o uso das tecnologias da informação e da comunicação no Brasil 2007: TIC domicílios e TIC empresas. São Paulo: Comitê Gestor da Internet no Brasil, 2008.

CGI.br. Pesquisa sobre o uso das tecnologias da informação e da comunicação no Brasil 2008: TIC domicílios e TIC empresas. São Paulo: Comitê Gestor da Internet no Brasil, 2009.

CGI. Comitê Gestor da Internet no Brasil. Disponível em < $\underline{\text { http://cgi.br/sobre- }}$ cg/definicao.htm>. Acesso em Out. 2012

CGI. Comitê Gestor da Internet no Brasil. Disponível em: <http://cetic.br/saude/>. Acesso em Nov. 2013

CGI. Pesquisa sobre o uso das tecnologias da informação e da comunicação no Brasil 2009: TIC domicílios e TIC empresas. São Paulo: Comitê Gestor da Internet no Brasil, 2010.

CGI. Pesquisa sobre o uso das tecnologias da informação e da comunicação no Brasil 2005-2009 (Edição Especial Comemorativa 5 anos). São Paulo: Comitê Gestor da Internet no Brasil, 2010b.

CGI. Pesquisa sobre o uso das tecnologias da informação e da comunicação no Brasil 2010: TIC domicílios e TIC empresas. São Paulo: Comitê Gestor da Internet no Brasil, 2011.

CGI. Pesquisa sobre o uso das tecnologias da informação e da comunicação no Brasil 2011: TIC domicílios e TIC empresas. São Paulo: Comitê Gestor da Internet no Brasil, 2012.

CHAHIN, A.; CUNHA, M. A.; KNIGHT, P.; PINTO S. E-Gov.br: a próxima revolução brasileira. São Paulo: Prentice Hall, 2004. 
CHEN, Y; YANG, M. QU, L. A new method to measure the information society in China. In: INTERNATIONAL CONFERENCE ON MANAGEMENT SCIENCE AND ENGINEERING, 15., 2008. Long Beach. 15th Annual Conference Proceedings. Long Beach: IEEE, 2008. P.44-49.

CHINN, M. D.; FAIRLIE, R. W. The determinants of the global digite: A cross-country analysis of computer. CENTER DISCUSSION PAPER NO. 881

CIBORRA, C. What does groupware mean for the Organizations hosting it? In:

CIBORRA, C. (ed.). Groupware and Teamwork . Invisible Aid or Technical Hidrance?. Chichester: Wiley, 1996

CRIADO, J.; RAMILO, M. e-Administración: ¿un Reto o una Nueva Moda para las Administraciones del Siglo XXI?. Algunos Problemas y Perspectivas de Futuro en torno a Internet y las Tecnologías de la Información y la Comunicación en las Administraciones Públicas. Revista Vasca de Administración Pública, v.61, n.1, p.1143,2001

CUNHA, M. A. V. C.; CUCLÓS, L. C.; BARBOSA, A. F. Institucionalização do egoverno como Instrumento de Legitimidade da Governança Eletrônica no Setor Público no Brasil, Chile e Peru In: Encontro da Associação Nacional de Programas de Pósgraduação em Administração, 30, 2006, Salvador. Anais do EnANPAD 2006. Salvador: ANPAD, 2006.

CUNHA, M. A. V. C; MIRANDA, P. R. M. A Pesquisa no Uso e Implicações Sociais das Tecnologias da Informação e Comunicação pelos Governos no Brasil: uma Proposta de Agenda a Partir de Reflexões da Prática e da Produção Acadêmica Nacional In: ENCONTRO DA ASSOCIAÇÃO NACIONAL DE PÓS-GRADUAÇÃO E PESQUISA EM ADMINISTRAÇÃO, 32., 2008, Rio de Janeiro. Anais do Enanpad 2008. Rio de Janeiro: ANPAD, 2008. p.1-16.

DAVIS, Fred D. Perceived Usefulness, perceived ease of use, and user acceptance of Information Technology. MIS Quartely, v.13, n.3, p. 319-340, 1989

DELlOITE; TOUCHE. The citizen as customer. CMA Management, v. 74, n;10, Dec2000/Jan2001, 2001

DINIZ, E. H.; MAURO, C. E. E.; SOUZA, T. T. E-commerce in the purchases process of the government. In: The Business Association of Latin American Studies. 2001, San Diego. Anais do BALAS 2001. San Diego: BALAS, 2001, p.1-10.

DINIZ, E. H.; PETRINI, M; BARBOSA, A, F.; CHRISTOPOULOS, T. P; SANTOS, H.M;. Abordagens Epistemológicas em Pesquisas Qualitativas: Além do Positivismo nas Pesquisas na Área de Sistemas de Informação. In: ENCONTRO DA ASSOCIAÇÃO NACIONAL DE PÓS-GRADUAÇÃO E PESQUISA EM ADMINISTRAÇÃO, 30., 2006, Salvador. Anais do Enanpad 2006. Bahia: ANPAD, 2006. p.1-16.

DINIZ, E. H.; BARBOSA, A. F.; JUNQUEIRA, A. R. B.; PRADO, O. O governo eletrônico no Brasil: perspectiva histórica a partir de um modelo estruturado de análise. Revista de Administração Pública, v. 43, n.1, p.23-48, 2009. 
DOONG, S. H.; HO, S. C. The impact of ICT development on the global digital divide. Eletronic Commerce Research and Applications, 2012.doi:10.1016/j.elerap.2012.02.002

EISENBERG, J. e CEPIK, M. (orgs.). Internet e Política: teoria e prática da democracia eletrônica. Belo Horizonte: Editora UFMG, 2002.

EU. European Interoperability Framework for Pan-European e-Government Services (version 1.0). Luxembourg: European Communities, 2004

FÁVERO, L. P.; BELFIORE, P.; SILVA, F.L.; CHAN, B.L. Dados: Modelagem Multivariada para Tomada de Decisões. Rio de Janeiro: Elsevier, 2009

FERREIRA, R. S. A Sociedade da Informação no Brasil: um ensaio sobre os desafios do Estado. Ciência da Informação, v.32, n.1, p. 36-41, 2003

FERNANDES, J. M.; DUTT-ROSS, S. Pequenas Ilhas de Inclusão em um Oceano de Exclusão Digital: Uma Análise da População Brasileira com Acesso à Internet ao longo do tempo, espaço e status socio-econômico. In: ENCONTRO DE ADMINISTRAÇÃO PÚBliCA E GOVERNANÇA, 2., 2006. São Paulo. Anais do EnAPG 2006. São Paulo: ANPAD, p.1-16.

FOWLER, F. J. Survey Research Methods. $4^{\text {th }}$ edition. London: Sage Publication, 2009.

GAMBOA, L. F.; GUTIÉRREZ, L. H. Public resale of mobile telephone minutes: An alternative access for low-income households in Colombia. Technology in Society, v.32, n.2, p. 122-129, 2010.

GARTNER GROUP. Key issues in e-government strategy and management. Research Notes. Maio, 2000.

GRANDE, J.; ARAUJO, M..; SERNA, M.. La necesidad de teoría(s) sobre gobierno electrónico: uma propuesta integradora. In: Concurso de ensayos y monografías del CLAD sobre reforma del estado y modernización de la administración pública. 16., 2002, Caracas. Anais eletrônicos... Caracas: Centro Latinoamericano de Administración para el Desarollo (CLAD), 2002.

HAIR, J. F., BLACK, W. C., BABIN, J. B., ANDERSON, R. E., TATHAM, R. L.; Multivariate Data Analysis. New Jersey: Pearson Prentice Hall, 2006.

HAMILTON, L. C. Statistics with Stata: Update for version 10. Belmont: Cencage Learning, 2009

HANAFIZADEH, M. R.; SAGHAEI, A.; HANAFIZADEH, P. An index for crosscountry analysis of ICT infrastructure and access. Telecommunications Policy, v. 33, n.7, p. 385-405, 2009a

HANAFIZADEH, P., HANAFIZADEH, M. R.; KHODABAKHSHI, M. Taxonomy of e-readiness assessment measures. International Journal of Information Management, v. 29, n. 3, p. 189-195, 2009b 
HIRSCHHEIM, R. Information Systems Epistemology: An Historical Perspective. In: Galliers, R. (ed.), Information Systems Research: Issues, Methods and Practical Guidelines, Blackwell Scientific Publications, Oxford, 1992, pp. 28-60.

ITU. Measuring the Information Society. p. 1-124, 2010

ITU. Measuring the Information Society. p. 1-174, 2011

IIZUCA, E. S. Um Estudo Exploratório sobre a Exclusão Digital e as Organizações sem Fins Lucrativos da cidade de São Paulo. 2003. Dissertação (Mestrado em Administração Pública e Governo) - EAESP/FGV, São Paulo.

KLECUN, E. Bringing lost sheep into the fold: questioning the discourse of the digital divide. Information Technology \& People, v.21, n.3, p. 267-282, 2008

KOZMA, R. B. National policies that connect ICT-based education reform to economic and social development. Human Technology, v. 1, n. 2, p. 117-156, 2005

KYRIAKIDOU, V.; MICHALAKELIS, C.; SPHICOPOULOS, T. Digital divide gap convergence in Europe. Technology in Society, v. 33, n.3-4, p. 265-270, 2011

LANVIN, B. LEWIN, A. The next frontier of e-government: local governments may hold the keys to global competition. Disponível em: $<$ http://siteresources.worldbank.org/EXTINFORMATIONANDCOMMUNICATIONA NDTECHNOLOGIES/Resources/NextFrontierE_Government.pdf $>$. Acesso em Ago. 2013

LAYNE, K.; LEE, J. Developing fully functional e-government: a four stage model. Government Information Quarterly, v.18, n.2, p.122-136, 2002

MACADAR, M. A.; REINHARD, N. Telecentros Comunitários possibilitando a Inclusão Digital: um estudo de caso comparativo de iniciativas brasileiras. In: ENCONTRO NACIONAL DA ASSOCIAÇÃO DE PÓS-GRADUAÇÃO EM ADMINISTRAÇÃO, 26., 2002, Salvador. Anais do EnANPAD 2002. Salvador: ANPAD, p.1-16.

MACHADO, J. G. R.; PAMPLONA, J. B. A ONU e o desenvolvimento econômico: uma interpretação das bases teóricas da atuação do PNUD. Economia e Sociedade, v. 17, n. 1, 2008.

MADON, Shirin; REINHARD, N.; ROODE, Dewald ; WALSHAM, Geoff . Digital inclusion projects in developing countries: Processes of institutionalization. Information Technology for Development, v. 15, p. 95-107, 2009.

MARTINS, G. A.; THEÓPHILO, C. R. Metodologia da Investigação Científica para Ciências Socias Aplicadas. 1.ed. São Paulo: Atlas, 2007.

MATTOS, Fernando Augusto M. de; CHAGAS, Gleison José do N. Desafios para a inclusão digital no Brasil. Perspectivas em Ciência da Informação, v.13, n.1, p.67-94, jan./abr. 2008. 
MENEZES, E; Bonadia, G. C.; Holanda, G. M. Indicadores para a Sociedade da Informação medindo as múltiplas barreias à Inclusão Digital. Caderno CPqD Tecnologia, v.5, n. 1, p. 7-20, jan/jul. 2009.

MORAES, I. H. S. D.; GÓMEZ, M. N. G. D. Informação e informática em saúde: caleidoscópio contemporâneo da saúde. Ciência \& Saúde Coletiva, v. 12, n. 3, 2007

MOON, M. The evolution of e-government among municipalities: rhetoric or reality? Public Administration Review, v.62, n.4, p.424-433, 2002.

MORI, C. K.; ASSUMPÇÃO, R. O. Brazilian Digital Inclusion Public Policy: achievements and challenges. The Journal of Community Informatics, v. 3, n. 3, p. $1-6,2007$.

MUSMANN, Klaus; KENNEDY, William H. Diffusion of innovations: a select bibliography. London: Greenwood, 1989, 250 p.

MUTULA, S. M. Digital divide and economic development: case study of sub-Saharan Africa. The Electronic Library, v. 26, n.4, p.468-489, 2008.

MYERS, M. D. Qualitative Research in Information Systems. MIS Quartely, v.21, n.2, p. 241-242, 1997.

NIC. Relatório de Atividades CGI.br e NIC.br. São Paulo: Comitê Gestor da Internet no Brasil, 2010.

NIC. Núcleo de Informação e Coordenação do Ponto Br. Disponível em: < http://www.nic.br/sobre-nic/nicbr.htm>. Acesso em Out. 2012

OECD. E-government: analysis framework and methodology. Paris: OCDE, 2001.

ORLIKOWSKI, W. The duality of Technology: Rethinking the Concept of Technology in Organisations. Organisation Science, v.3, n.3, p. 398-427, 1992.

ORLIKOWSKI, W. J. Using Technology and Constituting Structures: a Practice Lens for Studying Technology in Organisations. Organisation Science. v.11, n.4, p. 404428,2000

PASSOS, J. C.; ABREU, M. A. A. A Inclusão Digital como mecanismo de Inclusão Social: um olhar sobre os resultados de alguns projetos sociais. In: ENCONTRO DA ASSOCIAÇÃO NACIONAL DE PÓS-GRADUAÇÃO E PESQUISA EM ADMINISTRAÇÃO, 35., 2011, Rio de Janeiro. Anais do EnANPAD 2011. Rio de Janeiro: ANPAD, p. 1-16.

PEREZ, Gilberto. Adoção de inovações tecnológicas: um estudo sobre o uso de sistemas de informação na área de saúde. 2007. Tese (Doutorado em Administração) - Faculdade de Economia, Administração e Contabilidade, Universidade de São Paulo: São Paulo, 2007.

PORCARO, R. M. Tecnologia da Comunicação e Informação e Desenvolvimento: Políticas Estratégicas de Inclusão Digital no Brasil. Brasília: IPEA, 2006. 
PRADO, E. P. V.; SOUZA, C. A.; RAMALHO, N. C. L.;CUNHA, M. A.; REINHARD, N. Iniciativas de Governo Eletrônico: Análise das relações entre nível de governo e características dos projetos em casos de sucesso. Revista Eletrônica de Sistemas de Informação, v. 10, n.1. p.1-22, 2011.

PRENDERGAST, Renee. The concept of freedom and its relation to economic development - a critical appreciation of the work of Amartya Sen. Cambridge Journal of Economics, v. 29, n. 6 p. 1145-1170, 2005.

RAMOS, A. S. M.; MARTINS, D. A. Conceitos de Governo Eletrônico e Governança Eletrônica: Confrontação e Complementariedade. In: Encontro de Administração Pública e Governança. 3., 2008, Salvador. Anais do EnAPG 2008. Salvador: ANPAD, 2008. p.1-14.

REINHARD, N. Os Desafios do Acesso Universal: Modelos e Gestão - Um Convite à Pesquisa. In: Pesquisa Sobre o Uso das Tecnologias da Informação e da Comunicação no Brasil 2005-2009. São Paulo: Cetic.br, 2010, p. 89-98.

RIGGINS, F. J.; DEWAN, S. The Digital Divide: Current and Future Research Directions. Journal of the Association for Information Systems. v.6, n.12, p.298-337, 2011

ROBERTSON, A.; SOOPRAMANIEN, D.; FILDES, R. A segment-based analysis of Internet service adoption among UK households. Technology in Society, v.29, n.3, p. 339-350, 2007.

ROBEYNS, I. The Capability Approach: a theoretical survey. Journal of Human Development, v.6, n.1, p.93-117, 2002.

ROGERS, E. M. Diffusion of Innovations. 4.ed. New York: Free Press, 1995.

ROGERS, Everett. A prospective and retrospective look at the Diffusion Model. Journal of Health Communication, vol. 9, p. 13-19, 2004.

SACCOL, Amarolinda Iara da Costa Zanela. A Teoria da Hospitalidade e o processo de adoção de tecnologias da informação móveis e sem fio. 2005. Tese (Doutorado em Administração) - Faculdade de Economia, Administração e Contabilidade, Universidade de São Paulo, 2005.

SACCOL, A. I. C. Z.; REINHARD, N. Tecnologias de informação móveis, sem fio e ubíquas: definições, estado-da-arte e oportunidades de pesquisa. Revista de Administração Contemporânea, v.11, n.4, p. 175-198, 2007.

SAMPIERI, R. H.; COLLADO, C. F.; LUCIO, P. B. Metodologia de Pesquisa. 3.ed. São Paulo: McGraw-Hill, 2006.

SANTOS, E. M. Desenvolvimento e implementação de padrões de interoperabilidade em governo eletrônico no Brasil. 2008. Tese (Doutorado em Administração) - Faculdade de Economia, Administração e Contabilidade, Universidade de São Paulo, 2005. 
SANTOS, E. M.; REINHARD, N. Usos de Serviços de Governo Eletrônico no Brasil: um estudo exploratório. In: Encontro da Associação Nacional de Pós-Graduação e Pesquisa em Administração, 35., 2011, Rio de Janeiro. Anais do EnANPAD 2011. Rio de Janeiro: ANPAD, 2011. p.1-15.

SEN, Amartya. Commodities and capabilities. New Delhi: Oxford University Press, 1999.

SEN, A. K. Desenvolvimento como Liberdade. São Paulo: Companhia das Letras, 2000 .

SIAU, K.; LONG, Y. Innovations through information technology. Hershey: Idea Group Inc., 2004.

SILVEIRA, S. A. Exclusão Digital: A miséria na era da informação. São Paulo: Fundação Perseu Abramo, 2001.

SILVERSTONE, R.; HADDON, L. Design and the domestication of Information and Communications Technologies: technical change and everyday life. In: SILVERSTONE, R.; MANSELL, R. (ed.). Communications by design: the politics of Information and Communications Technologies. Oxford: Oxford University Press, 1996.

SORJ, B. Brasil@povo.com: a luta contra a desigualdade na Sociedade da Informação. Rio de Janeiro: Jorge Zahar, 2003.

SORJ, B.; GUEDES, L. E. Exclusão Digital: Problemas conceituais, evidências empíricas e políticas públicas. Novos Estudos, n.72, p101-117, 2005

TAKAHASHI, Tadao (Org.) Sociedade da Informação no Brasil: Livro Verde. Brasília: Ministério da Ciência e Tecnologia, 2000.

TAKASE, SONIA. Impacto da Revolução Tecnológica na dimensão Humana da Informação. 2007. Dissertação (Mestrado em Ciência da Informação) - Faculdade de Economia, Administração, Contabilidade e Ciência da Informação e Documentação, Universidade de Brasília, Brasília, 2007.

UCLA. How can I perform a factor analysis with categorical (or categorical and continuous) variables? Institute for Digital Research and Education (idre). Disponível em: <http://www.ats.ucla.edu/stat/stata/faq/efa_categorical.htm>. Acesso em Ago. 2013

UN. Global e-government readiness report 2005: from e-government to einclusion. New York: UN, 2005.

UN. Global e-government Survey. New York: UN, 2003.

VEHOVAR, V.; SICHERL, P.; HÜSING, T.; DOLNICAR, V. Methodological Challenges of Digital Measurements. The Information Society, v.22, n.5, p.279-290, 2006.

VENKATESH, V.; DAVIS, F. D. A theoretical extension of the Technology Acceptance Model: four longitudinal field studies. Management Science, v. 46, n. 2, p. 186-204, 2000. 
VENKATESH, V.; MORRIS, M.; DAVIS, G. B.; DAVIS, F. User acceptance of information technology: toward a unified view. MIS Quartely, v. 27, n. 3, p.425-478, 2003.

VIANA, A. L.; ELIAS, P. E. Saúde e desenvolvimento. Ciência \& Saúde Coletiva, v.12, n.3, 2007.

VICENTE, M. R.; LÓPEZ, A. J. Assessing the regional divide across the European Union-27. Telecommunication Policy, v.35, n.3, p.220-237, 2011

WALSHAM, G.; HAN, C. K. Structuration theory and information systems research. Management Studies Group at the Department of Engineering, Cambridge University, Research Paper, n.11, 1990.

WALSHAM, G. Interpretive case studies in IS research: nature e method. European Journal of Information Systems, v. 4, p. 74-81, 1995.

WERTHEIN, J. A Sociedade da Informação e seus desafios. Revista Ciência da Informação, v. 29, n.2, p.71-77, 2000.

WINKLER, I. A implementação de políticas públicas brasileiras de Inclusão Digital. 2005. Dissertação (Mestrado em Administração) - Universidade Federal da Bahia - Núcleo de Pós-Graduação em Administração, Bahia. 